International Scientific-Technical and Production Journal

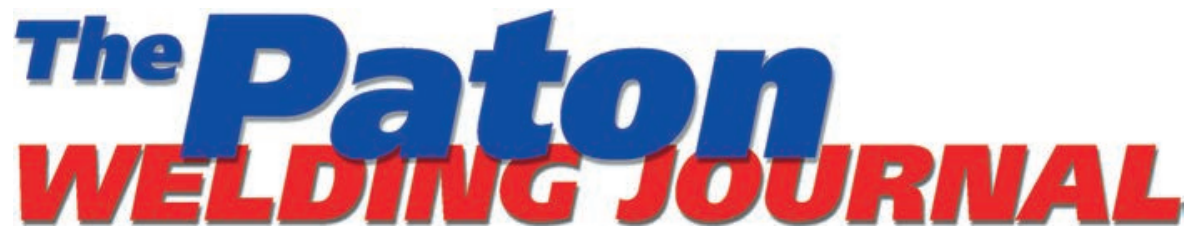

\section{EDITORIAL BOARD \\ Editor-in-Chief B.E. Paton}

Scientists of PWI, Kyiv S.I. Kuchuk-Yatsenko (vice-chief ed.),

V.N. Lipodaev (vice-chief ed.)

Yu.S. Borisov, G.M. Grigorenko,

A.T. Zelnichenko, V.V. Knysh,

I.V. Krivtsun, Yu.N. Lankin,

L.M. Lobanov, V.D. Pon yakov,

I.A. Ryabtsev, K.A. Yushchenko

Scientists of Ukrainian Universities V.V. Dmitrik, NTU «KhPI», Kharkov V.V. Kvasnitsky, NTUU «KPI», Kyiv

E.P. Chvertko, NTUU «KPI», Kyiv

Foreign Scientists

N.P. Alyoshin

N.E. Bauman MSTU, Moscow, Russia Guan Qiao

Beijing Aeronautical Institute, China

M. Zinigrad

Ariel University, Israel V.I. Lysak

Volgograd STU, Russia Ya. Pilarç $k$

Welding Institute, Gliwice, Poland U. Reisgen

Welding and Joining Institute, Aachen, Germany G.A. Turichin

St. Petersburg SPU, Russia

Founders

E.O. Paton Electric Welding Institute, NASU

International Association «Welding» Publisher

International Association «Welding» Translators

A.A. Fomin, O.S. Kurochko, I.N. Kutianova Editor

N.G. Khomenko

Electron galley

D.I. Sereda, T.Yu. Snegiryova Address

E.O. Paton Electric Welding Institute,

International Association «Welding»

11 Kazimir Malevich Str. (former Bozhenko Str.), 03150, Kyiv, Ukraine

Tel.: (38044) 20060 16, 2008277

Fax: (38044) 20082 77, 2008145

E-mail: journal@paton.kiev.ua

www.patonpublishinghouse.com

State Registration Certificate

KV 4790 of 09.01 .2001

ISSN 0957-798X

DOI: http://dx.doi.org/10.15407/tpwj Subscriptions

$\$ 384,12$ issues per year

air postage and pack ging included. Back issues aa ilable.

All rights resere $\mathrm{d}$.

This publication and each of the articles contained herein are protected by copyright.

Permission to reproduce material contained in this journal must be obtained in writing from the Publisher.

\section{CONTENTS}

\section{SCIENTIFIC AND TECHNICAL}

Krivtsun I.V., Demchenko V.F., Krikent I.V., Kovalenko D.V. and

Kovalenko I.V. Effect of current and arc length on characteristics of arc discharge in nonconsumable electrode welding

Kvasnytskyi V.V., Kvasnytskyi V.F., Matviienko M.V., Buturlya E.A. and Yermolayev G.V. Stress-strain state of welded and brazed assemblies from dissimilar materials with soft interlayer at thermal loading

Borisov Yu.S., Borisova A.L., Grishchenko A.P., Vigilyanskaya N.V., Kolomytsev M.V. and Vasilkovskaya M.A. Structure and phase composition of $\mathrm{ZrB}_{2}-\mathrm{SiC}-\mathrm{AIN}$ plasma coatings on the surface of $\mathrm{C} / \mathrm{C}-\mathrm{SiC}$ composite material

\section{INDUSTRIAL}

Gruzevich A.V. and Derecha D.A. Gas-powder spraying as

a high-efficient method of increasing the operation reliability of power equipment

Yurzhenko M.V. Peculiarities of technology and modern trends in the field of butt welding of polyethylene pipes (Review)

\section{NEWS}

«Kyiv Technical Fair - 2019»

CALENDAR OF MAY 


\title{
EFFECT OF CURRENT \\ AND ARC LENGTH ON CHARACTERISTICS OF ARC DISCHARGE IN NONCONSUMABLE ELECTRODE W LDING*
}

\author{
I.V . KRIVTSUN, VF.D EMCHENKO,I .V.K RIKENT,D .V.K OVALENKO and IV .K OVALENKO \\ E.O. Paton Electric Welding Institute of the NAS of Ukraine \\ 11 Kazimir Malevich Str., 03150, Kyiv, Ukraine. E-mail: office@paton.kiev.ua
}

\begin{abstract}
The method of mathematical modeling was used for investigation of the effect of current and length of atmospheric pressure argon arc with refractory (tungsten) cathode on heat, electromagnetic and gas-dynamic characteristics of arc plasma, including the characteristics of its thermal, electric and dynamic (force) impact on the anode surface. A short review of the mathematical models used for this purpose is given. The temperature fields and patterns of current flow in the arc column are illustrated with corresponding isotherms and current lines. Analysis of force effect of arc current on its column plasma is based on calculation data on distribution of magnetic pressure in arc plasma and corresponding magnetic force acting on plasma. Peculiarities of distribution of total pressure and velocity of plasma movement in the arc column are also analyzed. The calculation data are given on distribution of density of electric current and heat flow on the surface of water-cooled and evaporating anode, as well as on distribution of plasma potential along the boundary of anode layer depending on current and arc length. The concepts of effective values of anode and cathode potential drop are introduced. Proceeding from the calculation value of heat flow into the anode and experimental watt-ampere characteristic of an argon arc with a refractory cathode, the data were obtained on the value of effective efficiency of such an arc in the current range of 50-300 A for an arc of 1.5; 2 and $3 \mathrm{~mm}$ length. Dependence of the dimensions of current channel and zone of thermal impact of the arc on the anode on current value and arc length was determined. 26 Ref., 22 Figures.
\end{abstract}

Keywords: arc with refractory cathode, arc current, arc length, arc plasma, arc column, anode layer, anode current density, anode heat flow, mathematical modeling

For effective application of electric arc as the heat source in fusion welding, it is necessary to have valid information on the thermal, electric and dynamic (force) impact of arc plasma on the metal being welded, depending on the welding process and mode. In the case of nonconsumable electrode welding, when the metal being welded is the arc anode, such an impact is determined by the set of processes of energy-, massand electric charge transfer in the plasma column and anode region of the arc, and its characteristics depend on current, arc length and shielding gas composition. As experimental determination of the characteristics of thermal, electromagnetic and gas-dynamic processes in arc plasma, as well as its thermal, electric and dynamic impact on the weld pool surface is difficult, the objective of this work is detailed quantitative study of the above characteristics by mathematical modeling methods. We will consider as an object of investigation the axially symmetrical argon arc with a refractory cathode, the scheme of which is shown in Figure 1, in the range of currents $I=50-300$ A and following values of arc length $L=1.5 ; 2 ; 3 \mathrm{~mm}$. These are exactly the arc discharge parameters which are characteristic for inert-gas nonconsumable (TIG) welding.

There exists a multitude of approaches and models for numerical study of the processes energy, pulse, mass and charge transfer in the plasma of electric arc column, as well as anode processes for TIG-welding conditions [1-13]. However, in the majority of the works on complex modeling of an arc with refractory cathode rather simplified models of the anode layer are used [1-7], whereas in the works specially devoted to study of anode phenomena [8-13], insufficient attention is given to their interrelation with the processes, running in the arc column. To correctly account for this relationship, we will use a self-consistent mathematical model of the column and anode region of the arc in nonconsumable electrode welding, proposed in [14], and modified in [15].

Cha a teristics 6 a c cb umn pla ma Let us first consider the distributed characteristics of the ther-

\footnotetext{
*Based on materials of a presentation at the IX International Conference «Mathematical modeling and information technologies in welding and related processes», September 10-14, 2018, Odessa.
} 
mal, electromagnetic and gas-dynamic processes in the plasma of the column of an argon arc, burning between the refractory cathode and copper water-cooled (nonevaporating) anode. Figure 2 presents the results of modeling the temperature field and pattern of current flowing in the arc of length $L=2 \mathrm{~mm}$ for three characteristic values of arc current $I=100,150,200 \mathrm{~A}$. Shown on the left are the current lines, which are the generatrices of the surfaces of revolution, limiting the area of the arc, within which a certain part of total current flows. The isotherms of arc plasma temperature field are given in the figures on the right. Configurations of current lines in near-electrode regions of the considered arc are indicative of its contraction in these regions: considerable near the cathode and essentially smaller near the anode. With increase of arc length, the isotherms and the current lines, accordingly, become wider that points to a reduction of the current density in longer arcs. Comparing the isotherms with the current lines, we can come to the conclusion that the dimensions of the current channel, in which $90 \%$ of the arc current flow, are approximately two times smaller than the current-conducting region of the arc column (argon plasma becomes electrically conducting at the temperature above $4500 \mathrm{~K}$ ).

Let us now consider the gas-dynamic characteristics of arc plasma. Electromagnetic force, resulting from interaction of the arc current with inherent mag-

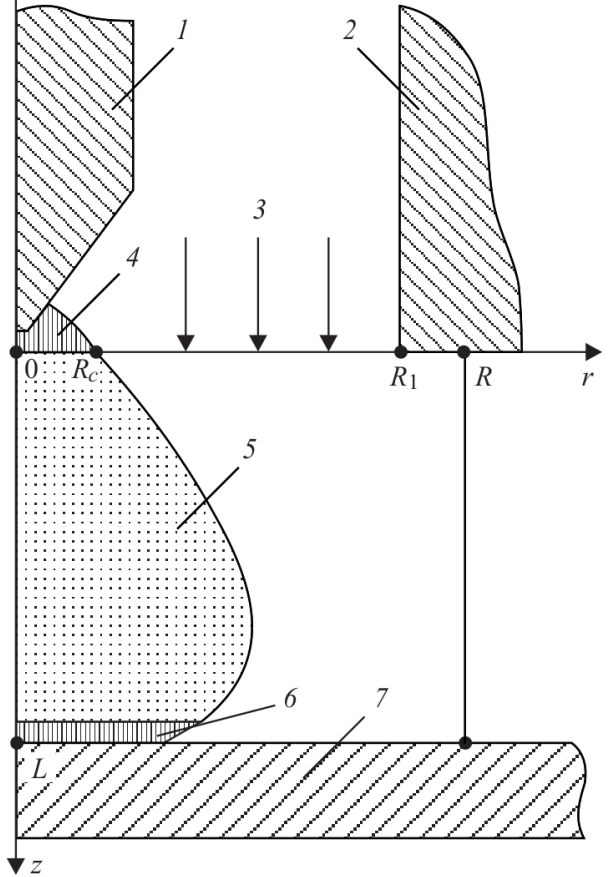

Fig re 1 Scheme for calculation of the characteristics of an arc with a refractory cathode: 1 - tungsten cathode; 2 - nozzle for shielding gas feeding; 3 - shielding gas; 4 - cathode region; 5 - arc column; 6 - anode layer; 7 - anode; $R_{c}$ - cathode region radius; $R_{1}$ - nozzle radius; $R$ - calculated area radius

netic field acts as the main force factor determining the gas-dynamic situation in the arc column. An actual component of this force is the vortex component of the Lorentz force [16]
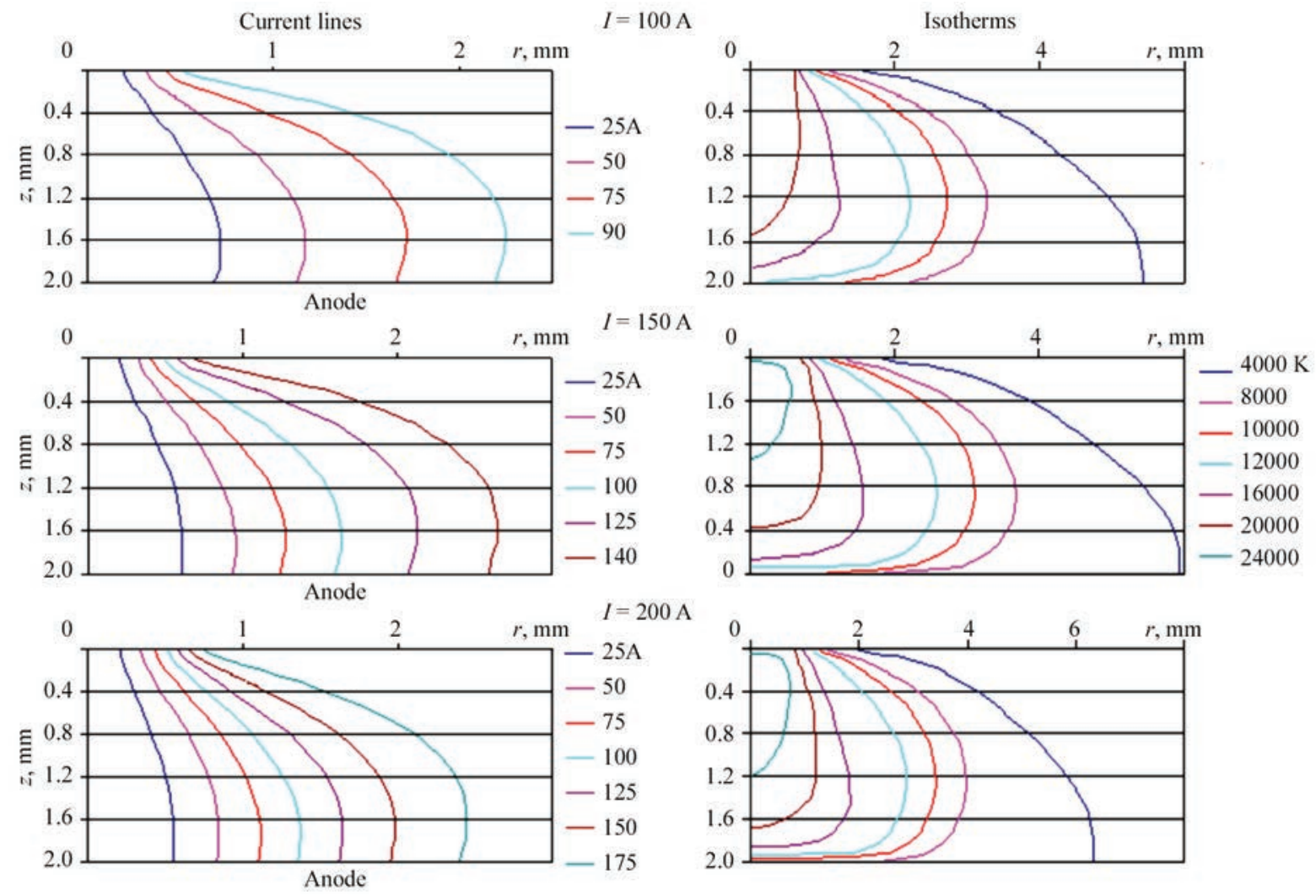

Fig re 2 Current lines and isotherms of temperature field in the arc column 

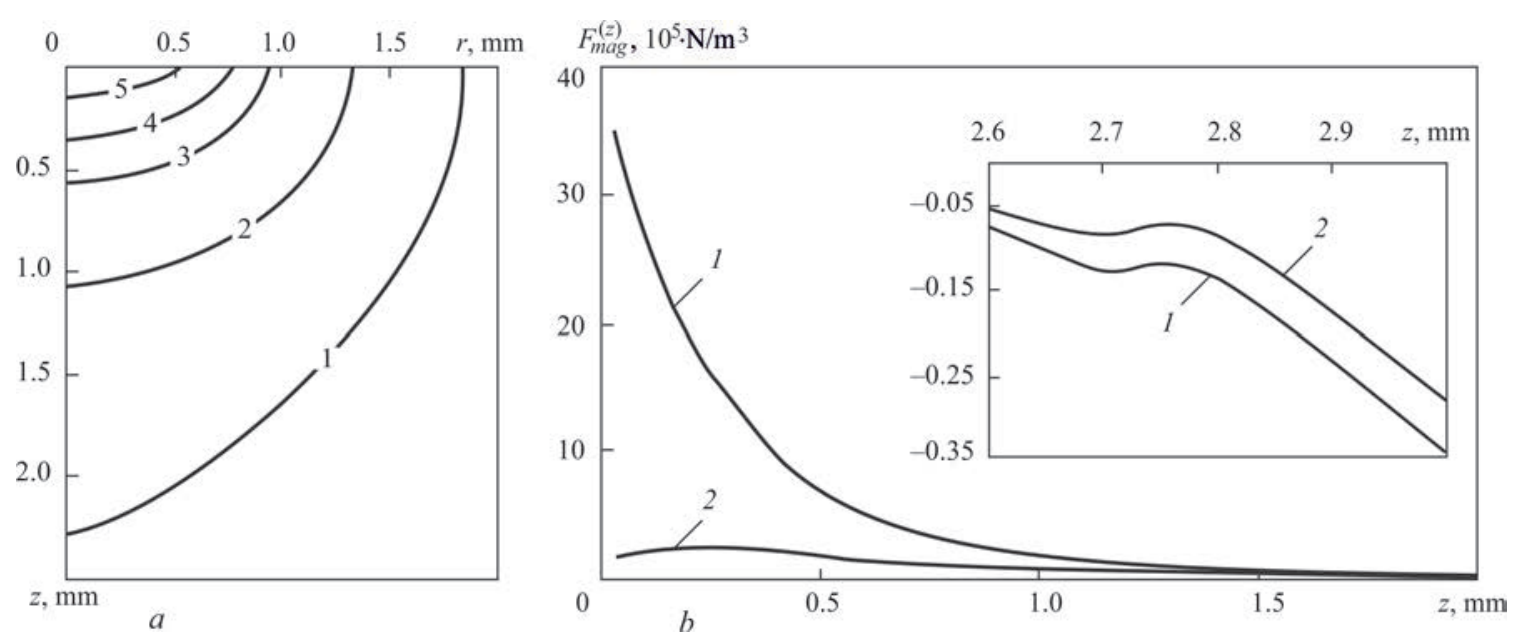

Fig re 3 Force characteristics of electromagnetic field in arc column: $a-$ magnetic pressure isobar field $\left(1-P_{\operatorname{mag}}=100 ; 2-200\right.$; $3-400 ; 4-600 ; 5-1000 \mathrm{~Pa}) ; b$ - distribution of axial component of the magnetic force along the arc column length (1 - on arc axis; 2 - at $r=1 \mathrm{~mm}$ )

$$
F_{r o t}^{\prime}(r, z)=-\mu_{0} \frac{I^{2}(r, z)}{4 \pi^{2} r^{3}} \vec{e}_{r}
$$

where $\{r, z\}$ are the cylindrical coordinates (see Figure 1$) ; \vec{e}_{r}$ is the unit radius-vector; $I(r, z)$ is the current flowing through a circle of radius $r$ in the axial section $z$ of the arc column; $\mu_{0}$ is the universal magnetic constant.

This centrifugal force induces magnetic pressure in the current channel

$$
P_{\text {mag }}(r, z)=-\int_{r}^{\infty} F_{r o t}(r, z) d r
$$

the gradient of which can be treated as a certain force of magnetic nature $\vec{F}_{\text {mag }}$, exciting the movement of arc plasma from the region of high values of magnetic pressure towards its decrease.

Results of the conducted computational experiments are indicative of the fact that in the arc column regions with a higher current density, the compressive action of vortex force $\vec{F}_{r o t}$ becomes stronger, and magnetic pressure rises, accordingly. Figure 3 illustrates the distribution of force characteristics of the electromagnetic field in the arc column $3 \mathrm{~mm}$ long at the current of $150 \mathrm{~A}$. Magnetic pressure value is maximum in the axial zone of the near-cathode region of the arc column, and decreases quickly along the radius and along coordinate $z$, measured from the cathode (see Figure 3,a). In the considered case, the maximum value of magnetic pressure does not exceed $1000 \mathrm{~Pa}$ that is equal to less than $1 \%$ of atmospheric pressure. However, a rapid change of magnetic pressure in the above region results in its gradient being quite significant. Thus, in the axial zone of near-cathode plasma the axial component of magnetic force $F_{\text {mag }}^{(z)}$ reaches the value of the order of $3 \cdot 10^{6} \mathrm{~N} / \mathrm{m}^{3}$ (see Figure $3, b$ ).
Magnetic force localizing in the axial zone of near-cathode plasma initiates movement of arc plasma, mainly, in the direction from the cathode to the anode. In the middle part of the arc column the magnetic pressure gradient becomes negligibly small, and plasma movement continues by inertia. Near the anode surface, this gradient changes its sign (see insert in Figure 3,b), i.e. magnetic force turns out to be directed away from the anode to the cathode. In the conditions considered here, the force of inertia of the plasma flow in the near-anode region of the arc column is greater than $F_{\text {mag }}^{(z)}$. Therefore, the action of the latter is limited just by partial deceleration of the plasma flow, alongside its gas-dynamic deceleration near the anode surface. In nonconsumable electrode welding, the anode current density can be significantly increased through application of special technological means, such as, for instance, use of activating flux [17], arc exposure to focused $\mathrm{CO}_{2}$-laser radiation [18]. In this case, the axial component of magnetic force near its surface, while remaining negative, rises in absolute value and at certain dimensions of the region of anode attachment of the arc, it remains capable of counteracting the force of inertia of the plasma flow. This can result in appearance of arc plasma movement towards the incoming plasma flow in near-anode plasma. Gas-dynamic interaction of these two flows is capable of creating two-vortex circulation of plasma in the arc column (see scenario 2 in work [16]).

Distribution of axial component of the vector of the velocity of plasma movement along the arc axis is given in Figure 4.

It is characteristic that at small values of arc current, the start of deceleration of the plasma flow is shifted closer to the cathode, whereas with current increase the deceleration region shifts towards the anode. Note also that with increase of arc length the 

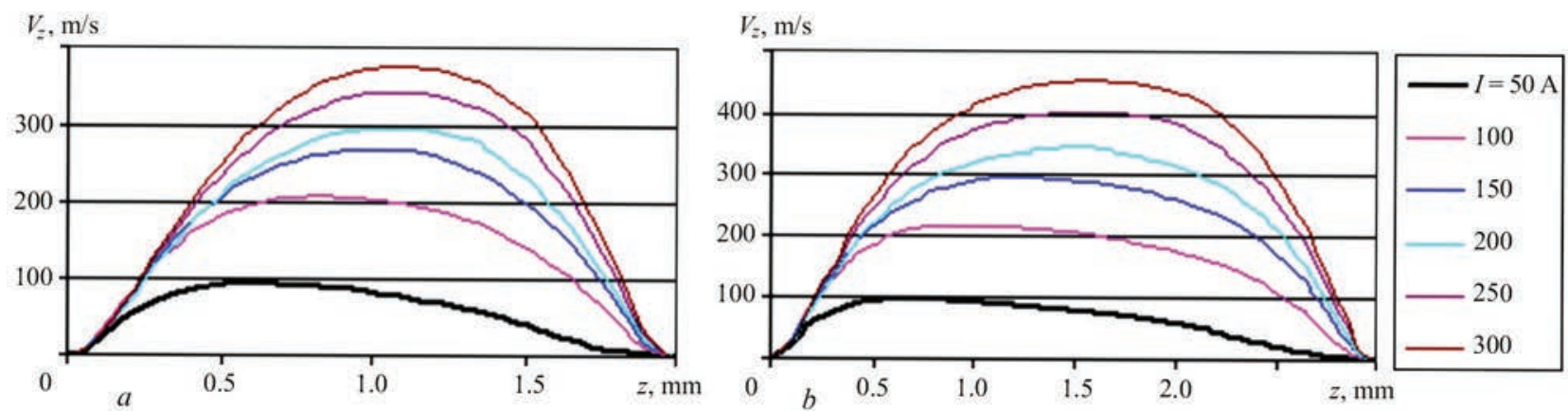

Fig re 4 Distribution of axial component of the vector of plasma velocity along the arc axis: $a-L=2 ; b-3 \mathrm{~mm}$
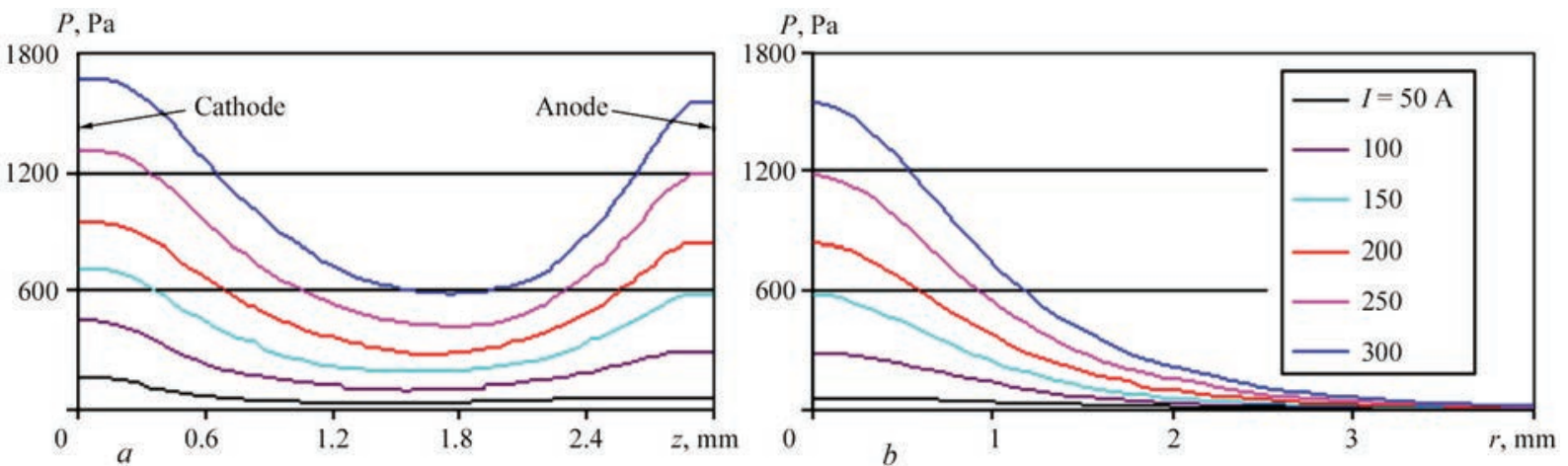

Fig re 5 Total pressure of plasma in $3 \mathrm{~mm}$ long arc: $a$ - on arc axis; $b$ - on anode surface

velocity of plasma flow movement rises markedly, which is accounted for by increase of transverse dimensions of its column (see Figure 2) and lowering of its gas-dynamic resistance, accordingly.

Distributions of total pressure on the axis of $3 \mathrm{~mm}$ long arc and on the anode surface are shown in Figure 5. Pressure varies nonmonotonically along the arc axis (see Figure 5, $a$ ): near the cathode it is higher as a result of the compressive impact of vortex force $\vec{F}_{\text {rot }}$ $(r, z)$ and high values of magnetic pressure, respectively (see Figure 3,a); in the center of arc column total pressure decreases as a result of radial unloading of the plasma flow and relatively small magnetic pressure, and near the anode the pressure rises again
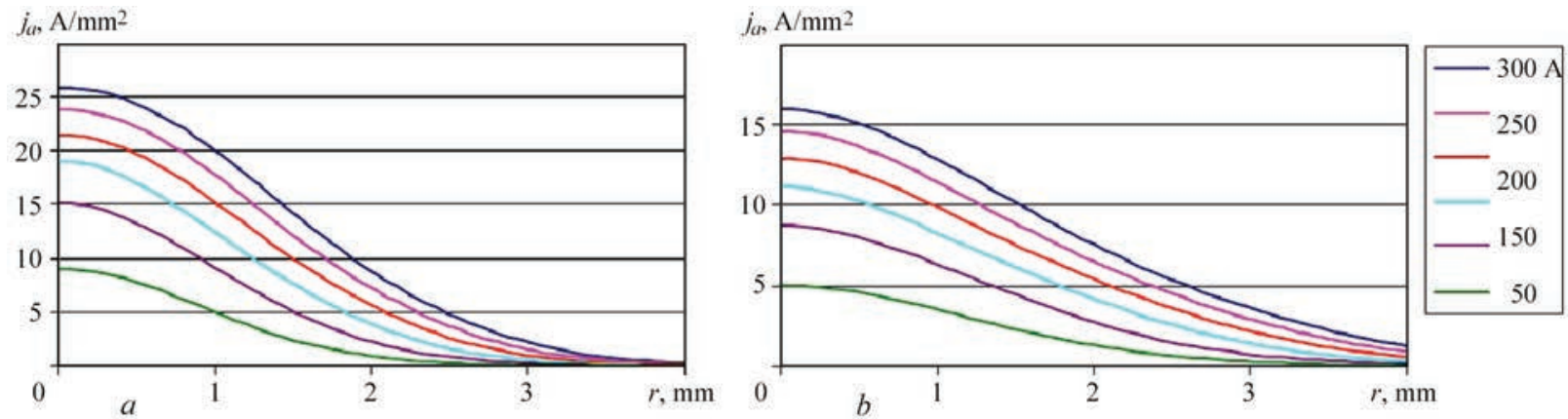

Fig re 6 Distribution of arc current density on anode surface: $a-L=2 ; b-3 \mathrm{~mm}$
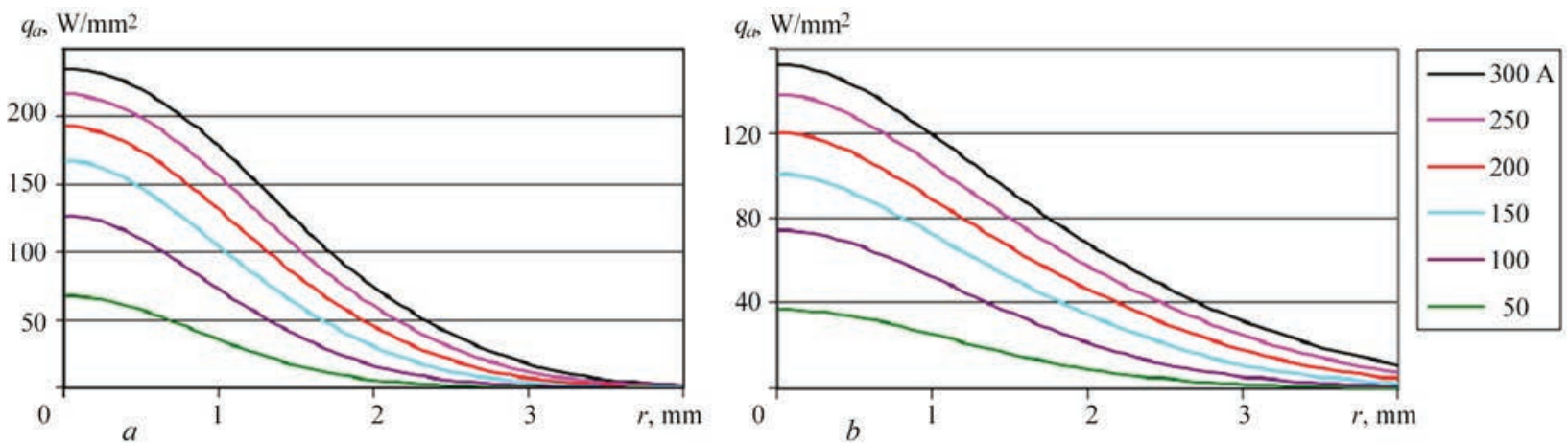

Fig re 7 Distribution of heat flow applied by the arc to the anode: $a-L=2 ; b-3 \mathrm{~mm}$ 


\section{SCIENTIFIC AND TECHNICAL}
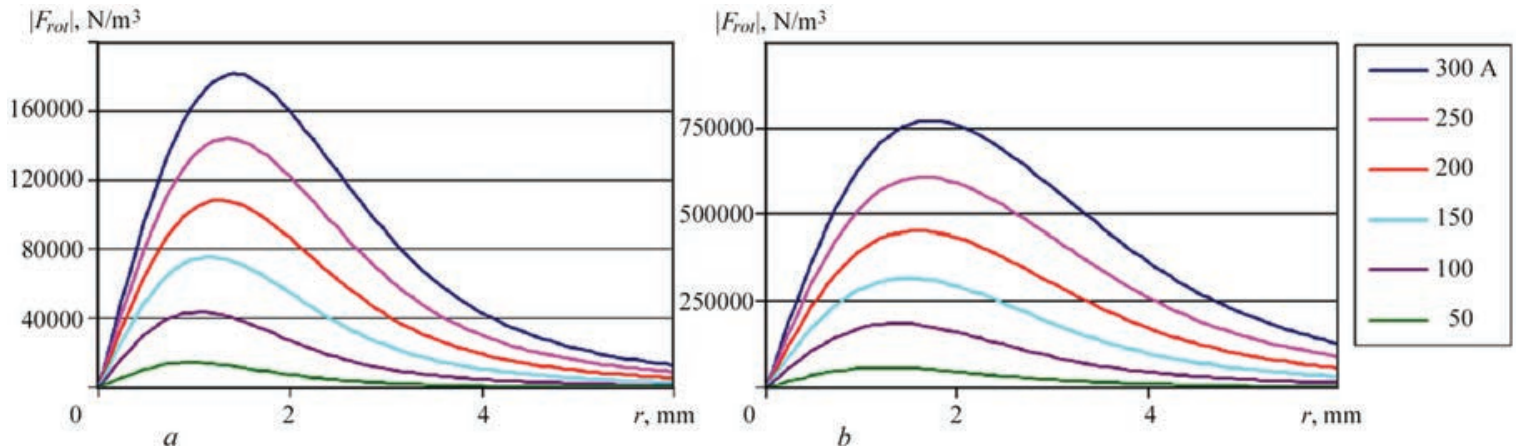

Fig re 8 Distribution of vortex component of the Lorentz force along the anode surface: $a-L=2 ; b-3 \mathrm{~mm}$
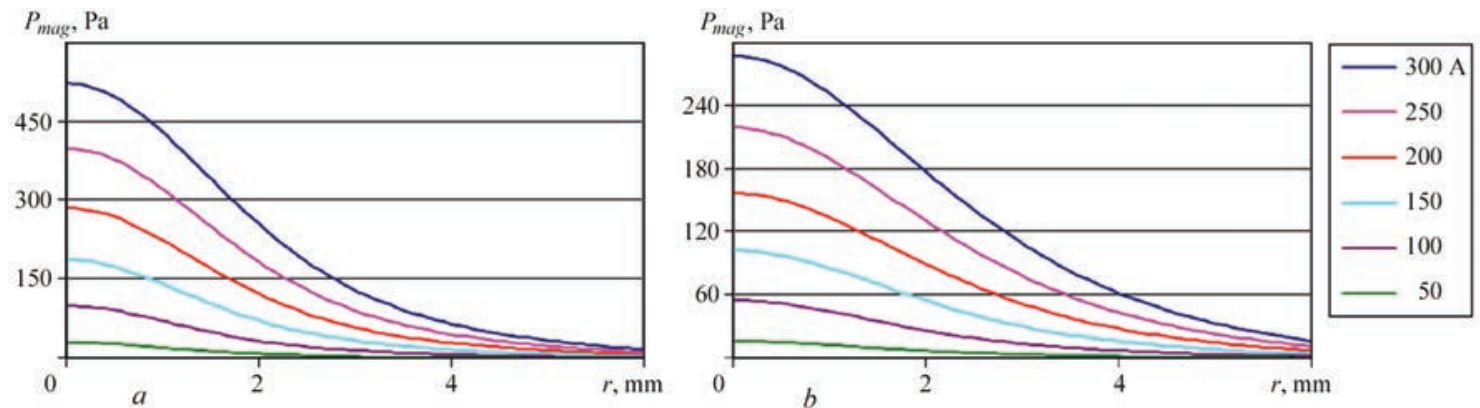

Fig re 9 Distribution of magnetic pressure along anode surface: $a-L=2 ; b-3 \mathrm{~mm}$
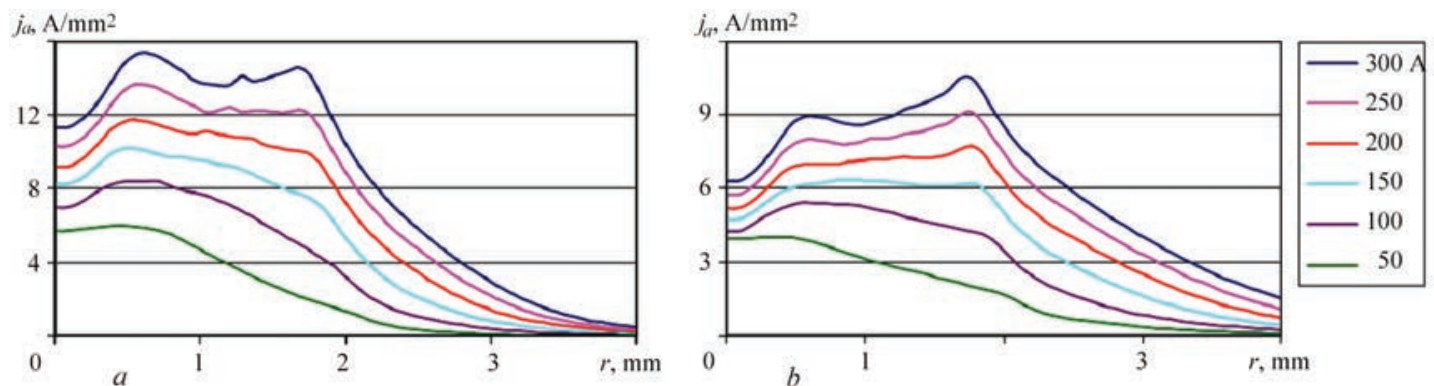

Fig re Distribution of arc current density over the surface of evaporating anode: $a-L=2 ; b-3 \mathrm{~mm}$
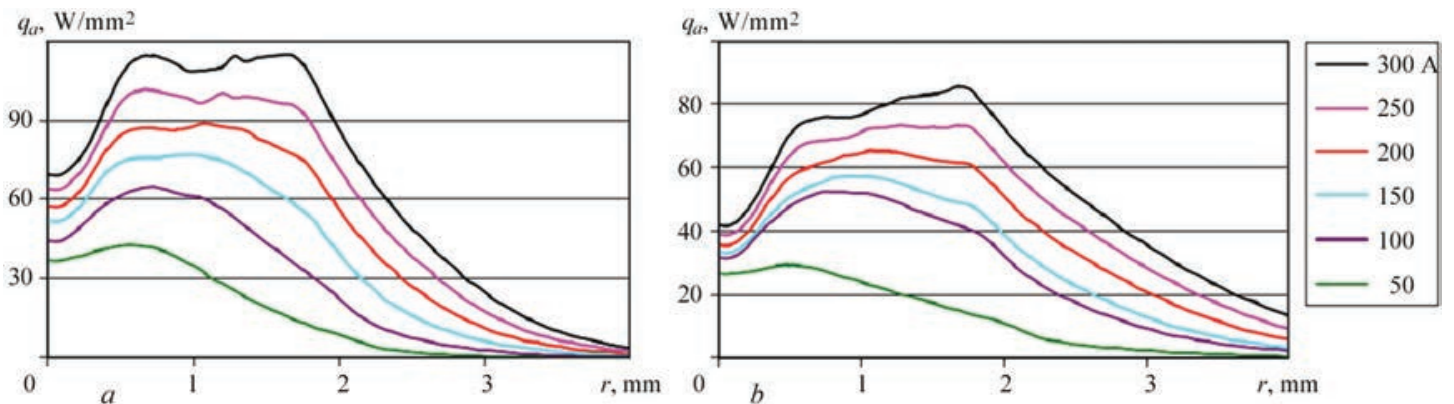

Fig re 11 Distribution of heat flow brought by the arc to the evaporating anode: $a-L=2 ; b-3 \mathrm{~mm}$
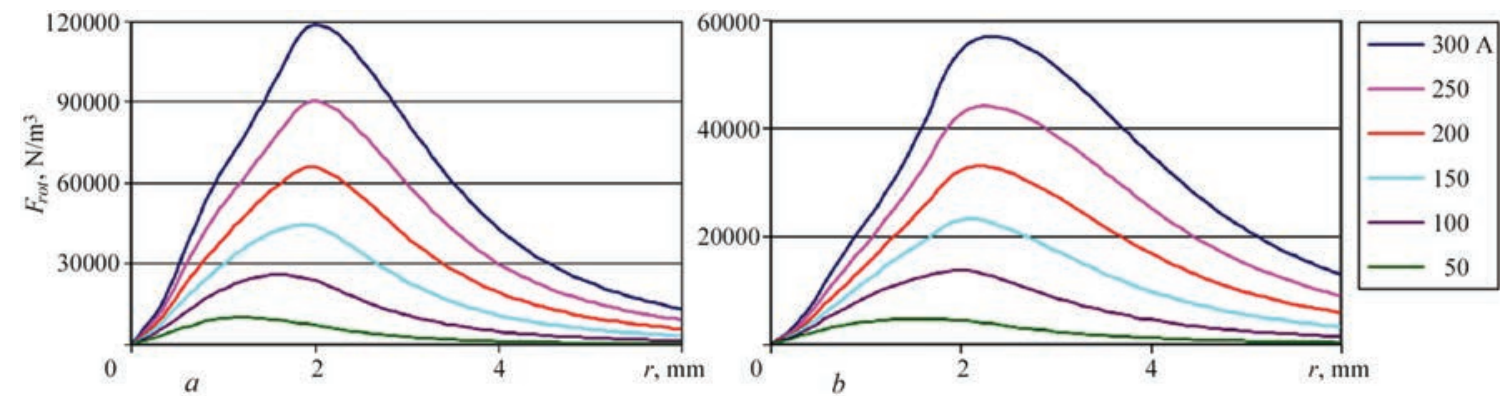

Fig re 2 Distribution of vortex component of Lorentz force along the evaporating anode surface: $a-L=2 ; b-3 \mathrm{~mm}$ 
as a result of deceleration of the plasma flow on its surface. Note that the fields of pressure in 2 and $3 \mathrm{~mm}$ long arcs differ only slightly. As regards total pressure on the anode surface, it rises with increase of arc current (see Figure 5, $b$ ).

It should be emphasized that the given in Figure $5, b$ distribution of total pressure over the anode surface forms as a sum of magnetic pressure and gas-dynamic pressure of incoming plasma flow. Considering that the jump of magnetic pressure on "plasma-anode metal interface» is equal to zero, from the view point of deformation of the weld pool free surface just the gas-dynamic pressure is relevant, which is the result of deceleration of the plasma flow near the above surface.

Cha a teristics 6 the a $\mathrm{c}$ a d e reg $n$. Let us consider the distributed characteristics of electric, thermal and force impact of arc plasma on the anode surface. Figures 6, 7 give the distributions of the density of electric current $j_{a}(r)$ and heat flow $q_{a}(r)$, brought by the arc to the anode, over the surface of water-cooled (nonevaporating) anode. As follows from calculated dependencies, shown in these Figures, the anode current density and specific heat flow to the anode decrease with increase of the arc length, that is in agreement with experimental data of work [19].

With shortening of the arc length, anode current contraction becomes higher: calculated values of anode current density on the axis of $2 \mathrm{~mm}$ long arc are more than 1.5 times higher compared to $3 \mathrm{~mm}$ arc (compare with Figure 6, $a, b$ ). The force impact of vortex component of Lorentz force $\vec{F}_{\text {rot }}$ increases accordingly, both on the weld pool surface, and in its volume, leading to intensification of gas-dynamic flow of the melt and higher penetrability of the arc [16]. Distributions of $\left|F_{\text {rot }}\right|$ over the anode surface for 2 and $3 \mathrm{~mm}$ long arcs are shown in Figure 8, and magnetic pressure distributions are presented in Figure 9.

An important factor, influencing the characteristics of arc column plasma and its interaction with the anode surface in nonconsumable electrode welding, is multicomponent nature of arc plasma, associated with metal evaporation from the weld pool surface. Figures 10-12 give the distributions of current density, heat flow and vortex component of the Lorentz force on the surface of an anode from low-carbon steel, evaporating in the diffusion mode, at model distribution of its temperature in the zone of anode attachment of the arc: $T_{s}(r)=\left(T_{s 0}-T_{\infty}\right) \exp \left(-a^{2} r^{2}\right)+$ $+T_{\infty}$, where $T_{s 0}=3050 \mathrm{~K}$ is the surface temperature on the arc axis; $T_{\infty}=500 \mathrm{~K}$ is the surface temperature at considerable distance from the axis, and the concentration ratio $a$ is determined so that the radius of the molten zone on the surface of the steel anode was equal to $2.5 \mathrm{~mm}$ [20].

As follows from comparison of Figure 10 and Figure 6 , the current density on the surface of the evaporating anode turns out to be considerably smaller than in the case of water-cooled anode, the most marked lowering of $j_{a}(r)$ being observed in the center of the region of anode attachment of the arc, where the local minimum of the above value is reached. Density of heat flow brought by the arc to the evaporating anode behaves in a similar way (compare Figure 11 and Figure 7). As regards reduction of the density of current and heat flow into the anode at increase of arc length (see Figures 6, 7), this tendency is preserved also for the evaporating anode (see Figure 10, $a, b$ and Figure $11, a, b)$.

The noted lowering of current density on the anode surface, allowing for its material evaporation, results in the respective reduction of vortex component of Lorentz force $\vec{F}_{\text {ot }}$ on the weld pool surface (see Figures 8,12 ), that leads to weakening of convective heat transfer in its volume, thus lowering the penetrability of an arc with evaporating anode.

Another factor, determining the characteristics of the electric, thermal and force impact of the arc on the anode surface, is the fact that the anode potential drop $U_{a}$, defined as the difference of anode surface potential $\varphi_{a}$ and plasma potential on anode layer boundary $\varphi_{p a}$, is not constant in the region of anode attachment of the arc. In view of the high conductivity of metallic materials, the anode surface is practically equipotential, that is why the anode electric potential $\varphi_{a}$ can be considered constant with good approximation. As regards value $\varphi_{p a}$, then, as its determining parameters (near-anode plasma temperature and anode current density) have nonuniform distributions along the anode surface (see Figure 2, b), the above value and, therefore, the anode potential drop also are nonuniform in the region of anode attachment of the arc [20].

As an illustration, Figure 13 gives the distributions of plasma potential along the boundary of anode layer with the column of the arc with refractory cathode and copper water-cooled anode, 2 and $3 \mathrm{~mm}$ long, in comparison with the respective distribution of near-anode plasma temperature. The large slope of $\varphi_{a}(r)$ dependence for $2 \mathrm{~mm}$ arc, compared to $3 \mathrm{~mm}$ arc at $100 \mathrm{~A}$ current (see Figure 13,a) is due to a similar nature of temperature curve change (see Figure 13, $b$ ).

As the anode layer boundary is isopotential, there exists a different from zero radial gradient of potential, and, accordingly, the current density vector has radial component $j_{r}$. Here, the greater the steepness of $\varphi_{p a}$ radial change, the larger is the respective component of current density. This effect is illustrated in Figure 4, 

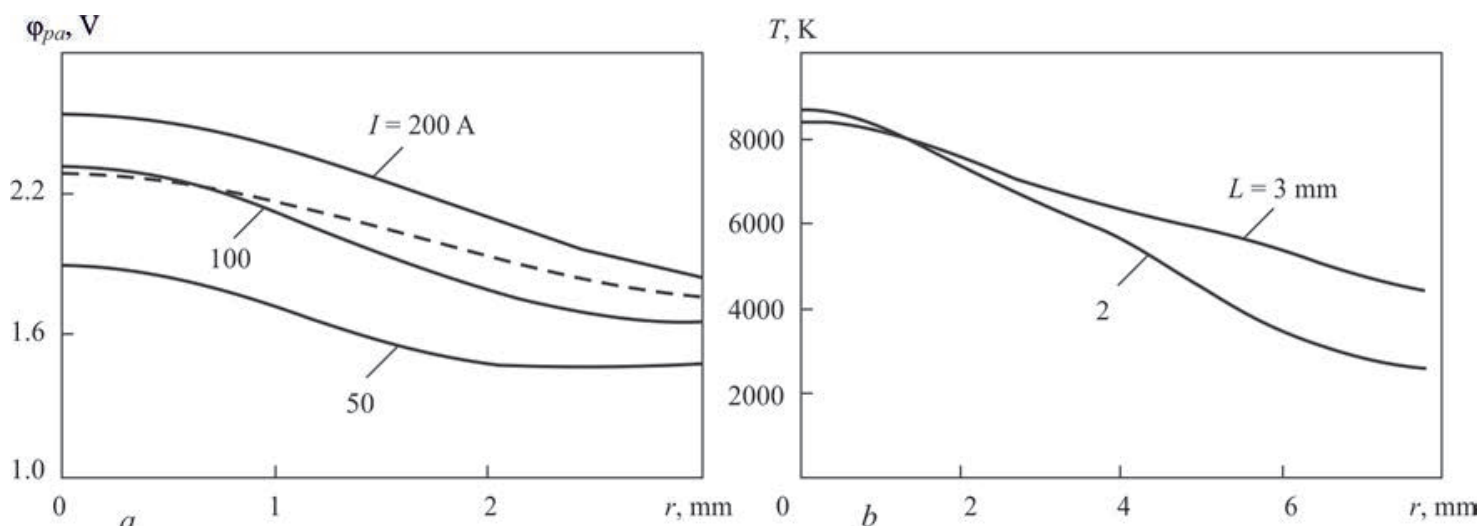

Fig re 3 Distributions of plasma potential along the boundary of anode layer and arc column $(a)$ at different values of current of $2 \mathrm{~mm}$ long arc (solid curves), and for $100 \mathrm{~A}$ arc of $3 \mathrm{~mm}$ length (dashed curve), as well as temperature distributions of near-anode plasma along the anode surface $(b)$ for $100 \mathrm{~A}$ arc of 2 and $3 \mathrm{~mm}$ length (anode surface potential is taken to be constant and equal to zero)

which shows the change of $j_{r}$ along the boundary of anode layer for 2 and $3 \mathrm{~mm}$ arcs at 100 A current. With $j_{r}$ increase (for shorter arcs) the angle between the vector of anode current density and arc axis increases, that is indicative of a stronger contraction of the current channel in the direction to the anode and higher anode current density, respectively (see Figure 6).

In conclusion of this section, special attention should be paid to the fact that the anode potential drop $U_{a}=U_{a}=\varphi_{a}-\varphi_{p a}$ in the considered arcs is negative, that is in agreement with the known calculated and experimental data $[8,13,21,22]$.

Integ $h$ cha a teristics 6 the a c. An important integral characteristic, determining the electric and energy properties of the arc discharge, is its volt-ampere characteristic (VAC), which relates voltage across the $\operatorname{arc}$ gap $U$ with arc current $I$. Figure 15 shows the results of approximation by the procedure, described in [23], of experimental data on VAC of an argon arc with a refractory cathode and copper water-cooled anode at different values of arc length: $L=1.5 ; 2,3 \mathrm{~mm}$. The volt-ampere characteristic of the arc can be associated with its watt-ampere characteristic, correlating arc power $P=I U$ with current $I$ (see Figure $15, b$ ).

Total arc voltage $U$ is usually presented as sum $U=$ $=U_{c}+U_{p}+U_{a}$, where $U_{c}$ is the cathode voltage drop;

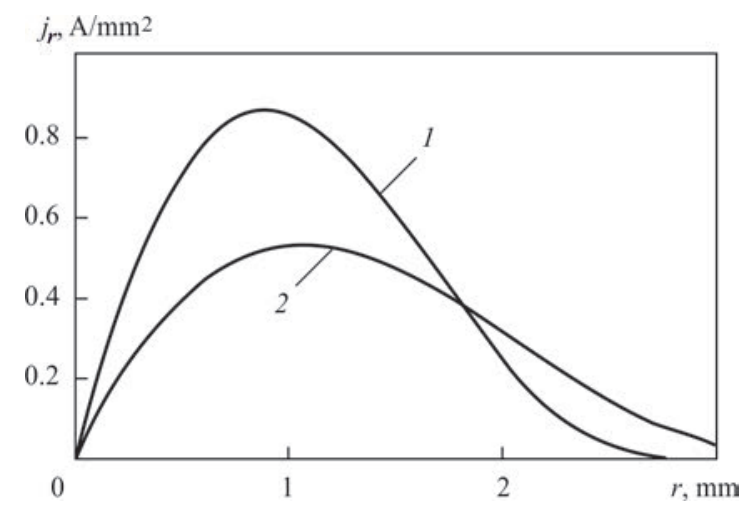

Fig re 1 Distributions of radial component of current density vector along the anode surface: $1-L=2 ; 2-3 \mathrm{~mm}$
$U_{p}$ is the arc column voltage; $U_{a}$ is the anode drop [24]. Accordingly, the arc power can be presented in the following form $P=P_{c}+P_{p}+P_{a}$, where $P_{c}=U_{c} I$, $P_{p}=U_{p} I$ and $P_{a}=U_{a} I$ are the powers released in the cathode region, arc column and anode region, respectively. Since the anode drop is negative $\left(U_{a}<0\right)$, as was noted above, arc power $P$ is smaller than the total power, released in the column and cathode region of the arc by value $\left|P_{a}\right|$, consumed for maintaining the anode layer. These, on the whole, correct relationships, require further refinement from the viewpoint of what should be understood by values $U_{c}, U_{p}, U_{a}$, allowing for the change of electric potential along the interfaces of the anode and cathode regions with the arc column.

In view of the high conductivity of anode and cathode metal, potentials $\varphi_{a}$ and $\varphi_{c}$ of their surfaces can be assumed to be practically constant. Therefore, total arc voltage can be determined as the difference of the respective potentials, i.e. $U=\varphi_{a}-\varphi_{c}$. Such a generally accepted definition of voltage in the form of the difference of potentials is not suitable for calculation of the cathode and anode drops, or arc column voltage. Therefore, another definition of the above values should be given, and so that integral Ohm and JouleLentz laws remained valid. With this purpose, we will introduce effective (averaged) values of potentials $\Phi_{p a}$ and $\Phi_{p c}$ on boundaries $\Gamma_{p a}$ and $\Gamma_{p c}$, separating the anode and cathode regions from the arc column, as follows:

$$
\Phi_{p a}=\frac{1}{I} \int_{\Gamma_{p a}} \varphi j_{n} d \Gamma_{p a} ; \Phi_{p c}=\frac{1}{I} \int_{\Gamma_{p c}} \varphi j_{n} d \Gamma_{p c}
$$

Then effective voltage drop across the arc column can be determined as the difference of effective values of the respective potentials, i.e. we can assume $\left\langle U_{p}\right\rangle=\Phi_{p a}-\Phi_{p c}$. Effective anode $\left\langle U_{a}\right\rangle=\varphi_{a}-\Phi_{p a}$ and cathode $\left\langle U_{c}\right\rangle=\stackrel{p c}{\Phi}_{p c}-\varphi_{c}$ potential drops are determined similarly. 

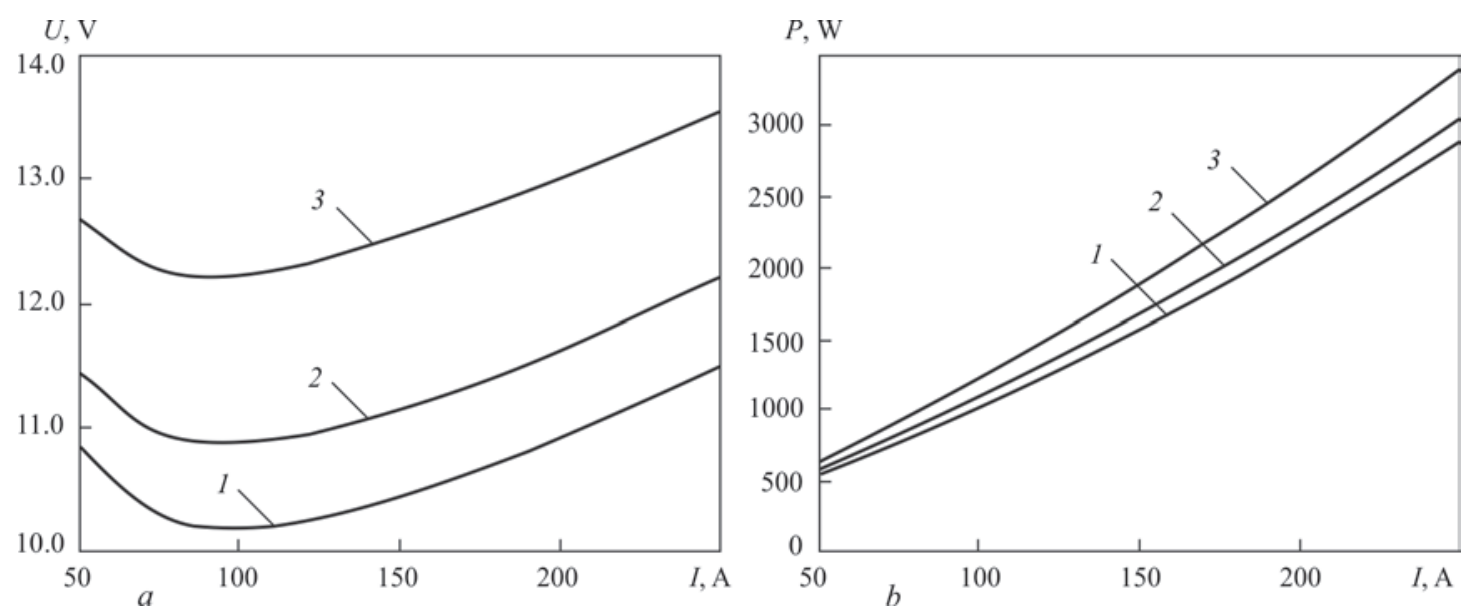

Fig re 5 Volt- $(a)$ and watt-ampere $(b)$ characteristics of an argon arc with refractory cathode and copper water-cooled (nonevaporating anode): $1-L=1.5 ; 2-2 ; 3-3 \mathrm{~mm}$

Figure 16 gives the scheme of distribution of electric potential $\varphi$ and effective components of voltage in the arc gap introduced as showed above. Here, total arc voltage can be presented as a sum of respective effective components: $U=\left\langle U_{c}\right\rangle+\left\langle U_{p}\right\rangle+\left\langle U_{a}\right\rangle$, allowing for $\left\langle U_{a}\right\rangle<0$. In terms of the introduced effective values of voltage drop in individual regions of the arc, the total balance of the respective powers can be written similarly: $P=\left\langle P_{c}\right\rangle+\left\langle P_{p}\right\rangle+\left\langle P_{a}\right\rangle$, where $\left\langle P_{c}\right\rangle=$ $=I\left\langle U_{c}\right\rangle,\left\langle P_{p}\right\rangle=I\left\langle U_{p}\right\rangle,\left\langle P_{a}\right\rangle=I\left\langle U_{a}\right\rangle$. Here, the integral Joule-Lenz law remains valid both for individual components of the arc discharge, and for the arc as a whole.

It does not seem possible to give a theoretical evaluation of effective value of cathode potential drop within the used model of the arc $[14,15]$, because of an approximate description of the cathode region. However, if the volt-ampere characteristic of the arc is known (see Figure 15, a), the effective cathode drop can be calculated from the following formula $\left\langle U_{c}\right\rangle=$ $=U-\left\langle U_{p}\right\rangle-\left\langle U_{a}\right\rangle$, using the calculated data on effective potential drops $\left\langle U_{p}\right\rangle,\left\langle U_{a}\right\rangle$, as well as experimentally measured arc voltage $U$.

Figure 17 gives the experimental and calculated dependencies of $U,\left\langle U_{p}\right\rangle,\left\langle U_{a}\right\rangle$ on current for an argon arc of $2 \mathrm{~mm}$ length, burning between the refractory cathode and copper water-cooled anode. The values of effective cathode potential drop, depending on arc current, calculated as shown above, are given in Figure 18. This figure also gives the results of experimental determination of the cathode drop [25]. Comparison of calculated and experimental data shows their correspondence with the accuracy not lower than $15 \%$ that is indicative of quite acceptable adequacy of the mathematical model, used in this work.

Let us now turn to integral characteristic of the anode processes in considered arcs. As follows from Figure 17, $b$, the effective anode potential drop in the argon arc with refractory cathode and copper water-cooled anode, being negative, increases in absolute value with increase of arc current. Its length has practically no effect on $\left\langle U_{a}\right\rangle$. The role of anode potential drop in the total arc voltage is quite significant. In particular, at current of $200 \mathrm{~A}$, the calculated value of effective anode drop for $3 \mathrm{~mm}$ long argon arc is $2.24 \mathrm{~V}$, that is equal to about $17 \%$ of arc voltage $U=$ $=13 \mathrm{~V}$ (see curve 3 in Figure 15, a). Energy consumption for maintaining the anode layer and the total arc power $P$ correlate likewise.

An important factor, affecting the anode potential drop in arcs with a refractory cathode, is anode material evaporation. Calculated dependencies of $\left\langle U_{a}\right\rangle$ on $I$ for $2 \mathrm{~mm}$ long arcs with copper water-cooled anode and steel evaporating anode are given in Figure 19. As follows from the curves shown in this Figure, effective value of anode drop in an arc with an evaporating cathode, while remaining negative, turns out to be smaller by absolute value than the respective value for an arc with a copper water-cooled anode practically in the entire considered current range.

In the theory of thermal processes in welding, it is accepted to evaluate the total heat flow:

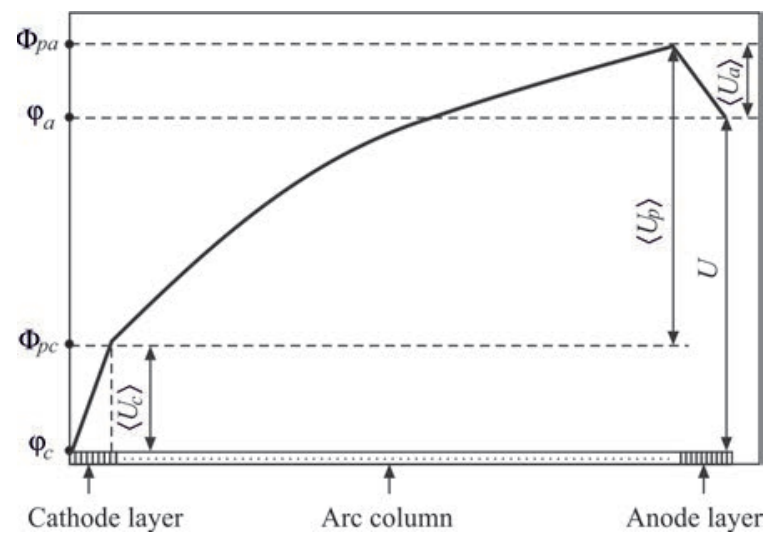

Fig re Scheme of electric potential distribution and effective components of arc voltage 

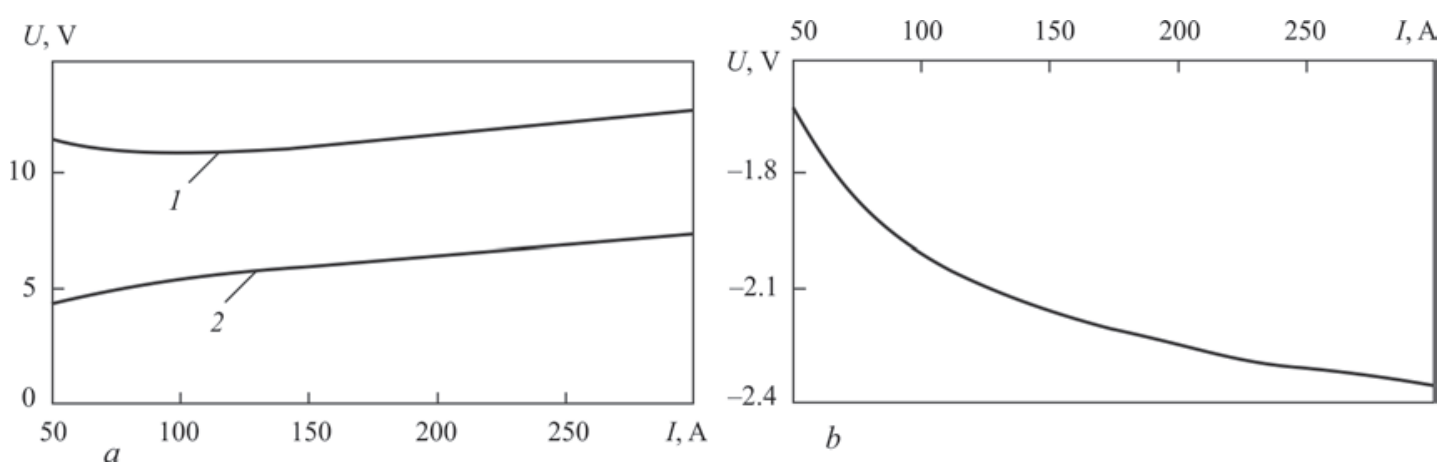

Fig re 1 Voltage of $2 \mathrm{~mm}$ long arc and its components, depending on current: $a$ - total arc pressure $U$ ( 1 - experiment); effective value of arc column voltage $\left\langle U_{p}\right\rangle\left(2\right.$ - calculation); $b$ - effective value of anode potential drop $\left\langle U_{a}\right\rangle$ (calculation)

$$
Q_{a}=2 \pi \int_{0}^{\infty} r q_{a}(r) d r
$$

brought by the arc to the anode, proceeding from a simple formula $Q_{2}=\eta P$, where $\eta$ is the effective efficiency of the arc, determined experimentally. This expression is not universal, as value $\eta$ at TIG welding depends on current and arc length, material being welded, shielding gas and other welding conditions. Therefore, determination of effective efficiency of the arc requires conducting the calorimetric measurements in each specific case that is unproductive. Instead of that, we can perform estimation of value $Q_{a}$, depending on current and length of the arc that will

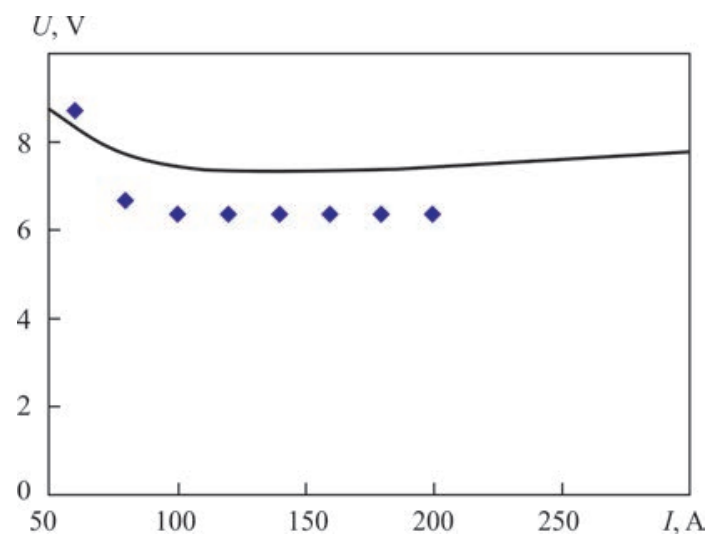

Fig re 8 . Effective cathode potential drop $\left\langle U_{c}\right\rangle$ : solid curve calculation; markers - experimental data [25]

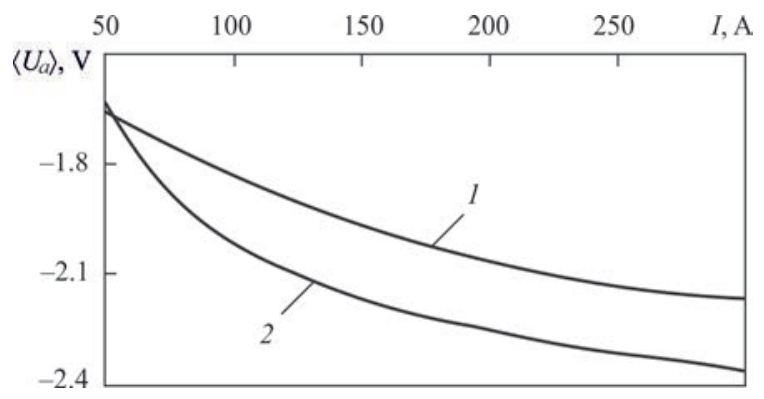

Fig re . Dependencies of effective value of anode potential drop on current of an arc with steel evaporating anode (1) and copper water-cooled anode (2) allow determination of respective $\eta$ value, knowing its watt-ampere characteristic.

Let us first evaluate the effective radius of the current or heat spots of the $\operatorname{arc}\left(R_{c}, R_{h}\right.$, respectively) on the surface of a copper water-cooled anode, depending on arc current and length. By effective radius of the current or heat spot we mean the radius of a circle, within which $95 \%$ of arc current $I$ or, accordingly, total heat flow $Q_{a}$ applied by the arc to the anode, are concentrated. Data given in Figure 20, show that in the entire considered range of currents $R_{c} \approx R_{h}$, and they increase practically linearly with $I$ rise. In addition, as was anticipated, the dimensions of the zone of current and thermal impact of the arc on the anode surface become larger with increase of arc length.

Calculated dependencies of total heat power

$$
Q_{a}=2 \pi \int^{\infty} r q_{a}(r) d r
$$

applied to the copper water-cooled anode on arc current and length, are given in Figure 21, from which it follows that value $Q_{a}$ grows practically linearly with increase of arc current. As was already noted, specific heat flow $q_{a}(r)$ included into $Q_{a}$ definition, decreases with increase of arc length (see Figure 7). Despite that, the total heat flow into the anode turns out to be even somewhat larger for a $3 \mathrm{~mm}$ arc than for 2 $\mathrm{mm}$ arc (see Figure 21). This feature of longer arcs is attributable, on the one hand, to increase of arc discharge power (arc voltage rises at the same current),

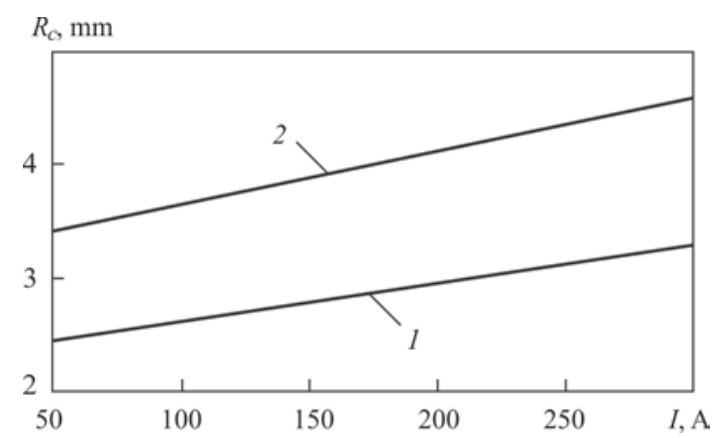

Fig re D Dimensions of current and heat spots of the arc on anode surface: $1-L=2 ; 2-3 \mathrm{~mm}$ 


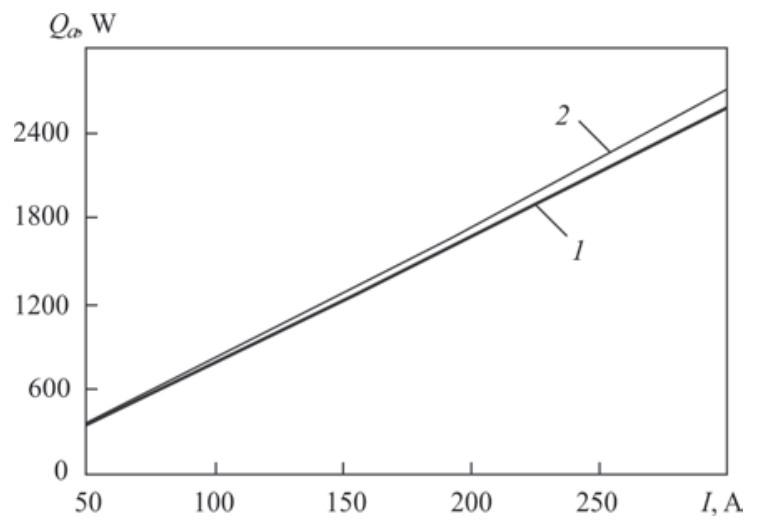

Fig re 21 Total heat flow brought by the arc to the anode: 1 $L=2 ; 2-3 \mathrm{~mm}$

and, on the other hand, increase of the diameter of the zone of thermal impact of the arc on the anode surface (see Figure 20). As regards comparison of calculated values with those measured experimentally, according to the data of [26], the above-mentioned value is equal to $2.05 \mathrm{~kW}$ at $I=200 \mathrm{~A}, L=3 \mathrm{~mm}$, and differs from calculated value $Q_{a}=1.8 \mathrm{~kW}$ (see curve 2 in Figure 21) by not more than $15 \%$.

Data given in Figure 21, together with the experimental data on watt-ampere characteristic of the arc (see Figure 15, $b$ ) allow conducting calculated-experimental estimate of effective efficiency by formula $\eta=$ $Q_{a} / P$. The thus calculated $\eta$ values for arcs of different length, depending on current, are shown in Figure 22, and are indicative of the fact that the arc efficiency decreases wit increases of its length, and, in addition, in the considered current range $\eta$ value has a maximum, which is in the interval from 130 up to $170 \mathrm{~A}$.

In conclusion of this section it should be noted that the processes of heating and melting of the metal being welded (temperature field, weld pool shape and dimensions) are determined not only by $Q_{a}$ or $\eta$ value, but also depend on such arc impact characteristics, distributed over the surface of metal being welded, as specific heat flow into the anode and density of electric current on its surface. These characteristics have different effects on thermal state of the metal being welded: the first of them is responsible for conductive energy transfer (heat conduction mechanism), and the second determines the intensity of hydrodynamic flows, and convective heat transfer in the molten metal, accordingly.

Discussin a d cn clusin s. Given in this work results of calculation of distributed and integral characteristics of free-burning argon arc with a refractory cathode and their dependencies on arc current and length are quite predictable in terms of quality. A new circumstance, which was revealed due to introduction of current lines into consideration, is the effect of constriction of the current channel in near-anode

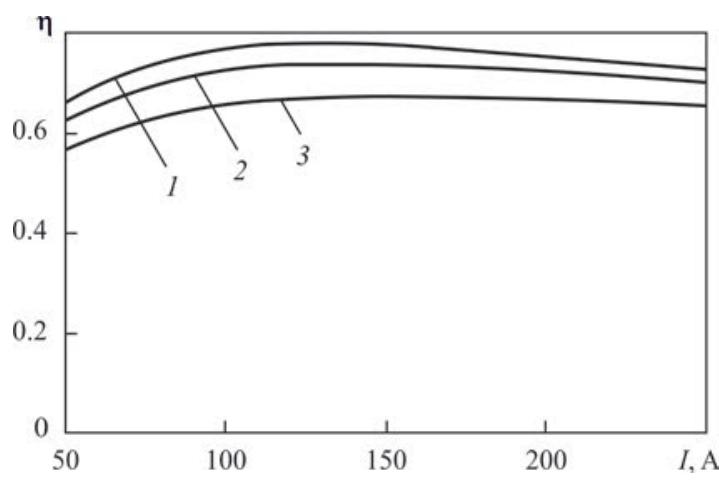

Fig re 2 Dependencies of effective efficiency of an arc with copper water-cooled cathode on arc current and length: $1-L$ $=1.5 ; 2-2 ; 3-3 \mathrm{~mm}$

region, which is manifested in the entire considered range of arc currents and lengths. With increase of the density of electric current on the surface of the anode (metal being welded), the force impact of arc current on weld pool metal becomes stronger, that promotes an increase of the velocity of melt flowing into the pool bottom part, and, as a result, greater depth of penetration of the metal being welded. Thus, unlike the theory of thermal processes in welding, based on heat conductance mechanism of energy transfer, the law of distribution of the density of heat flow into the anode is not the only characteristic, determining the weld pool shape. Another, not less important factor, influencing the arc penetrability, is the law of distribution of current density on the surface of the metal being welded. At all other conditions being equal, we should try to reduce the size of current channel, and increase the density of electric current on anode surface, accordingly повысить проницаемость дуги с тугоплавким катодом. In this context, the arc length is not the only parameter, allowing control of anode current distribution. There are a number of techniques in the arsenal of welding science, which allow increasing the anode current density: use of activating fluxes, selection of special composition of shielding gas (gas mixture), arc exposure to focused laser radiation, high-frequency pulse modulation of welding current, etc. Application of these effects, activating the arc process, and of their synergic combinations is a promising direction for improvement of the nonconsumable electrode welding process.

1. Hsu, K.C., Etemadi, K., Pfender, E. (1983) Study of the free-burning high-intensity argon arc. J. of Appl. Phys., 54, 3, 1293-1301.

2. Hsu, K.C., Pfender, E. (1983) Two-temperature modeling of the free-burning high-intensity arc. Ibid., 54, 8, 4359-4366.

3. Lowke, J.J., Morrow, R., Haidar, J. (1997) A simplified unified theory of arcs and their electrodes. J. Phys. D: Appl. Phys., B , 2033-2042.

4. Haidar, J. (1999) Non-equilibrium modeling of transferred arcs. Ibid, $\mathbf{3}, 263-272$. 
5. Sansonnets, L., Haidar, J., Lowke, J.J. (2000) Prediction of properties of free burning arcs including effects of ambipolar diffusion. Ibid., 3 , 148-157.

6. Masquere, M., Freton, P., Gonzalez, J.J. (2007) Theoretical study in two dimensions of the energy transfer between an electric arc and an anode material. Ibid.,, $432-446$.

7. Tanaka, M., Yamamoto, K., Tashiro, S. et al. (2008) Metal vapour behaviour in gas tungsten arc thermal plasma during welding. Welding in the World, 52(11 ), 82-88.

8. Dinulescu, H.A., Pfender, E. (1980) Analysis of the anode boundary layer of high intensity arcs. J. of Appl. Phys, 5 , 3149-3157.

9. Dyuzhev, G.A., Nemchinsky, V.A., Shkolnik, S.M. et al. (1983) Anode processes in high-current arc discharge. Khimiya Plazmy, , 169-209 [in Russian].

10. Nazarenko, I.P., Panevin, I.G. (1989) Analysis of the near-anode processes character in argon arc discharge of high pressure. Contrib. Plasma Phys., 2 , 251-261.

11. Jenista, J., Heberlein, J.V.R., Pfender, E. (1997) Numerical model of the anode region of high-current electric arcs. IEEE Trans. on Plasma Science, $\mathbf{z}$, 883-890.

12. Amakawa, T., Jenista, J., Heberlein, J. et al. (1998) Anodeboundary-layer behavior in a transferred, high intensity arc. $J$. Phys. D: Appl. Phys., 3 , 2826-2834.

13. Tanaka, M., Ushio, M., Wu, C.S. (1999) One-dimensional analysis of the anode boundary layer in free-burning argon arcs. Ibid., $\mathbf{3}, 605-611$.

14. Krivtsun, I.V., Demchenko, V.F., Krikent, I.V. (2010) Model of the processes of heat, mass and charge transfer in the anode region and column of the welding arc with refractory cathode. The Paton Welding J., 6, 2-9.

15. Krikent, I.V., Krivtsun, I.V., Demchenko, V.F. (2014) Simulation of electric arc with refractory cathode and evaporating anode. Ibid., 9, 17-24.

16. Demchenko, V.F., Krivtsun, I.V., Krikent, I.V. et al. (2017) Force interaction of arc current with self magnetic field. Ibid.,3, 15-24.
17. Yushchenko, K.A., Kovalenko, D.V., Krivtsun, I.V. et al. (2009) Experimental studies and mathematical modeling of penetration in TIG and A-TIG stationary arc welding of stainless steel. Welding in the World, 53( ), 253-263.

18. Krivtsun, I.V., Krikent, I.V., Demchenko, V.F. et al. (2015) Interaction of $\mathrm{CO}_{2}$-laser beam with electric arc plasma in hybrid (laser-arc) welding. The Paton Welding J., 3 , 6-15.

19. Yushchenko, K.A., Kovalenko, D.V., Kovalenko, I.V. (2005) Peculiarities of A-TIG welding of stainless steel. In: Proc. of the 7th Int. Conf. on Trends in Welding Research - Pine Mountain, Georgia, USA, 367-376.

20. Krivtsun, I., Demchenko, V., Krikent, I. et al. (2015) Distributed and integrated characteristics of the near-anode plasma of the welding arc in TIG and hybrid (TIG $+\mathrm{CO}_{2}$-laser) welding. In: Mathematical Modelling of Weld Phenomena $11-$ Techn. Universität Graz, Austria, 837-874.

21. Tanaka, M., Ushio, M. (1999) Observations of the anode boundary layer in free-burning arcs. J. Phys. D: Appl. Phys., 3 , 906-912.

22. Sanders, N.A., Pfender, E. (1984) Measurement of anode falls and anode heat transfer in atmospheric pressure high intensity arcs. J. of Appl. Phys., 5 , 714-722.

23. Sydorets, V.N., Krivtsun, I.V., Demchenko, V.F. et al. (2016) Calculation and experimental research of static and dynamic volt-ampere characteristics of argon arc with refractory cathode. The Paton Welding J., 2, 2-8.

24. Lancaster, J.F. (1986) The physics of welding. 2nd Ed. Pergamon Press.

25. Uhrlandt, D., Baeva, M., Kozakov, R. et al. (2013) Cathode fall voltage of TIG arcs from a non-equilibrium arc model. In: IIW Essen, 2013, Group 212 - Physics of Welding.

26. Nestor, O.H. (1962) Heat intensity and current density distributions at the anode of high current, inert gas arcs. J. of Appl. Phys., 33(5), 1638-1648.

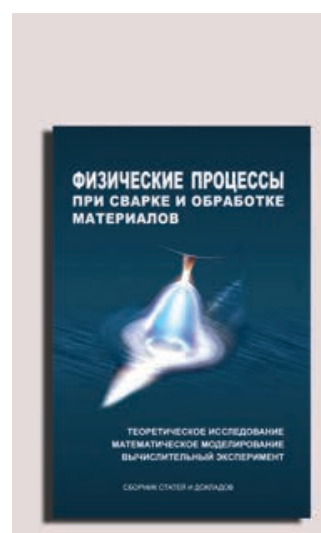

\section{WEW BOOK}

Physical processes in welding and material treatment. Theoretical investigation, mathematical modelling, numerical simulation collection of articles and reports: Collection of articles and reports edited by Prof. I.V. Krivtsun. Kyiv: International Association «Welding», 2018. - 642 p. ISBN 978-617-7015-74-0 (in Russian, English, Ukrainian).

The collection includes 86 papers and reports of research workers of the Department of physics of gas discharge and plasma technique at the E.O. Paton Electric Welding Institute of the NAS of Ukraine, being published in the period of 1978-2018. It generalizes the forty-year experience of research activity of the Department in the field of theoretical research and computer modelling of physical phenomena taking place in arc, plasma, laser and hybrid processes of welding, surfacing and coating deposition. It can be interesting and useful to the scientists, engineers and technologists dealing with the problems of arc, plasma, laser and hybrid welding and material treatment as well as post graduates and students studying theoretical basics of welding and related processes.

Orders for the collection, please send to the Editorial Board.

Collection in the open acces:

https://patonpublishinghouse.com/compilations/Krivtsun_Sbornik_2018_small.pdf 


\title{
STRESS-STRAIN STATE OF W LDED AND BRAZED ASSEMBLIES FROM DISSIMILAR MATERIALS W TH SOFT INTERLAYER AT THERMAL LOADING
}

\author{
V.V.K VASNYTSKYI ${ }^{1}$, VF . KVASNYTSKYI ${ }^{2}$ M .V.M ATVIIENKO ${ }^{2}$, \\ EA .B UTURLYA ${ }^{2}$ and G.V . YERMOLAYEV ${ }^{2}$ \\ ${ }^{1}$ National Technical University of Ukraine «Igor Sikorsky Kyiv Polytechnic Institute» \\ 37 Peremohy Prosp., Kyiv-56, Ukraine. E-mail: kvas69@ukr.net \\ ${ }^{2}$ National University of Shipbuilding \\ 9 Heroiv Ukrainy Prosp., 54025, Mykolaiv, Ukraine. E-mail: welding@nuos.edu.ua
}

\begin{abstract}
Computer modeling by finite element method was used to study the stress-strain state in joints of homogeneous materials under axial load. The studies were carried out taking into account plastic deformations in soft interlayers, which are usually used in diffusion welding to activate surfaces and reduce residual stresses. In brazing the intermediate layer is the braze weld, that differs from the base metal in its physical and mechanical properties. It is shown that along the butt, both in the metals being joined, and in the interlayer, equivalent stresses are distributed more uniformly than during elastic deformation. Plastic deformations in the interlayer are absent in the zone of stagnation (on the axis of the cylindrical assembly) and are almost linearly increased, reaching maximum values (about $6.5 \%$ ) at the outer cylindrical surface of the assembly. A high level of plastic deformations indicates the feasibility of using thermal loading in diffusion welding of dissimilar materials with soft interlayers. The degree of «softness» of the interlayer and its effect on the stress-strain state of the assembly during plastic deformation is mainly determined by its strength (yield limit) and almost does not depend on its rigidity (moludus of elasticity). 8 Ref., 1 Table, 10 Figures.
\end{abstract}

Ke y wor $\boldsymbol{d} \boldsymbol{s}:$ welded and brazed assemblies, soft interlayer, computer modeling, stress-strain state, thermal loading

Brazing and diffusion welding are becoming ever wider applied in modern engineering, as they allow producing assemblies from dissimilar materials, which cannot be connected by fusion welding. However, one of the problems in such components is their strength under force and thermal loading.

Stressed state and work of the joints with interlayers, in particular, with a soft interlayer, was studied in $[1,2]$ by analytical methods, which do not allow taking into account all the factors of the influence of stress-strain state (SSS).

ANSYS program package, based on finite element (FE) method was used in this work, which allows taking into account the design and technological factors, material features, kinds of loading, etc., as well as establishing the main regularities of SSS formation [3, 4].

In [5] it was established that in the joints with a soft interlayer, a bulk stressed state forms on the assembly generatrix and in the immediate vicinity of the butt under the impact of axial load, at which softening of the stronger and strengthening of the weaker metal is possible that influences the joint performance. The same effect can occur at cooling after welding and at the change of temperature during assembly operation. This work is timely, considering that SSS formation in the assemblies with an interlayer is little studied, and is important not only for joint formation, but also for their performance.

The objective of this work was investigation of SSS of welded and brazed assemblies from dissim- ilar materials, in particular, dissimilar steels with a copper-based soft interlayer under thermal loading by variation of temperature, taking into account plastic deformation of interlayer material, which was determined by Mises yield criterion.

Investigations were conducted on cylinder-cylinder $(\mathrm{C}-\mathrm{C})$ assemblies from materials of the same rigidity and strength with softer interlayers. Assembly dimensions were as follows: total height $2 h=40 \mathrm{~mm}$, diameter $d=20 \mathrm{~mm}$ and interlayer thickness $s=$ $=0.05 \mathrm{~mm}$ (Figure 1).

The materials being joined had different temperature coefficients of linear expansion (TCLE), equal to $20 \cdot 10^{-6}$ and $10 \cdot 10^{-6} \mathrm{l} / \mathrm{deg}$ in materials 1 and 2 , and interlayer material 3 had average TCLE value equal to $15 \cdot 10^{-6}$ and $10 \cdot 10^{-6} \mathrm{l} / \mathrm{deg}$ (Table).

As is seen from Table, in variants $1^{\prime}$ and $2^{\prime}$ joined are the materials having the same moduli of elasticity and yield limits, but the joint is made through a «soft» interlayer, having a lower yield limit, than the materials being joined, and lower (variant $1^{\prime}$ ) or the same (variant $2^{\prime}$ ) modulus of elasticity. Yield limit values of the base materials and interlayer in this variant were selected so that only the interlayer material was plastically deformed, and base material deformed only elastically. The strengthening coefficient at plastic deformation of interlayer material was taken to be equal to $1 \cdot 10^{3} \mathrm{MPa}$ for variant $1^{\prime}$ and $2 \cdot 10^{3} \mathrm{MPa}$ for variant $2^{\prime}$. Comparison of the variants allows isolating the ef- 

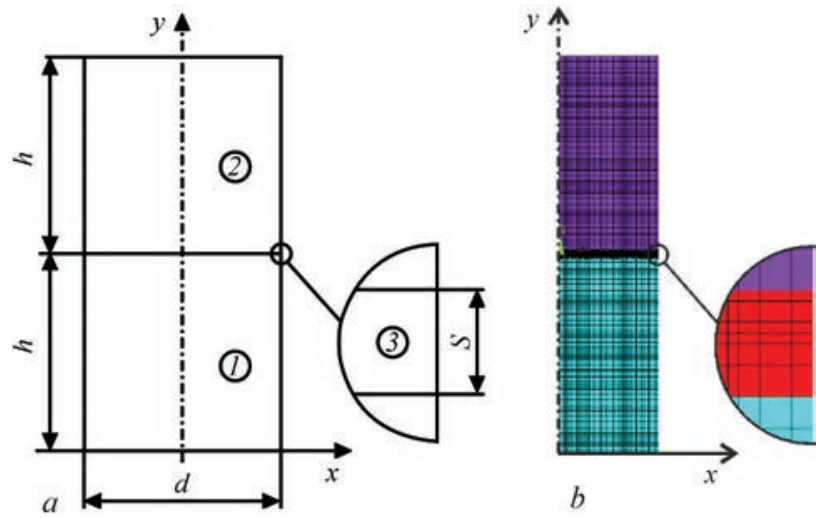

Fig re 1 Physical $(a)$ and FE $(b)$ models of components of $\mathrm{C}-\mathrm{C}$ type with an interlayer (1,2 are materials 1,2 , respectively; 3 interlayer)

fect of exactly the plastic component of deformation on the assembly SSS.

Loading was performed by lowering the assembly temperature by $100 \mathrm{deg}$ after formation of the joint, in which SSS is created due to different TCLE of the materials being joined. When cooling is replaced by heating by $100 \mathrm{deg}$, the level of stresses and strains does not change, and the signs are reversed.

Results were compared with similar assemblies (interlayers of small and medium rigidity) at elastic deformation (variants 1,2 ) considered in work [6].

Analysis of the fields and curves of all the components of stresses in the assemblies, and their comparison with the results of modeling the SSS of similar assemblies with an interlayer when working at the elastic stage (variants 1 and 2) showed that SSS in the materials being joined near the butt and in the interlayer is of a complex bulk nature, with nonuniform distribution across the assembly cross-section, both in the elastic and plastic variants, but the level of stresses decreases on the greater part of the butt due to plastic deformations.

Nature of distribution of radial $\sigma_{x}$ and circumferential $\sigma_{z}$ stresses in the assembly in the presence of plastic deformations is preserved, on the whole, but their value changes. They reach maximum values in the materials being joined in the vicinity of the butt plane (on the interfaces with the interlayer) in its middle part, but decrease more abruptly than at purely elastic deformation, when moving away from the butt (Figure 2). Along the butt in the base metal (Figure $3, a, b$ ) the radial stresses are more nonuniformly distributed in the interlayer in the presence of plastic deformations, decreasing quickly from the maximum

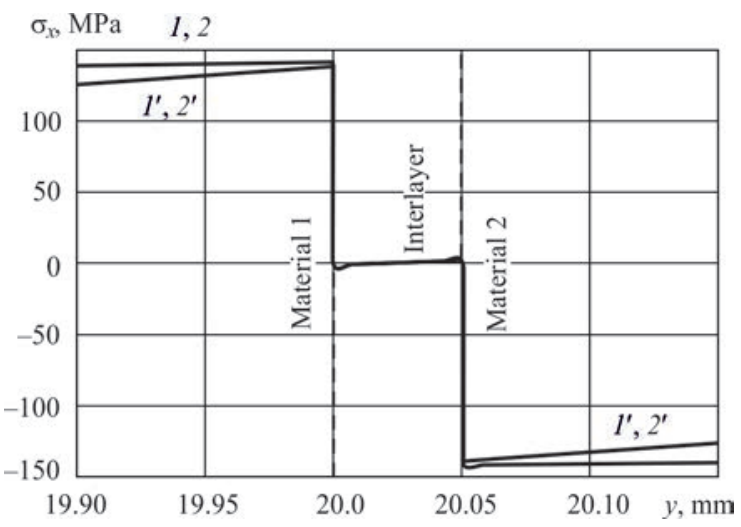

Fig re 2 Curves of radial stresses along the cylinder axis near the butt (variants $1,2,1^{\prime}$ and $2^{\prime}$ )

on the assembly axis to a minimum near the edge and abruptly increasing again on the very edge.

Along the butts the nature of radial stress distribution inside the interlayer is more uniform, they being small on the greater part of the butt (not exceeding $5 \mathrm{MPa}$ ), and increasing markedly (up to $90 \mathrm{MPa}$ ) near the outer cylindrical surface of the assembly (Figure 3,c,d). Here, the nature and level of stresses in materials 1,2 and interlayer on the boundaries with them differ only by their sign.

Maximum axial stresses $\sigma_{y}$, similar to the elastic stage of the work, are concentrated near the butt in immediate vicinity of the cylinder outer surface and decrease, when moving away from them (Figures 4, $5)$. Here, the nature and level of stresses in materials 1 and 2 also differ only by their sign. On the greater part of the butt and the side surface axial stresses are markedly lower than at the elastic stage of the work.

Tangential stresses are concentrated near the interlayer, having the largest value on the interfaces of the interlayer and base materials. They increase only slightly on the greater part of butt length, to a smaller degree than at the elastic stage of deformation, reaching a maximum at the very edge of the butt (Figure 6). Maximum tangential stresses in the presence of a soft interlayer (with a low yield limit) decrease similarly in both the materials and assemblies, irrespective of the interlayer rigidity. On the interfaces of both materials and the interlayer the dependence differs only by the stress sign.

Maximum equivalent stresses, similar to all the other components, are concentrated near the butts, i.e. the interfaces of materials 1,2 and the interlayer. Here, unlike the elastic stage, in the materials being joined they decrease up to two times with greater distance from the assembly axis, and only at the very

Variants of combinations of material properties (moduli of elasticity $E$, yield limits $\sigma_{\mathrm{y}}$ and TCLE $\alpha$ in the assemblies)

\begin{tabular}{|c|c|c|c|c|c|c|c|c|c|}
\hline \multirow{2}{*}{$\begin{array}{c}\text { Variant } \\
\text { number }\end{array}$} & \multicolumn{3}{|c|}{ Material 1 } & \multicolumn{3}{c|}{ Material 2 } & \multicolumn{3}{c|}{ Interlayer } \\
\cline { 2 - 10 } & $E, 10^{5} \mathrm{MPa}$ & $\sigma_{\mathrm{y}}, \mathrm{MPa}$ & $\alpha, 10^{-6} \cdot 1 / \mathrm{deg}$ & $E, 10^{5} \mathrm{MPa}$ & $\sigma_{\mathrm{y}}, \mathrm{MPa}$ & $\alpha, 10^{-6} \cdot 1 / \mathrm{deg}$ & $E, 10^{5} \mathrm{MPa}$ & $\sigma_{\mathrm{y}}, \mathrm{MPa}$ & $\alpha, 10^{-6} \cdot 1 / \mathrm{deg}$ \\
\hline 1 & 2 & - & 20 & 2 & - & 10 & 1 & - & 15 \\
\hline 2 & 2 & - & 20 & 2 & - & 10 & 2 & - & 15 \\
\hline$l^{\prime}$ & 2 & 200 & 20 & 2 & 200 & 10 & 1 & 38 & 15 \\
\hline $2^{\prime}$ & 2 & 200 & 20 & 2 & 200 & 10 & 2 & 38 & 15 \\
\hline
\end{tabular}



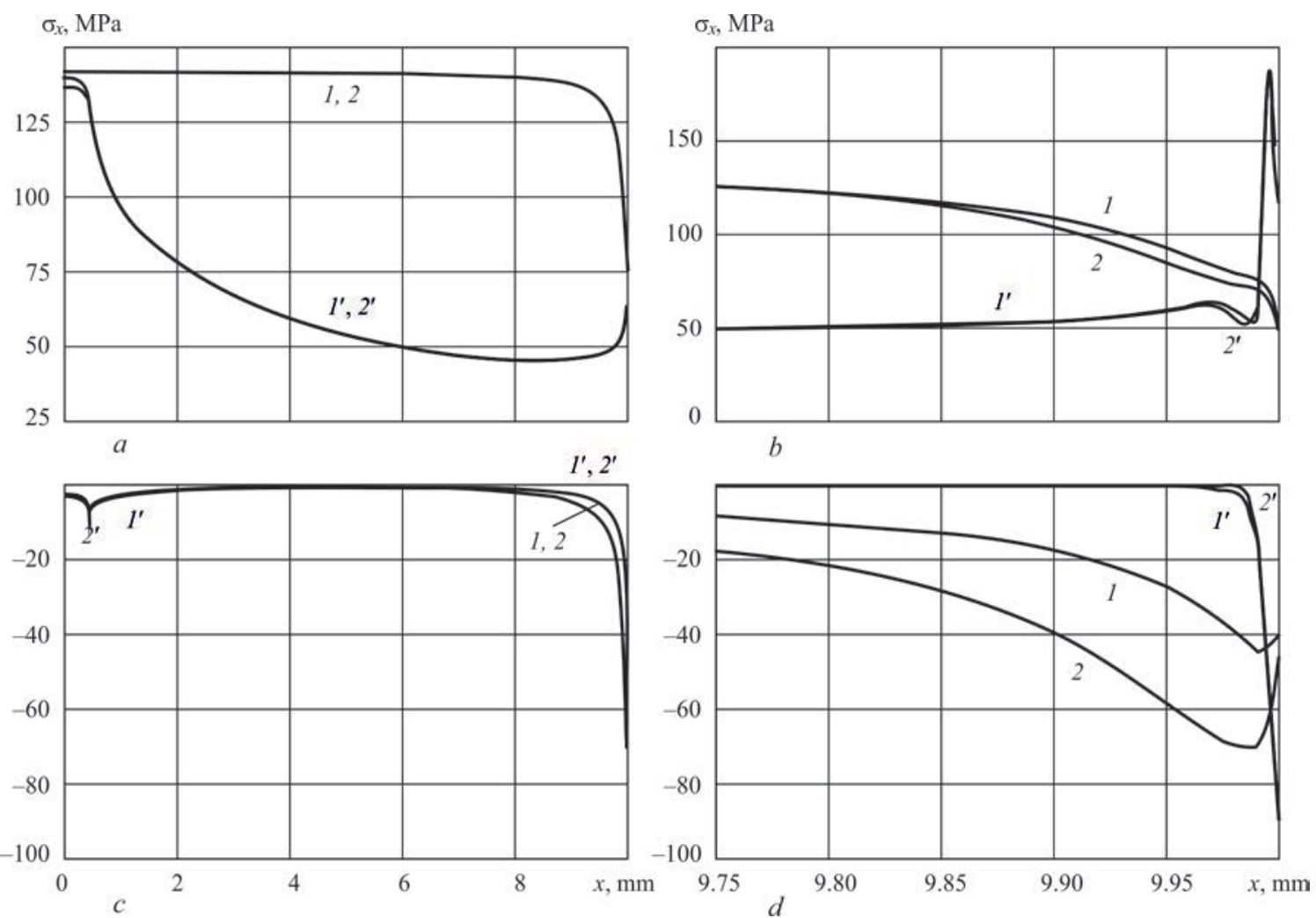

Fig re 3 Curves of radial stresses $\sigma_{x}$ in metal $l(a, b)$ and interlayer $(c, d)$ over the entire butt $(a, c)$ and near the outer edge $(b, d)$ of the assemblies (variants $1,2,1^{\prime}$ and $2^{\prime}$ )

edge of the butt they increase abruptly up to $200 \mathrm{MPa}$ (Figure 7, $a, b$ ).

In the interlayer, equivalent stresses are much lower, than at the elastic stage of the work, somewhat exceeding the yield limit of the interlayer material due to strengthening at plastic deformation and are practically uniformly distributed along the entire butt (Figure 7, $c, d$ ).

Plastic deformations in the interlayer along the butt are nonuniformly distributed, practically the same in variants $l^{\prime}$ and $2^{\prime}$ with an interlayer of different rigidity (Figure 8 ). They are absent in the «stagnation zone» [7] on the axis of the cylindrical assembly and increase gradually, when moving closer to the cylinder surface generatrix, reaching maximum values $(6.5 \%)$. The high level of plastic deformations is

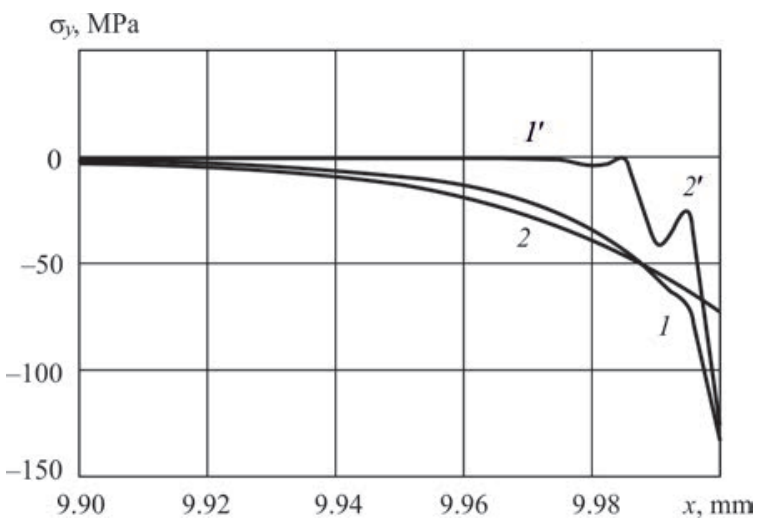

Fig re 4 Curves of axial stresses $\sigma$ over the butt of base metal 1 and interlayer near the outer edge (variants $1,2,1^{\prime}$ and $2^{\prime}$ )

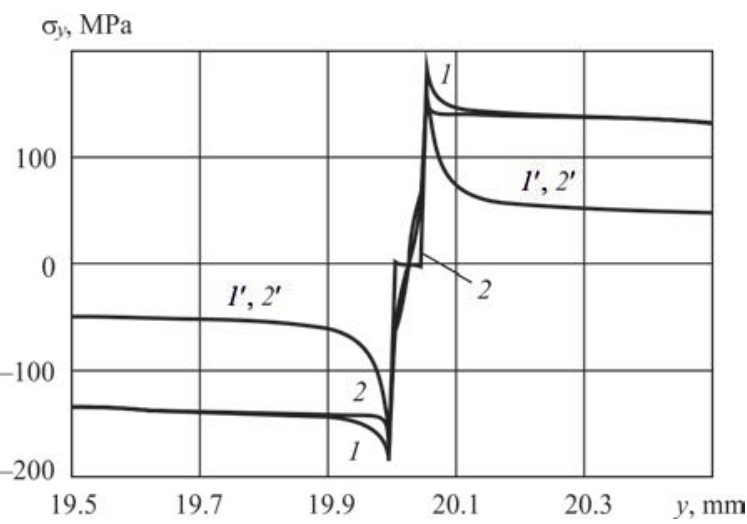

Fig re 5 Curves of axial stresses along the cylinder generatrix near the interlayer (variants $1,2,1^{\prime}$ and $2^{\prime}$ )

indicative of the rationality of application of thermal loading in diffusion welding with soft interlayers.

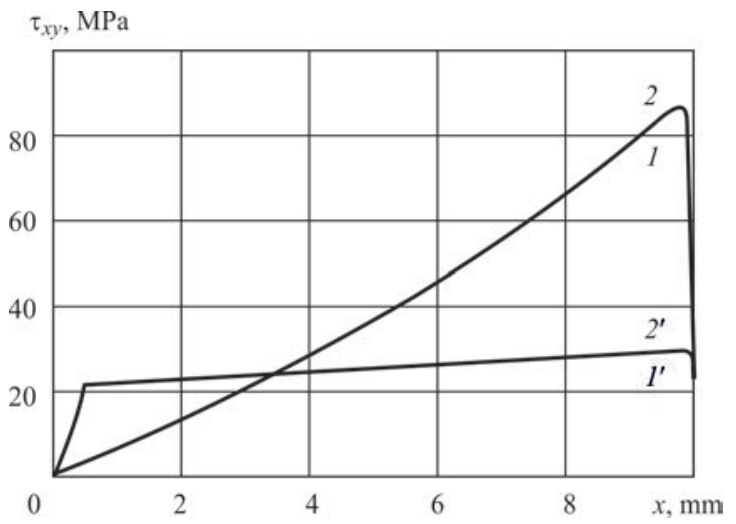

Fig re 6 Curves of tangential stresses $\tau_{x y}$ over the butt of base metal and interlayer (variants $1,2,1^{\prime}$ and $2^{\prime}$ ) 

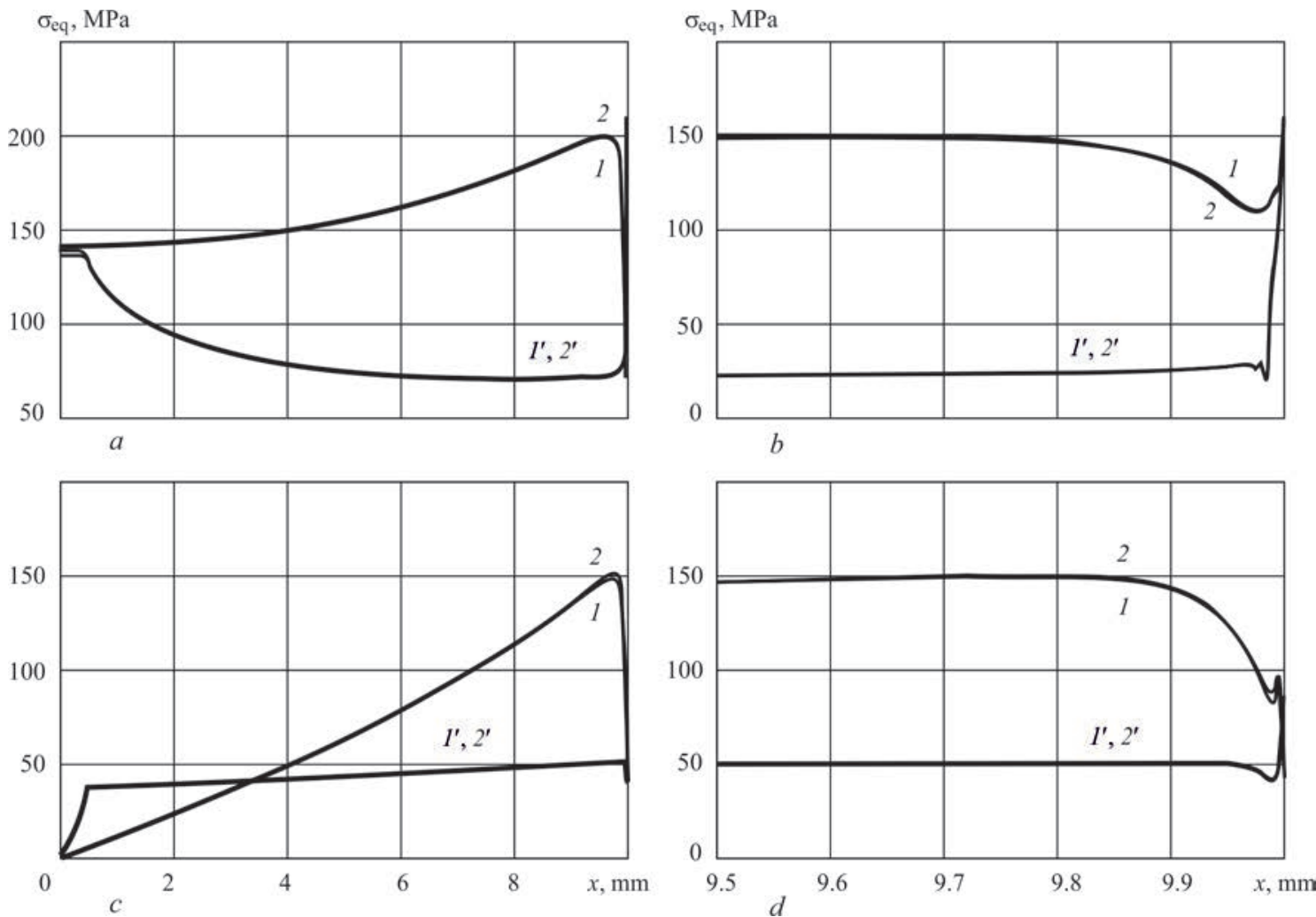

Fig re 7 Curves of equivalent stresses $\sigma_{\text {eq }}$ in the base metal $(a, b)$ and in the interlayer $(c, d)$ all over the butt $(a, c)$ and near its outer edges $(b, d)$

Diagrams in Figures 9 and 10 give the most complete and visual presentation of the change of maximum values of all the stress components in assembly materials in the presence of a soft interlayer, allowing for plastic deformations in it (var. $l^{\prime}$ and $2^{\prime}$ ), and comparison with the elastic stage of the work (var. 1 and 2) of assemblies with an interlayer of low (var. 1 and 1 ) and normal (var. 2 and 2') rigidity.

Maximum radial stresses in the presence of a soft interlayer (var. $l^{\prime}$ and $2^{\prime}$ ) increase in both the materials being joined, somewhat more in variant $2^{\prime}$, i.e. in the assemblies with an interlayer, where the «softness» is determined only by a lower yield limit at the same modulus of elasticity as that of the base metal (Figure 9).

Maximum axial stresses in the presence of a «soft» interlayer (var. $l^{\prime}$ and $2^{\prime}$ ), unlike the assemblies with an interlayer of a low rigidity at the elastic stage

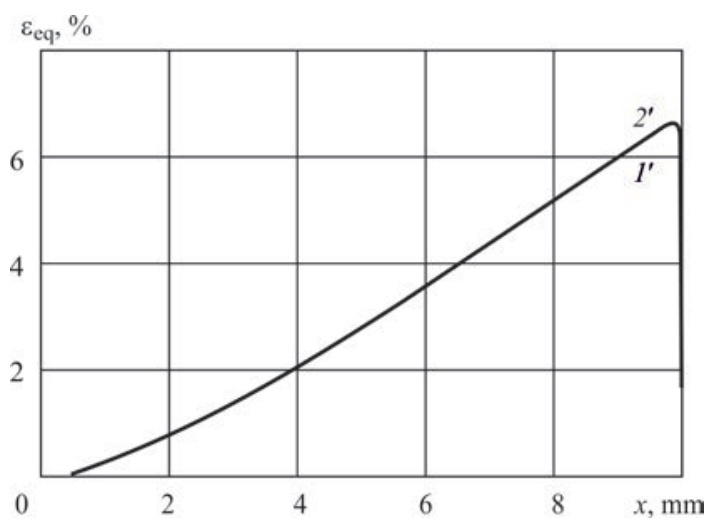

Fig re 8 Curves of plastic deformations in the interlayer on the butts with materials being joined (variants $1^{\prime}$ and $2^{\prime}$ )

(var. 2), remain practically the same, as in the assemblies with an interlayer of normal rigidity at the elastic loading stage (var. $1^{\prime}$ ), i.e. in this case the effects of lowering of the rigidity and strength of interlayer material are different [8].

Maximum circumferential stresses in both the variants of the soft interlayer remain practically the same, as at the elastic loading stage, i.e. plastic deformations, developing in the interlayer, only slightly influence their magnitude.

Maximum tangential stresses in the presence of a soft interlayer (var. $l^{\prime}$ and $2^{\prime}$ ) decrease the most markedly (more than 2 times), to the same degree in both the assembly variants.

Despite the change of maximum values of individual stress components, maximum equivalent stresses

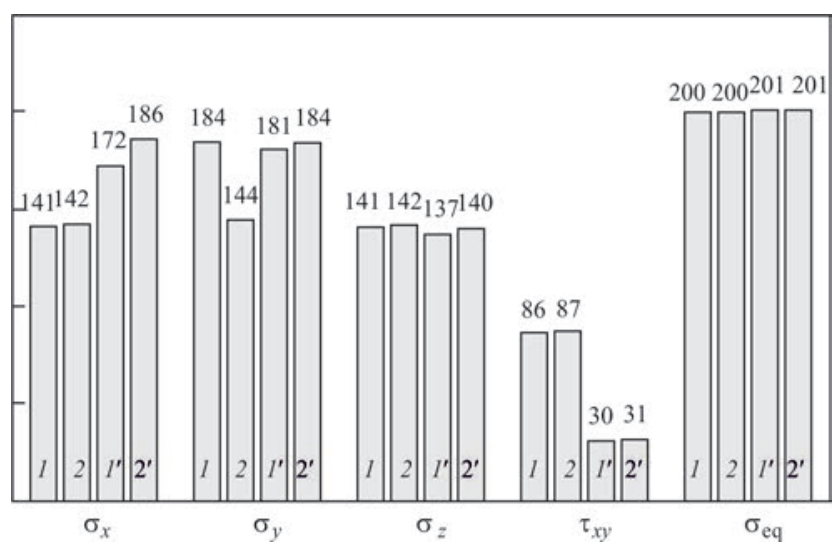

Fig re 9 Maximum (by modulus) stresses (MPa) in materials 1 and 2 of $\mathrm{C}-\mathrm{C}$ assemblies (variants $1,2,1^{\prime}$ and $2^{\prime}$ ) 
in the base metal remain practically on the same level, as under assembly loading at the elastic stage.

In the interlayer the pattern is different (Figure 10). Plastic deformations noticeably change both the individual components, and the equivalent stresses, but the change of the modulus of elasticity (rigidity) of the interlayer practically does not influence the level of maximum stresses.

Radial stresses in the presence of plastic deformations increase up to two times, compared to elastic deformation of assemblies with an interlayer of low rigidity (var. 1 ) and by $30 \%$, compared to an interlayer of normal rigidity (var. 2).

Axial stresses, contrarily, increase markedly at plastic deformation of the interlayer, only compared to the variant of elastic deformation of the interlayer of normal rigidity (var. 2), and only slightly, compared to the interlayer of low rigidity (var. 1). Here, the level of these stresses at plastic deformation, is practically independent on interlayer rigidity (var. $l^{\prime}$ and $2^{\prime}$ ).

Circumferential stresses in the soft (low-strength) interlayer increase markedly, compared to the elastic loading stage (more than 2 times), practically the same, irrespective of the rigidity (modulus of elasticity) of the interlayer.

Tangential stresses in plastically deformed soft interlayer (var. $1^{\prime}$ and $2^{\prime}$ ), contrarily, are much (by more than 2 times) lower, than at the elastic stage of the work, both at its normal (var. $2^{\prime}$ ), and low (var. $l^{\prime}$ ) rigidity.

Plastic deformation of the interlayer material significantly (up to three times) lowers also the equivalent stresses in it. Here their level is also independent on the interlayer modulus of elasticity.

\section{Co clusin $s$}

1. At thermal loading under the conditions of instantaneous plasticity in the assemblies with a «soft» interlayer, having a lower yield limit, than the base metal, the SSS in the assemblies near the butts is of a complex bulk nature, with non-uniform distribution across the assembly cross-section both in the elastic and plastic variants, similar to assemblies with an interlayer with a smaller modulus of elasticity in the elastic problem.

2. In the considered variants, when cooling is replaced by heating, all the components of stresses in the materials being joined change only their sign, and equivalent stresses are completely the same. Here, their level on the greater part of the assembly, both in the materials being joined and in the interlayer, decreases due to plastic deformations, and is practically independent on the modulus of elasticity.

3. Computer modeling of SSS showed that the main regularities, established for the elastic stage of deformation, are preserved.

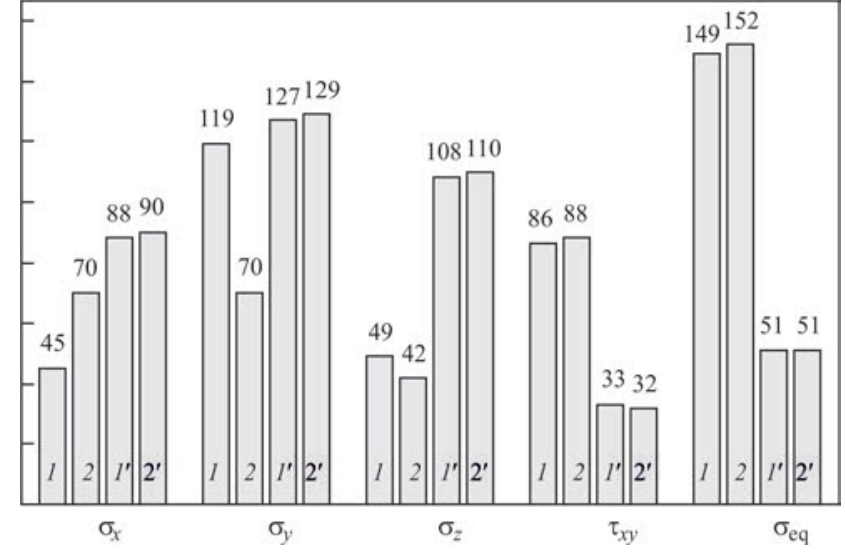

Fig re Maximum (by modulus) stresses (MPa) in interlayer 1 and 2 of $\mathrm{C}-\mathrm{C}$ assemblies (variants $1,2,1^{\prime}$ and $2^{\prime}$ )

4. Plastic deformations in the interlayer along the butt are distributed nonuniformly, and are independent on the modulus of elasticity. They form a stagnation zone on the assembly axis, and increase with greater distance from it, reaching maximum values (about $6.5 \%)$ at the outer cylindrical surface of the assembly that is indicative of the rationality of application of thermal loading in diffusion welding with soft interlayers, i.e. diffusion welding with thermal cycling.

5. Degree of interlayer «softness» and its influence on assembly SSS at plastic deformation is determined chiefly by its yield limit and is practically independent on its modulus of elasticity that should be taken into account at selection of interlayer or braze alloy material.

1. Bakshi, O.A., Kachanov, L.M. (1965) On stressed state of plastic interlayer under axisymmetric deformation. Izv. AN SSSR, Mekhanika, 2, 134-137 [in Russian].

2. Bakshi, O.A., Shron, R.Z. (1971) On calculated evaluation of strength of welded joints with soft interlayer. Svarochn. Proizvodstvo, 3, 3-5 [in Russian].

3. Chigarev, A.V., Kravchuk, A.S., Smalyuk, A.F. (2004) ANSYS for engineers: Refer. Book. Moscow, Mashinostroenie-1 [in Russian].

4. Basov, K.A. (2005) ANSYS: User directory. Moscow, DMK Press [in Russian].

5. Kvasnytskyi, V.V., Kvasnytskyi, V.F., Dong Chunlin et al. (2018) Stressed state of welded and brazed assemblies from similar materials with a soft interlayer under axial loading. The Paton Welding J., 4, 6-10.

6. Kvasnytskyi, V.V., Yermolayev, H.V., Matviienko. M.V. (2017) Mechanics of bonds in diffusion welding, soldering and spraying of dissimilar materials under elasticity conditions. In: Monography. Nikolaev, NUK [in Russian].

7. Makhnenko, V.I., Kvasnitsky, V.V. (2009) Peculiarities of formation of stress-strain state in diffusion bonds between dissimilar materials. The Paton Welding J., 8, 7-11.

8. Ermolaev, G.V., Martynenko, V.A., Olekseenko, S.V. et al. (2017) Effect of the rigid interlayer thickness on the stressstrain of metal-graphite assemblies under thermal loading. Strength of Materials, 49(3), 422-428. 


\title{
STRUCTURE AND PHASE COMPOSITION OF ZrB_-SiCA IN PLASMA COATINGS ON THE SURFACE OF C/CS IC COMPOSITE MATERIAL
}

\author{
YUS .B ORISOV ${ }^{1}$, AL . BORISOVA ${ }^{1}$, AP . GRISHCHENKO ${ }^{1}$, \\ N.V . VIGILYANSKAYA ${ }^{1}, M$.V.K OLOMYTSEV ${ }^{1}$ and MA . VASILKOVSKAYA ${ }^{2}$ \\ ${ }^{1}$ E.O. Paton Electric Welding Institute of the NAS of Ukraine \\ 11 Kazimir Malevich Str., 03150, Kyiv, Ukraine. E-mail: office@paton.kiev.ua \\ ${ }^{2}$ I.M. Frantsevich IPM of the NAS of Ukraine \\ 3 Krzhizhanovskii str., 03142, Kyiv, Ukraine
}

\begin{abstract}
The process of protective plasma $\mathrm{ZrB}_{2}-\mathrm{SiC}-\mathrm{AlN}$ coating deposition on the surface of $\mathrm{C} / \mathrm{C}-\mathrm{SiC}$ composite material was studied. Coating was sprayed using subsonic $\mathrm{Ar} / \mathrm{N}_{2}$-plasma jet and supersonic jet of air-gas plasmatron. The role of interphase phenomena occurring during plasma spraying in the volume of particles of $\mathrm{ZrB}_{2}-\mathrm{SiC}-\mathrm{AlN}$ composite powder in formation of the coating layer was established. It is shown that the composition and velocity of the plasma spray jet affects the structure and phase composition of the forming $\mathrm{ZrB}_{2}-\mathrm{SiC}-\mathrm{AlN}$ coating. Resistance of the produced coatings to thermal cyclic heating was tested by a flame jet of oxygen-propane-butane torch. Coating of $400 \mu \mathrm{m}$ thickness showed concervation of protective properties after 15 thermal cycles. Effect of thermal cyclic heating on formation of a three-zone structure in the protective coating, as a result of oxidation process was studied. Its texture and phase composition was examined by XRD and MXRD techniques. It is found that the surface layer of the coating after thermal cyclic heating consists of $\mathrm{Al}_{2} \mathrm{SiO}_{5}$-based matrix with submicron $\mathrm{ZrO}_{2}$ inclusions. 25 Ref., 3 Tables, 9 Figures.
\end{abstract}

Keywords : plasma spraying, protective coating, composite material, ultra high temperature ceramics, microstructure, phase composition, interphase interaction, oxide microinclusions

Composite materials $(\mathrm{CM})$, consisting of carbon matrix, strengthened with fibers of carbon or silicon carbide $(\mathrm{C} / \mathrm{C}, \mathrm{C} / \mathrm{SiC}, \mathrm{C} / \mathrm{C}-\mathrm{SiC})$, have a series of high service characteristics due to combination of high-temperate strength, high thermal conductivity, low values of CTE, resistance to thermal shocks and ablation wear. This promoted an interest to their practical application, including in aerospace industry in manufacture of parts of rockets and space vehicles [1-5]. A disadvantage of these materials lies in small value of heat resistance, which limits their application in temperatures above $500{ }^{\circ} \mathrm{C}$, and resistance to erosion wear at high temperatures.

In this connection it is relevant to develop the compositions and techniques for deposition on $\mathrm{C} / \mathrm{C}$ and $\mathrm{C} / \mathrm{C}-\mathrm{SiC} \mathrm{CM}$ coatings providing reliable operation of parts and assemblies of aerospace equipment under extreme conditions of their operation.

Efficiency of service and life time of protective coatings on $\mathrm{C} / \mathrm{C}$ and $\mathrm{C} / \mathrm{C}-\mathrm{SiC} \mathrm{CM}$ is determined by level of fulfillment of a complex of the next requirements:

- corrosion resistance in oxidizing medium at heating to $2000{ }^{\circ} \mathrm{C}$ including under conditions of cyclic heating;

- resistance to variable thermal loads in thermal fatigue and thermal shock mode;
- presence of thermal barrier properties for protection of substrate from $\mathrm{CM}$;

- resistance to erosion wear (ablation) under effect of high-temperature gas jet;

- ensuring the necessary level of mechanical characteristics of material of substrate from CM.

In realizing the requirements mentioned above the method and technology of formation of protective coatings of specific composition shall provide regulation of adhesion strength of coating with substrate from CM (at substrate-coating interface) as well as cohesion strength of layers of the formed coating and products of its interaction with environment, generating under its operation.

A series of review papers considers the experience of development of compositions for coatings of such designation as well as technologies of their deposition accumulated in the recent time in RF, Western Europe, USA and PRC. The analysis of these reviews shows a variety of compositions of investigated coatings, covering refractory oxides $\left(\mathrm{ZrO}_{2}, \mathrm{HfO}_{2}\right)$, carbides (TiC, $\mathrm{TaC}, \mathrm{ZrC}, \mathrm{HfC})$, borides $\left(\mathrm{ZrB}_{2}, \mathrm{HfB}_{2}, \mathrm{TiB}_{2}, \mathrm{~B}_{4} \mathrm{C}\right)$, silicides $\left(\mathrm{MoSi}_{2}, \mathrm{TiSi}_{2}\right)$, nitrides $\left(\mathrm{Si}_{3} \mathrm{~N}_{4} \mathrm{BN}\right)$, including their combinations referred to a class of ultra high temperature ceramics (UHTC), namely $\mathrm{ZrB}_{2}-\mathrm{SiC}$, $\mathrm{HfB}_{2}-\mathrm{SiC}$, etc. [6-10]. 
A list of presented methods and technology of coating deposition for protection of CM based on carbon and results of their application includes:

- deposition of powder suspensions from components of coating with next annealing;

- deposition of $\mathrm{SiC}, \mathrm{SiC}-\mathrm{ZrC}-\mathrm{SiC}$ etc., layers using CVD method;

- plasma spraying;

- impregnation by polymer followed by pyrolysis (PIP);

- sol-gel method;

- thermal diffusion deposition (for example, siliciding $\mathrm{C} / \mathrm{C}$ )

as well as processes consisting of combination of these technologies. For example, it is formation on $\mathrm{C} / \mathrm{C} \mathrm{CM}$ surface of $\mathrm{SiC}$ underlayer by siliciding method with next application of a layer of suspension from $\mathrm{ZrB}_{2}-$ $\mathrm{SiC}$ and annealing in inert medium and production of $\mathrm{SiC}$ upper layer using CVD method. However, usage of the combined CVD technologies and deposition of suspensions are related with long (2-10 h) spreading procedures of heat treatment in vacuum or protective medium at $1000-1150{ }^{\circ} \mathrm{C}$.

The plasma spraying method differs from other by absence of the stages of high-temperature and longterm heat treatment, necessary for formation of adhesion forces with substrate surface and inner cohesion strength of coating layer. Not the least is the possibility of formation in plasma spraying of the layers of several millimeters. This allows using it for manufacture of free-standing products from the materials being sprayed.

The widest complex of investigations in the field of plasma spraying of $\mathrm{ZrB}_{2}-$ SiC-based coatings in a chamber with vacuum, increased pressure, inert medium was carried out in Italy by Rome University «La Sapienza» and Centro Sviluppo Materiali S. p.A. [1116] staff members. The investigation was carried out for determination of effect of coating annealing on air at $1200,1400,1600$ and $1800^{\circ} \mathrm{C}$ during $10 \mathrm{~h}$ on phase composition and coating oxidation, effect of coating heat treatment at $1800{ }^{\circ} \mathrm{C}$ during 160 and $1800 \mathrm{~s}$ on structure and phase composition of $\mathrm{ZrB}_{2}-\mathrm{SiC}$ at $\mathrm{ZrB}_{2}-\mathrm{SiC}$ relationship variation [11-17]. One of the important results of their investigations is determination of efficiency of performance of «passivating» annealing stage for $\mathrm{ZrB}_{2}-\mathrm{SiC}$ coating at $1100{ }^{\circ} \mathrm{C}$ during $6 \mathrm{~h}$. This allows rising coating resistance to oxidation followed by heating to $1600{ }^{\circ} \mathrm{C}$ [13].

Experiments on coating deposition on $\mathrm{C} / \mathrm{C}-\mathrm{SiC}$ $\mathrm{CM}$ surface using plasma spraying in air were carried out in PRC with formation of double-layer coatings of $\mathrm{Er}_{2} \mathrm{SiO}_{8} / \mathrm{LaMgAl}_{11} \mathrm{O}_{19}$ and $\mathrm{Yb}_{2} \mathrm{SiO}_{5} / \mathrm{LaMgAl}_{11} \mathrm{O}_{19}$ characterizing with high oxidation resistance $[18,19]$.
The task of the present work lied in investigation of effect of thermal cyclic heating in air on phase and structure state of plasma coating of composite powder (CP) $60 \mathrm{ZrB}_{2}-20 \mathrm{SiC}-20 \mathrm{AlN}$ (wt.\%) sprayed on a substrate from $\mathrm{C} / \mathrm{C}-\mathrm{SiC} \mathrm{CM}$ using atmospheric plasma spraying method.

Composite ceramics based on $\mathrm{ZrB}_{2}$ of specified composition was developed by staff members of IPM of NASU and the process of high-temperature oxidation of its hot-pressed samples at temperatures to $1650^{\circ}$ during $5 \mathrm{~h}[20]$ was investigated.

Methd s a d ma erih s. Composition of CP and technology of its manufacture from mechanical mixture of $\mathrm{ZrB}_{2}, \mathrm{SiC}, \mathrm{AlN}$ components by granulation method on a couplant from polyvinyl alcohol was developed by IMP of the NAS of Ukraine.

The initial powders of $\mathrm{ZrB}_{2}, \mathrm{SiC}, \mathrm{AlN}$ for $\mathrm{CP}$ manufacture were of around $99.5 \%$ purity with particle size $0.5-1.0 \mu \mathrm{m}$. Figure 1 shows appearance and structure of powder particles, a histogram of distribution of its grain-size composition is given in Figure 2.

A plate of $\mathrm{C} / \mathrm{C}-\mathrm{SiC} \mathrm{CM}$ of $20 \times 20 \times 5.7 \mathrm{~mm}$ size was used as a substrate for spraying. Before spraying its surface was sandblasted.

Two methods of plasma spraying in open atmosphere (in air medium) were used for coating deposition in this work. They differ by composition of plasma gas $\left(\mathrm{Ar} / \mathrm{N}_{2}\right.$, air), plasmatron power $(24$ and $82 \mathrm{~kW}$,
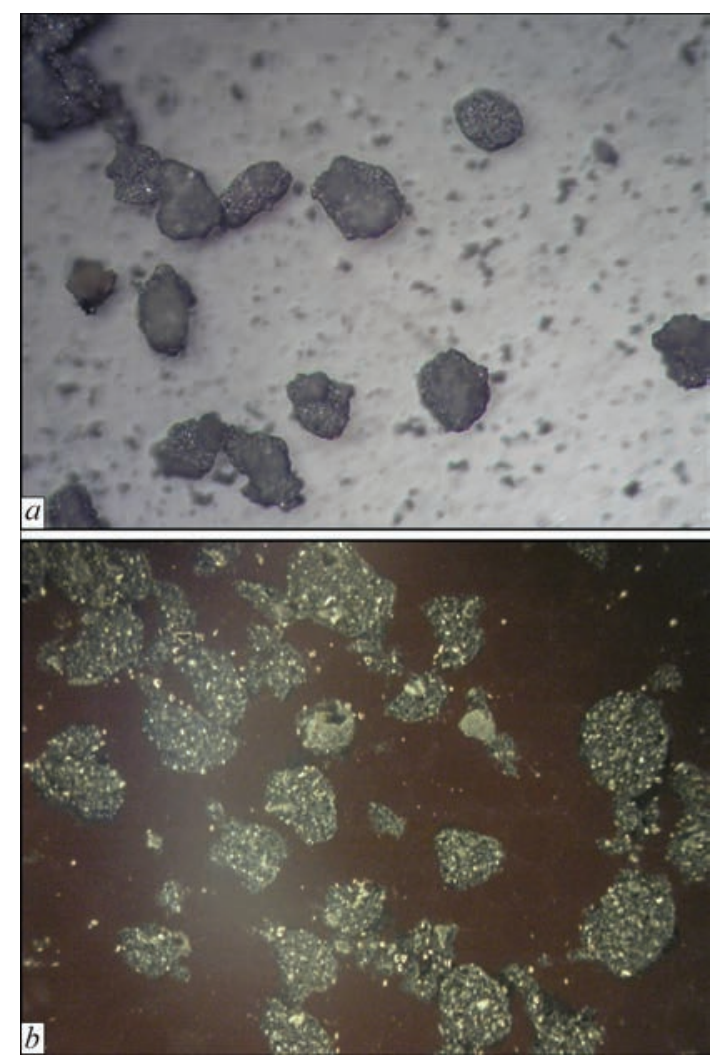

Fig re 1 Appearance of $60 \mathrm{ZrB}_{2}-20 \mathrm{SiC}-20 \mathrm{AlN}$ (wt.\%) powder (a) and structure of particles in polarized light $(b)$ 


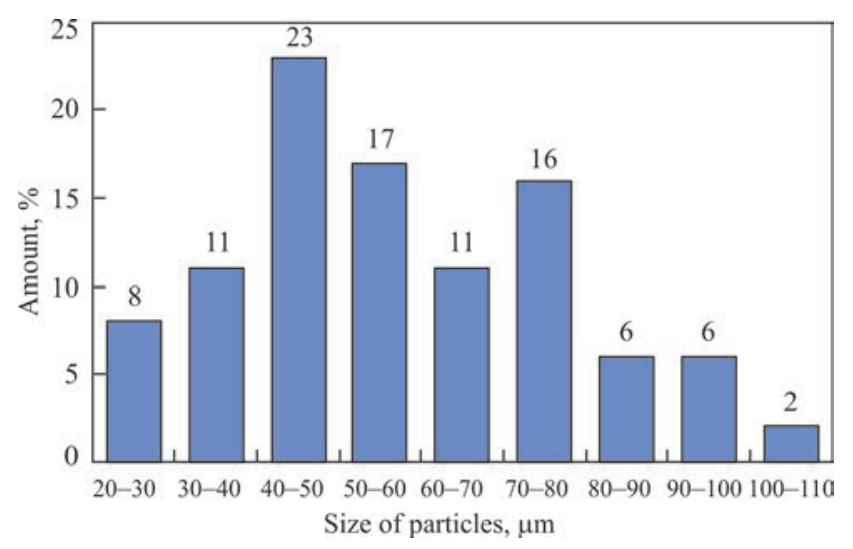

Fig re 2 Histogram of distribution of grain-size composition of $60 \mathrm{ZrB}-20 \mathrm{SiC}-20 \mathrm{AlN}$ powder (wt.\%)

respectively) and velocities of plasma jet (sub and supersonic), (PS - subsonic Ar/ $\mathrm{N}_{2}$ plasma spraying; SAGPS - supersonic air-gas plasma spraying).

Application of program for computer simulation of a process of plasma powder spraying CASPSP [21] and available experimental data on velocities of particles under conditions of plasma spraying using similar gases [22] allowed carrying out evaluation of velocities of $\mathrm{ZrB}_{2}-\mathrm{SiC}-\mathrm{AlN} \mathrm{CP}$ particles of selected composition and duration of time of their staying in plasma jet $-\tau_{\mathrm{p}}$ taking into account their diameter $d$ and spraying distance $-h$.

Acceleration and heating of spray particle under effect of plasma jet depend on its size and density.

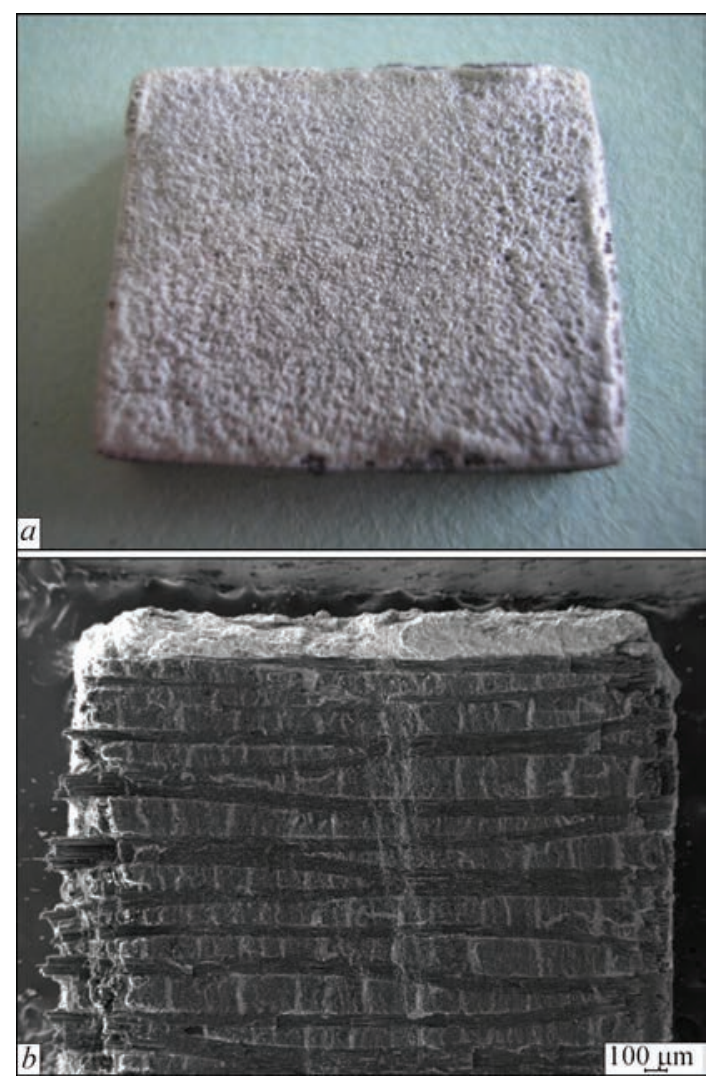

Fig re 3 Appearance of surface $(a)$ and section $(b)$ of sample with plasma coating $\mathrm{ZrB}_{2}-\mathrm{SiC}-\mathrm{AlN}$ after 15 cycles of heating
Converting $60 \mathrm{ZrB}_{2}-20 \mathrm{SiC}-20 \mathrm{AlN}$ wt. $\%$ composition in vol.\% we get $\mathrm{CP} 43 \mathrm{ZrB}_{2}-28.5 \mathrm{SiC}-28.5 \mathrm{AlN}$ (vol.\%) and volume density of such composition is $4.4 \mathrm{~g} / \mathrm{cm}^{3}$ (without binder consideration).

The results of carried calculations provided a complex of characteristics of conditions of plasma atmospheric spraying at subsonic and supersonic modes of plasma jet flow used for coating deposition:

- subsonic: plasma gas $-\mathrm{Ar} / \mathrm{N}_{2}, T_{\mathrm{pl}} \sim 10000 \mathrm{~K}$, $W_{\mathrm{pl}} \sim 600 \mathrm{~m} / \mathrm{s}, W_{\mathrm{p}} \sim 100-130 \mathrm{~m} / \mathrm{s}, \tau_{\mathrm{p}}(d=60 \mu \mathrm{m}, h=$ $=100 \mathrm{MM}) \sim 1,5 \mathrm{p} \mathrm{ms}$;

- supersonic: plasma gas - air $T_{\mathrm{pl}} \sim 6000 \mathrm{~K}, W_{\mathrm{pl}} \sim$ $\sim 2500 \mathrm{~m} / \mathrm{s}, W_{\mathrm{p}} \sim 300-350 \mathrm{~m} / \mathrm{s}, \tau_{\mathrm{p}}{ }^{\mathrm{pl}} \sim d=60 \mu \mathrm{m}, h=$ $=180 \mathrm{~mm}) \sim 0,5 \mathrm{~ms}$.

A calculation time of complete staying in plasma jet volume of $\mathrm{ZrB}_{2}-\mathrm{SiC}-\mathrm{AlN} \mathrm{CP}$ particles of $40-80 \mu \mathrm{m}$ size under conditions of subsonic spraying makes $0.5-3.0 \mathrm{~ms}$, at supersonic it is $0.2-1.5 \mathrm{~ms}$.

Resistance of protective coating on $\mathrm{C} / \mathrm{C}-\mathrm{SiC} \mathrm{CP}$ surface to high-temperature cyclic loads is one of the most important its functional characteristics.

Thermal cyclic heating of the sample with $400 \mu \mathrm{m}$ thickness coating was carried out with the help of jet of oxygen-propane-butane flame of GN-2 torch. Temperature of flame made around $2000{ }^{\circ} \mathrm{C}$, distance from torch tip to sample surface was $70-80 \mathrm{~mm}$. In a mode of cyclic heating the sample was heated for 2 min reaching an incandescence state during $10 \mathrm{~s}$ with next cooling in air during about $10 \mathrm{~min}$ before following heating.

Appearance of surface and section of the sample with $\mathrm{ZrB}_{2}-\mathrm{SiC}-\mathrm{AlN}$ coating produced by SAGPS method, after 15 cycles of heating (Figure 3 ), indicate the absence of indices of coating failure and preservation of its protective properties under conditions of used mode of its heat resistance testing.

Results 6 ine stig in . Microstructure of coatings from $\mathrm{ZrB}_{2}-\mathrm{SiC}-\mathrm{AlN} \mathrm{CP}$ sprayed on $\mathrm{C} / \mathrm{C}-\mathrm{SiC}$ $\mathrm{CM}$ (Figure 4), is characterized with heterogeneity, high density, absence of defects and delaminations at boundary with the substrate.

In coatings' structure it is possible to determine the alternating areas of light and darker phases (probably, mixture of several phases), at that separate areas of the coatings demonstrate a lamellar-like structure. The difference in the structure of coatings produced by sub- and supersonic plasma spraying methods, determined at metallographic examination, lies in relationship of visible area of light and dark phases. Portion of dark phase prevails in the case of supersonic spraying. Structure of dark phase has a glass-like nature.

The results of X-ray structural phase analysis (XRD) of sprayed coatings (Figure 5) showed that interaction of the components of initial powder (Figure 5, $a$ ) with environment (air) and between them- 


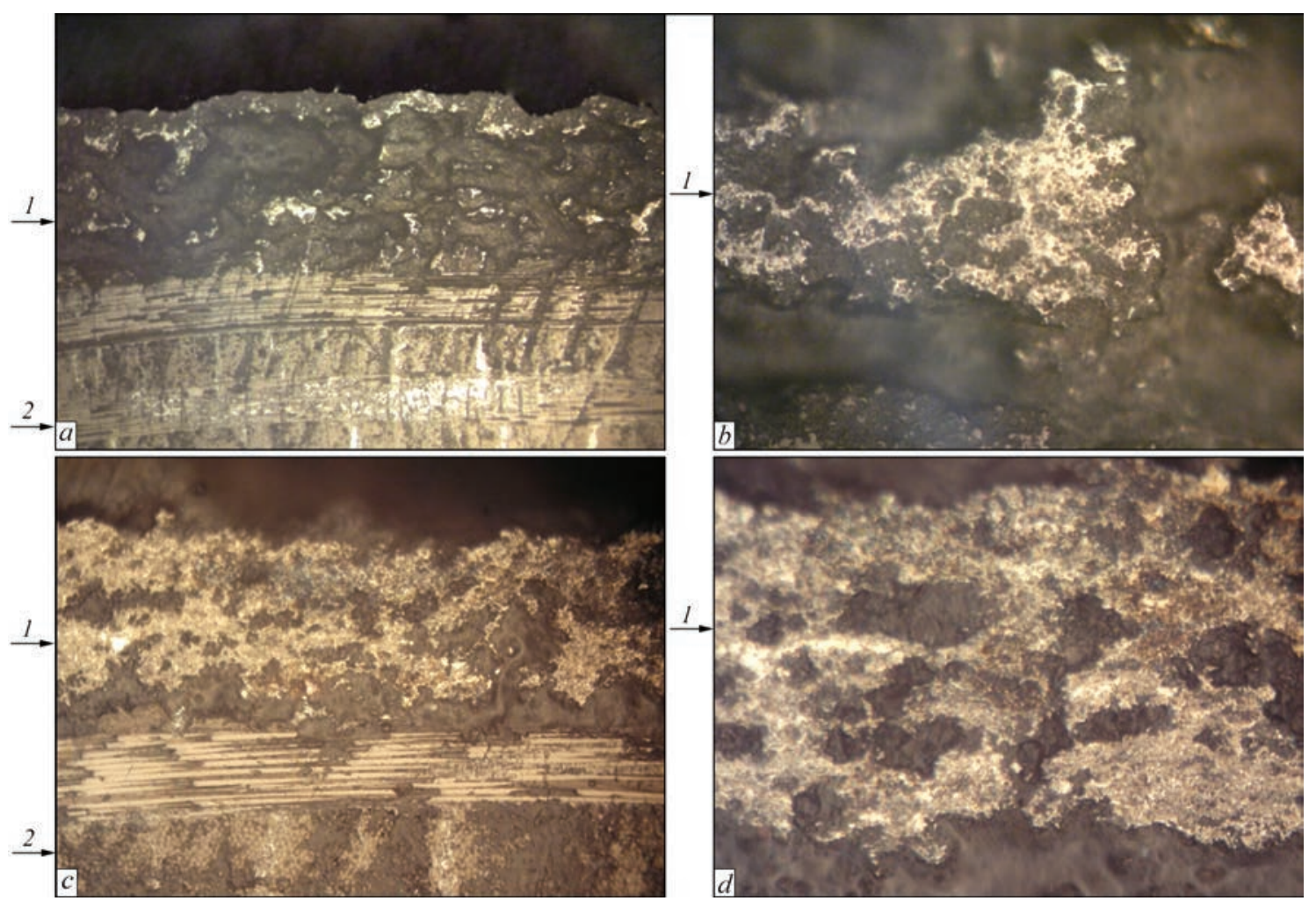

Fig re 4 Microstructure of plasma coatings of $60 \mathrm{ZrB}_{2}-20 \mathrm{SiC}-20 \mathrm{AlN}$ (wt.\%) CP obtained by methods of subsonic $(a, b)$ and supersonic $(c, d)$ spraying: $1-$ coating; $2-\mathrm{C} / \mathrm{C}-\mathrm{SiC}$ substrate $(a-\times 100 ; c-\times 200 ; b, d-\times 400)$

selves takes place during the process of plasma spraying, due to what there is formation of oxide phases in the deposited material. Thus, in the coating produced by method of subsonic plasma spraying (Figure $5, b$ ) this is $\mathrm{ZrSiO}_{4}, \mathrm{Al}_{2} \mathrm{SiO}_{5}$ and $\mathrm{ZrO}_{2}$ (Figure 5, b). Use of supersonic spraying method (Figure 5,c) $\mathrm{ZrSiO}_{4}$ phase is not found in the initial deposited coating, however, a «halo» can be observed on X-ray pattern in $24-29^{\circ}$ angle interval. It indicates presence in the coating of amorphous phase (Figure 5,c), as may be supposed $\mathrm{SiO}_{2}$, as a product of $\mathrm{ZrSiO}_{4}$ decomposition.

A comparison of intensity of X-ray reflections $\mathrm{ZrB}_{2}, \mathrm{SiC}, \mathrm{AlN}$ of the initial powder and coatings indicate significant decrease of $\mathrm{ZrB}_{2}$ content as a result of its oxidation during spraying process.

Joint consideration of the results of metallographic examinations and XRD of the initial coatings (Figures 4,5 ) obtained by different methods of plasma spraying allows making a conclusion that amount of oxide phases observed in the coatings produced using subsonic plasma jet is more considerable. A reason for this is apparently lower velocity of particle movement and, respectively, larger time of particle staying in the oxidation zone.

Most probably, the oxide phases $\left(\mathrm{ZrO}_{2}, \mathrm{Al}_{2} \mathrm{SiO}_{5}\right)$ on the section are dark colored and metal-like $\left(\mathrm{ZrB}_{2}\right.$, $\mathrm{SiC}, \mathrm{AlN}$ ) are light.

Only oxide phases, namely $\mathrm{ZrO}_{2}$ (in form of tetragonal and monoclinic modifications) and $\mathrm{Al}_{2} \mathrm{SiO}_{5}$ were found in both cases (Figure 6, $a, b$ ) at X-ray structural phase analysis of the coatings after thermal cycling in the surface layer. Amorphous phase, which was found in the initial coating at SAGPS, is absent in this case.

Since components of the initial powder $\left(\mathrm{ZrB}_{2}\right.$, $\mathrm{SiC}, \mathrm{AlN}$ ) were not found in the surface layer of these coatings, the analysis of separated from substrate and refined SAGPS-coating (Figure 6,c) was carried out. All three phases were found at that, however, in smaller amount than in the initial coating (Figure 5,c).

Examination of chemical composition of the separate structural constituents of the coating in initial state and after thermal cycling was performed using a method of scanning electron microscopy together with X-ray spectrum microanalysis (MXRD) (Figures 7,8$)$. At that a surface layer of the coatings as well as transverse section along all its thickness were analyzed. Content of the elements included in $\mathrm{CP}$ composition (B, C, N, Al, Si, Zr) and oxygen, was determined by scanning of five-seven segments of $50 \times 50 \mu \mathrm{m}$ size and averaging at all area (Figure 8, $b$ ) of surface layer of the coating or its segment (Figure $7, b$, Table 1). The analysis of content of structural constituents was carried out locally using electron probe of $1.5 \mu \mathrm{m}$ size (Tables 2, 3).

Thus, it is determined that in process of plasma spraying due to oxidation of $\mathrm{ZrB}_{2}-\mathrm{SiC}-\mathrm{AlN} \mathrm{CP}$ particles the relative amount of $\mathrm{Al}, \mathrm{Si}$ and $\mathrm{Zr}$ in comparison with initial powder reduce and content of oxygen 

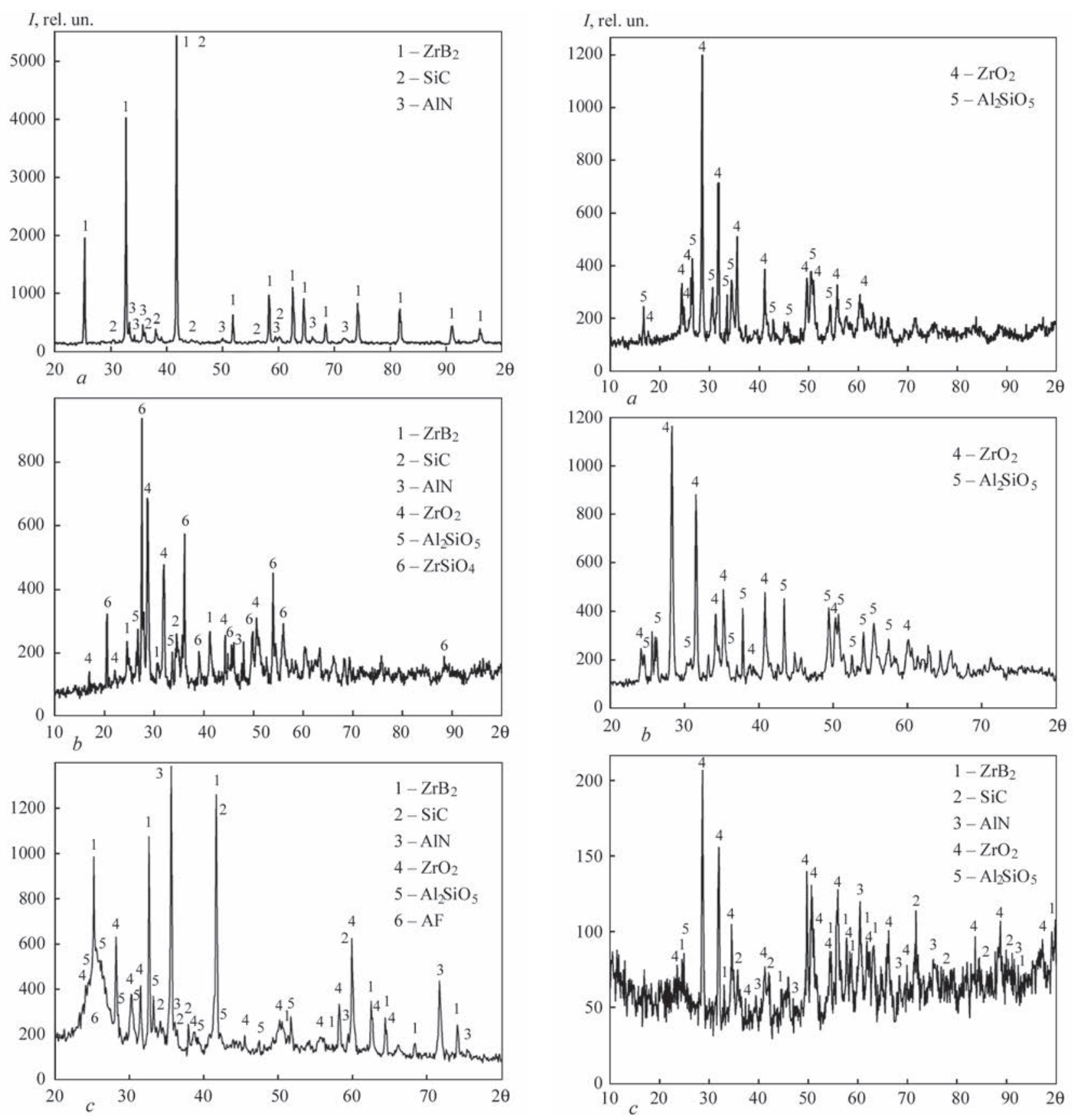

Fig re 5 X-ray patterns of initial powder $(a)$ and coatings obtained by methods of subsonic (PS) (b) and supersonic (SAGPS) (c) plasma spraying

reaches around $30 \mathrm{wt} . \%$. As a result of thermal cycling the phases containing $\mathrm{B}, \mathrm{C}$ and $\mathrm{N}$ on the surface of coating are absent and amount of oxygen in the subsurface layer rises to $48 \%$ (Table 1). Local analysis of composition of plasma coating after thermal cycling along its depth demonstrates reduction of oxygen content from 48 to $30 \mathrm{wt} . \%$ (spectra $1-4$, Figure $8, a$ ). The results of MXRD (Tables 2, 3) on the one hand completely prove XRD results, namely presence of $\mathrm{ZrO}_{2}, \mathrm{Al}_{2} \mathrm{SiO}_{5}$ and $\mathrm{ZrSiO}_{4}$ oxide phases in the coatings, and on the other hand allow assuming presence of amorphized boron silicate $\left(\mathrm{B}_{2} \mathrm{O}_{3} \times \mathrm{SiO}_{2}\right)$ phases as well. It is determined that thermal cycling

Fig re $6 \mathrm{X}$-ray patterns of plasma coatings of $60 \mathrm{ZrB}_{2}-20 \mathrm{SiC}-$ 20AlN (wt.\%) CP on surface of $\mathrm{C} / \mathrm{C}-\mathrm{SiC} \mathrm{CM}$ after thermal cycling: $a$ - PS-coating, surface layer; $b-$ SAGPS-coating, surface layer; $c$ - SAGPS-coating, composition averaged on all thickness

process promotes structural changes of the surface layer to a depth (Figures 3, $b$ and 8, $a$ ), sizes of which are determined by temperature mode set in coating volume at its thermal cycling heating.

Anh $\mathbf{y}$ is 6 b the ned results. Formation of a protective coating layer on the surface of $\mathrm{C} / \mathrm{C}-\mathrm{SiC} \mathrm{CM}$ takes place under conditions of atmospheric spraying of $60 \mathrm{ZrB}_{2}-20 \mathrm{SiC}-20 \mathrm{AlN}$ (wt.\%) CP.

The peculiarity of the process of plasma spraying of coating from $\mathrm{ZrB}_{2}-\mathrm{SiC}-\mathrm{AlN} \mathrm{CP}$ is formation at heating in a plasma jet of particles being sprayed, 
Tb le 1 Total content of elements of SAGSP-coating, wt.\%

\begin{tabular}{|c|c|c|c|}
\hline Element & Powder & $\begin{array}{c}\text { Coating in initial } \\
\text { state }^{*}\end{array}$ & $\begin{array}{c}\text { Coating after } \\
\text { thermal cycling }\end{array}$ \\
\hline $\mathrm{B}$ & 11.55 & $21.58 \pm 4.71$ & 2.01 \\
\hline $\mathrm{C}$ & 5.99 & $16.77 \pm 3.95$ & 2.02 \\
\hline $\mathrm{N}$ & 6.84 & $1.90 \pm 1.33$ & 0.00 \\
\hline $\mathrm{O}$ & 0.20 & $33.16 \pm 6.98$ & 47.73 \\
\hline $\mathrm{A} 1$ & 15.16 & $6.25 \pm 1.36$ & 19.28 \\
\hline $\mathrm{Si}$ & 14.01 & $7.26 \pm 0.89$ & 9.39 \\
\hline $\mathrm{Zr}$ & 48.75 & $12.34 \pm 2.54$ & 17.40 \\
\hline $\begin{array}{l}\left.{ }^{*} \text { Averaged composition on all thickness (Figure } 7, b, \text { points } 1,2-5\right) \\
{ }^{* *} \text { Composition of surface layer averaged on area } 600 \times 600 \mu \mathrm{m}(\text { Fig- }\end{array}$ \\
ure 8, $b$, spectrum 1).
\end{tabular}

consisting of a mixture of $\mathrm{ZrB}_{2}, \mathrm{SiC}$, AlN melts. Ordanyan $\mathrm{S}$. S. with colleagues when studying $\mathrm{ZrB}_{2}-\mathrm{SiC}$ phase diagram carried out heating of $\mathrm{ZrB}_{2}$ and $\mathrm{SiC}$ mixture to a stage of co-melting at $2900{ }^{\circ} \mathrm{C}$ and did not find at that interaction of these melts. On the other hand in $\mathrm{ZrB}_{2}-\mathrm{SiC}$ system they determined existence of eutectics, namely $77 \%$ of $\mathrm{SiC}$ [23], at $2270{ }^{\circ} \mathrm{C}$. It is assumed that its presence prevents the phenomenon of $\mathrm{SiC}$ decomposition in heating that provides co-melting of $\mathrm{ZrB}_{2}$ and $\mathrm{SiC}$ at plasma spraying [15].

The fact of $\mathrm{ZrB}_{2}-\mathrm{SiC} \mathrm{CP}$ transition under conditions of plasma spraying into melting stage was experimentally determined by staff members of Rome University «La Sapienza» and Centro Sviluppo Materiali S. p.A [12]. It is indicated by type of obtained deformed particles of melt, i.e. splats, and effect on them of plasma spraying modes.

In this connection it is possible to state that formation of coating layer from $\mathrm{ZrB}_{2}-\mathrm{SiC}-\mathrm{AlN} \mathrm{CP}$ under used conditions of plasma spraying is carried out by means of cooling and solidification on $\mathrm{C} / \mathrm{C}-\mathrm{SiC}$ surface $\mathrm{CM}$ of particles of a melt from mixture of components of $\mathrm{ZrB}, \mathrm{SiC}$, AlN CP, passing the stages of melting and interphase interaction, including with formation of oxidation products $\left(\mathrm{ZrO}_{2}, \mathrm{SiO}_{2}, \mathrm{Al}_{2} \mathrm{O}_{3}\right)$.

The level of development of this process in a disperse medium of plasma jet depends on dimensions of particles of sprayed powder determining position of trajectory of their flight in a jet volume.
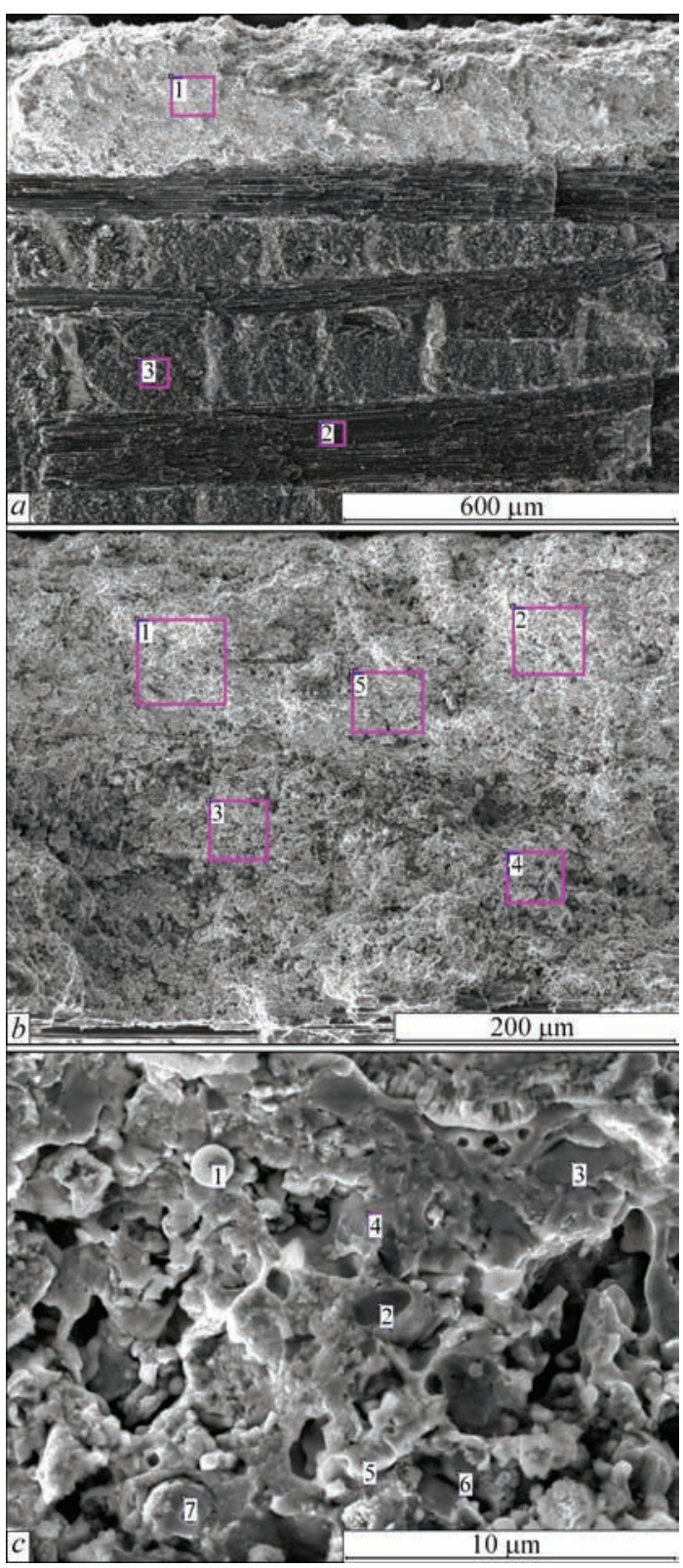

Fig re 7 Electron micrograph of initial plasma SAGPS-coating of $\mathrm{ZrB}_{2}-\mathrm{SiC}-\mathrm{AlN} \mathrm{CP}$ on surface of $\mathrm{C} / \mathrm{C}-\mathrm{SiC} \mathrm{CM}: a-$ section of sample with plasma coating (1 - coating; 2 - carbon fiber; 3 $\mathrm{C} / \mathrm{C}-\mathrm{SiC} \mathrm{CM}) ; b$ - coating section, general view; $c$ - structural elements on coating fracture (decoding the composition on spectra 1, 2 etc. in Figure 7, $b, c$, presented in Tables 1,2)

Tb le 2 Content of elements (at.\%) in structural constituents of initial plasma SAGPS-coating

\begin{tabular}{|c|c|c|c|c|c|c|c|}
\hline \multirow{2}{*}{ Element } & \multicolumn{7}{|c|}{ Number of spectrum (Figure 7,c) } \\
\hline & 1 & 2 & 3 & 4 & 5 & 6 & 7 \\
\hline $\mathrm{B}$ & 4.8 & 0.0 & $\underline{55.4}$ & 0.0 & 0.0 & 0.0 & $\underline{52.5}$ \\
\hline C & 7.1 & $\underline{42.0}$ & 6.4 & 0.6 & 0.0 & 2.2 & 5.1 \\
\hline $\mathrm{N}$ & 2.9 & 1.1 & 1.1 & 0.0 & 0.0 & $\underline{46.7}$ & 0.6 \\
\hline $\mathrm{O}$ & $\underline{60.4}$ & 2.4 & 10.3 & $\underline{76.9}$ & 71.4 & $\underline{10.6}$ & 13.6 \\
\hline $\mathrm{Al}$ & 0.5 & 0.9 & 0.1 & 2.7 & $\underline{14.8}$ & $\underline{38.8}$ & 0.3 \\
\hline $\mathrm{Si}$ & 0.2 & $\underline{51.6}$ & 0.2 & 7.4 & 7.2 & 0.9 & 0.6 \\
\hline $\mathrm{Zr}$ & $\underline{30.0}$ & 2.0 & $\underline{26.5}$ & $\underline{8.9}$ & 0.3 & 0.8 & $\underline{27.3}$ \\
\hline Main phase & $\mathrm{ZrO}_{2}$ & $\mathrm{SiC}$ & $\mathrm{ZrB}_{2}$ & $\mathrm{ZrSiO}_{4}$ & $\mathrm{Al}_{2} \mathrm{SiO}_{5}$ & AlN & $\mathrm{ZrB}_{2}$ \\
\hline
\end{tabular}



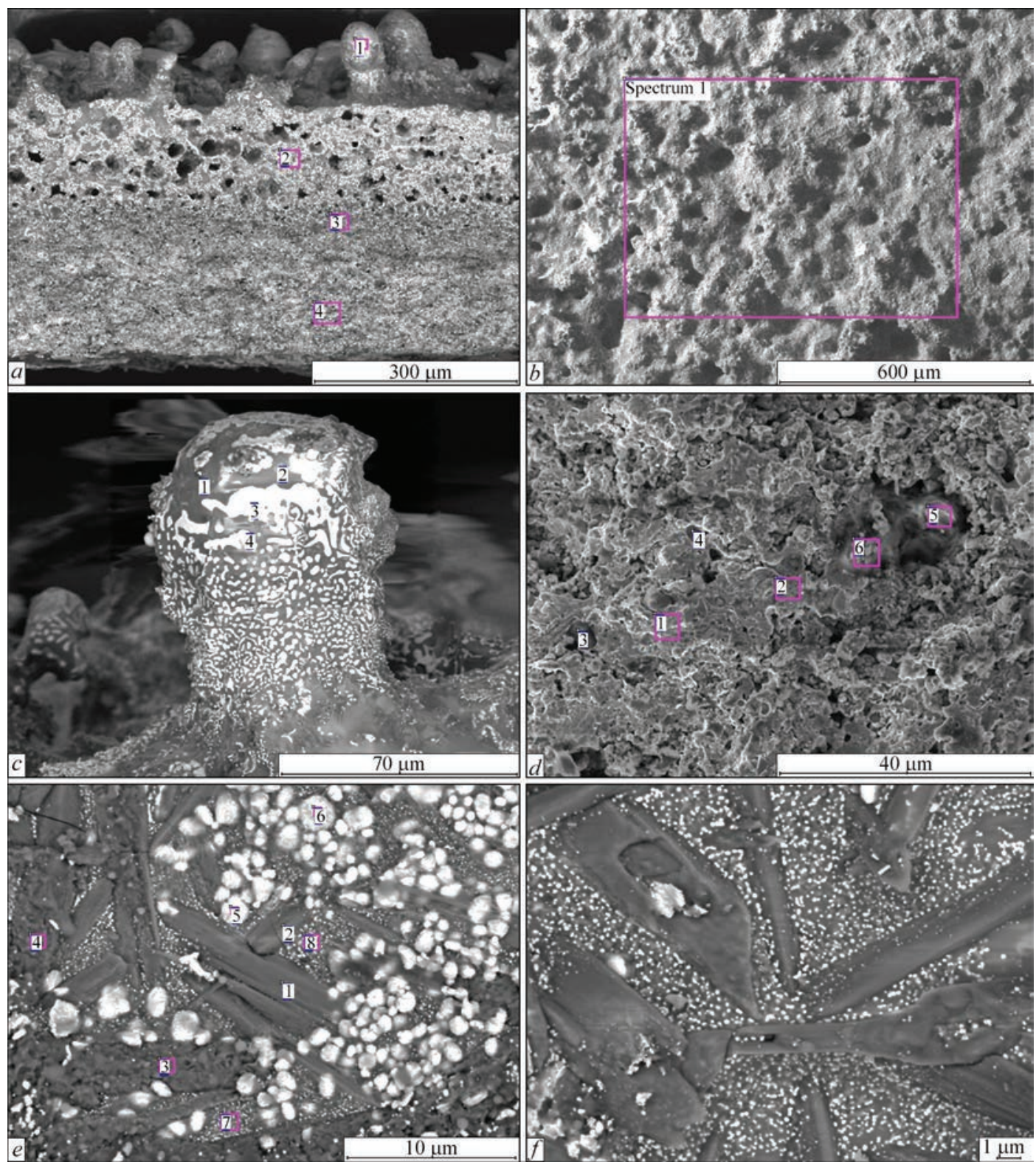

Fig re 8 Electron micrograph of plasma SAGPS-coating of $\mathrm{ZrB}_{2}-\mathrm{SiC}-\mathrm{AlN} \mathrm{CP}$ on surface of $\mathrm{C} / \mathrm{C}-\mathrm{SiC} \mathrm{CM}$ after thermal cycling: $a$ - section of sample with plasma coating; $b$ - general view of coating surface; $c$ — buildup on surface; $d$ - coating section, general view; $e, f$ - structure elements on coating surface

In a period of movement of particles of sprayed metal under conditions of atmospheric plasma spraying their interaction with environment oxygen and formation of products of their oxidation, that, in par-

ticular, is determined during deposition of coating from $\mathrm{ZrB}_{2}$ [14], is inevitable.

When particles reach the substrate surface the effect of impact pressure results in deformation of

Tb le 3 Content of elements (at.\%) in structural constituents of SAGSP-coating after thermal cycling

\begin{tabular}{|c|c|c|c|c|c|c|c|c|c|c|c|c|}
\hline \multirow{2}{*}{ Element } & \multicolumn{8}{|c|}{ Number of spectrum (Figure $8, d$ ) } & \multicolumn{4}{|c|}{ Number of spectrum (Figure $8, c$ ) } \\
\hline & 1 & 2 & 3 & 4 & 5 & 6 & 7 & 8 & 1 & 2 & 3 & 4 \\
\hline $\mathrm{B}$ & 1.2 & 1.5 & 1.8 & 0.0 & 1.7 & 0.9 & 3.2 & 0.0 & 0.0 & 0.0 & 0.0 & 2.6 \\
\hline $\mathrm{C}$ & 0.7 & 0.7 & 0.5 & 0.4 & 1.8 & 2.8 & 2.1 & 0.9 & 1.6 & 0.6 & 4.3 & 3.7 \\
\hline $\mathrm{N}$ & 0.0 & 0.0 & 0.0 & 0.0 & 0.0 & 0.0 & 0.0 & 0.0 & 0.0 & 0.0 & 0.0 & 0.0 \\
\hline $\mathrm{O}$ & $\underline{69.6}$ & $\underline{61.1}$ & $\underline{65.4}$ & $\underline{67.7}$ & $\underline{71.9}$ & $\underline{71.1}$ & $\underline{51.6}$ & $\underline{72.4}$ & $\underline{62.1}$ & $\underline{61.3}$ & $\underline{73.0}$ & $\underline{62.0}$ \\
\hline $\mathrm{Al}$ & 21.7 & 24.4 & 26.6 & 26.6 & 3.7 & 3.6 & 21.0 & 10.6 & 27.0 & 21.6 & 0.2 & 0.6 \\
\hline $\mathrm{Si}$ & $\underline{6.5}$ & 6.7 & $\underline{5.1}$ & $\underline{4.6}$ & 3.0 & 2.0 & $\underline{16.0}$ & 12.5 & 13.2 & 16.2 & 0.1 & 0.0 \\
\hline $\mathrm{Zr}$ & 0.1 & 0.3 & 0.2 & 0.2 & 17.3 & 18.9 & 4.2 & 2.4 & 2.6 & 0.1 & 34.0 & 30.2 \\
\hline $\begin{array}{l}\text { Main } \\
\text { phase }\end{array}$ & \multicolumn{4}{|c|}{$\mathrm{Al}_{2} \mathrm{SiO}_{5}$} & \multicolumn{2}{|c|}{$\mathrm{ZrO}_{2}$} & \multicolumn{2}{|c|}{$\begin{array}{l}\text { Mixture } \mathrm{Al}_{2} \mathrm{SiO}_{5} \\
\text { and } \mathrm{Al}_{2} \mathrm{O}_{3}\end{array}$} & \multicolumn{2}{|c|}{$\mathrm{Al}_{2} \mathrm{SiO}_{5}$} & \multicolumn{2}{|c|}{$\mathrm{ZrO}_{2}$} \\
\hline
\end{tabular}


sprayed particle with formation of splats. Simultaneously, there is oxidation of surface of particles forming the coating.

The size of splats, their thickness, determining the cooling rate of their material, is related with value of impact pressure, which is determined by particle velocity and its density. Thus, in the case of application of method of plasma subsonic spraying for $60 \mathrm{ZrB}_{2}$ 20SiC-20AlN CP particles of $60 \mu \mathrm{m}$ size the impact pressure makes 50-75 $\mathrm{MPa}$ and at supersonic method it is $400-500 \mathrm{MPa}$. In both cases it exceeds the indices used in technology of hot pressing of UHTC of similar composition (48 MPa) [20].

Thus, considered above circumstances of formation of coatings from UNTC of $\mathrm{ZrB}_{2}-\mathrm{SiC}-\mathrm{AlN} \mathrm{CP}$ during plasma spraying in air using operations of preliminary heating of $\mathrm{C} / \mathrm{C}-\mathrm{SiC} \mathrm{CM}$ surface being sprayed show that the process takes place by means of fast heating of the particles on initial length of plasma jet up to complete melting of material of all components with formation of particles from mixture of $\mathrm{ZrB}_{2}, \mathrm{SiC}$ and $\mathrm{AlN}$ melts not interacting with each other. The processes of interphase interaction of particle surface with ambient oxygen-containing medium develop at the stage of movement of these particles into the volume of plasma jet with variable values of its temperatures, velocities and composition of environment. This results in formation of oxidation products, recirculation of these products into the particle volume that causes their interphase interaction with formation of complex compounds. Presence of silicate phases $\mathrm{Al}_{2} \mathrm{SiO}_{5}$ and $\mathrm{ZrSiO}_{4}$ in the structure of initial coating indicate the processes of oxidation in a volume of spray particles at interaction with environment in time of its movement in plasma jet as well as interphase phenomena into a volume with mullite phases and zircon synthesis.

Described scheme of the process of formation of composition and structure of initial plasma coating is proved by data of XRD of spray powder and coating (Figure 5). Absence of boron-containing phases is apparently related with temperature mode of particle heating, promoting transition of $\mathrm{B}_{2} \mathrm{O}_{3}$ into gas or amorphous phase. Found amorphous phase can be also related with appearance of silicate $\mathrm{Al}-\mathrm{Si}-\mathrm{O}$ phase.

During cyclic heating of coating surface there is formation in its volume a temperature field related with heating mode, power of heat source, thermal physical properties of coating and substrate, sample and coating sizes. Pattern of temperature distribution determines the development of phase transformations over coating thickness.

The coating, presented in Figure 8, $a$, consists of three zones. Formation of pores in the upper part of coating layer (Figure 8,a) is connected with temperature fields formed in coating volume during thermal cycling process. The reason for appearance of pores is change in coating material volume taking place in oxidation of $\mathrm{ZrB}_{2}$ according to reaction $\mathrm{ZrB}_{2}+2.5 \mathrm{O}_{2}=$ $=\mathrm{ZrO}_{2}+\mathrm{B}_{2} \mathrm{O}_{3}$. At that there is formation of $1 \mathrm{~g} / \mathrm{mole}$ of $\mathrm{ZrO}_{2}$ and $1 \mathrm{~g} / \mathrm{mole}$ of $\mathrm{B}_{2} \mathrm{O}_{3}$, which have volume of $22.4 \mathrm{~cm}^{3}$ and $38 \mathrm{~cm}^{3}$. That results in increase of initial volume of $\mathrm{ZrB}_{2}$ component to $60.4 \mathrm{~cm}^{3}$ or in 3.3 times. Active evaporation of $\mathrm{B}_{2} \mathrm{O}_{3}$ and formation of porous structure of this layer occur in subsequent coating heating to $1100{ }^{\circ} \mathrm{C}$. Thickness of porous coating layer is approximately $150 \mu \mathrm{m}$ that is obviously related with value of depth of its heating in thermal cycling to around $1100{ }^{\circ} \mathrm{C}$. Vapors of $\mathrm{B}_{2} \mathrm{O}_{3}$ come out from the coating forming the channels (Figure $8, c$ ) and entrailing the material of aluminum silicate melt $\mathrm{Al}_{2} \mathrm{SiO}_{5}$ with appearance of buildups on the surface (Figure 8,c).

Examination of thin structure of surface and coating section (Figure 8,e, Table 3) showed the presence of high-disperse $(0.1-2.0 \mu \mathrm{m})$ inclusions of $\mathrm{ZrO}_{2}-$ phase in $\mathrm{Al}_{2} \mathrm{SiO}_{5}$ matrix phase. It can be explained following form presence of quasi-binary system of phase equilibrium $\mathrm{Al}_{2} \mathrm{SiO}_{5}-\mathrm{ZrO}_{2}$, where transition of $\mathrm{ZrO}_{2}$ in $\mathrm{Al}_{2} \mathrm{SiO}_{5}$ melt is shown [25] (Figure 9).

In respect of this the process of thermal cycling leads to precipitation of more refractory phase $\mathrm{ZrO}_{2}$
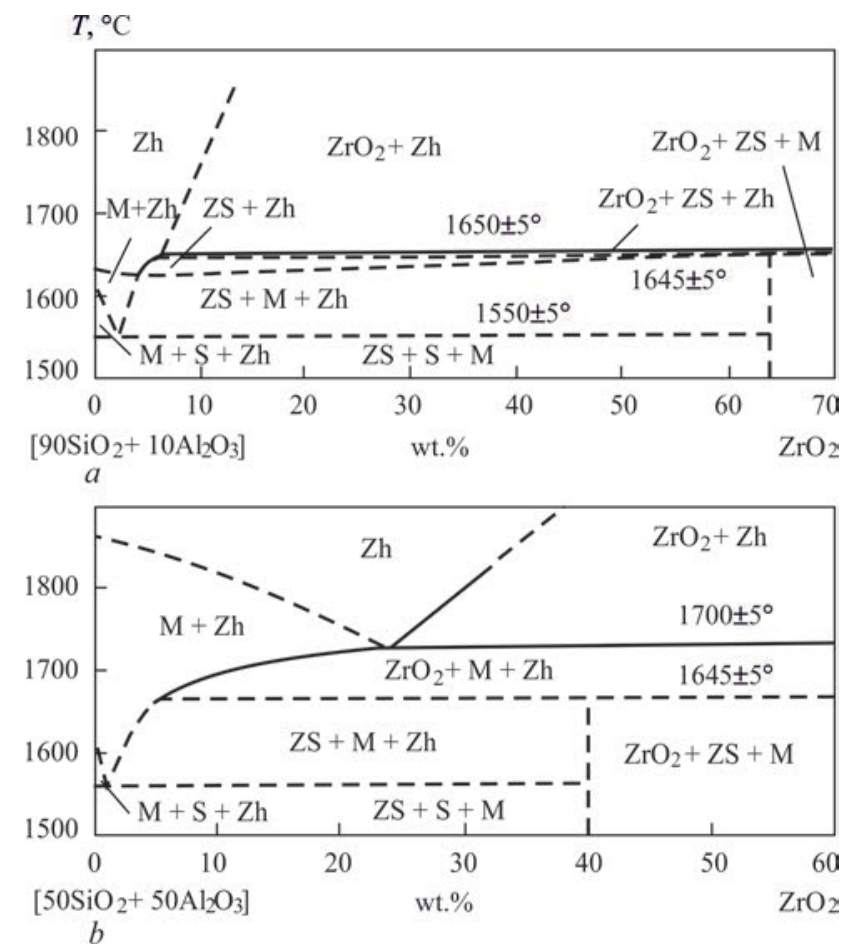

Fig re 9 Diagram of state of several sections of particular triple system $3 \mathrm{Al}_{2} \mathrm{O}_{3} 2 \mathrm{SiO}_{2}-\mathrm{ZrO}_{2}-\mathrm{SiO}_{2}$ (on Quercshi and Brett): $a$ - section $\left[90 \mathrm{SiO}_{2}+10 \mathrm{Al}_{2} \mathrm{O}_{3}\right]-\mathrm{ZrO}_{2} ; b-\operatorname{section}\left[50 \mathrm{SiO}_{2}+\right.$ $50 \mathrm{Al}_{2} \mathrm{O}_{3}-\mathrm{ZrO}_{2}$ ]; $\mathrm{C}$ - crystobalite; $\mathrm{M}$ - mullite 
from $\mathrm{Al}_{2} \mathrm{SiO}_{5}$ matrix, having melting temperature $1850{ }^{\circ} \mathrm{C}$.

Presence of porosity and $\mathrm{ZrO}_{2}$ inclusions shall assist decrease of heat conductivity of coating material in this zone that allows it performing functional characteristic of thermal protection from external heat source.

Content of the second below zone of the coating of around $100 \mu \mathrm{m}$ thickness following the analysis results includes $\mathrm{ZrO}_{2}, \mathrm{Al}_{2} \mathrm{SiO}_{5}$ and $\mathrm{B}_{2} \mathrm{O}_{3}$ and has dense structure that indicates its formation under conditions of temperatures below $1100{ }^{\circ} \mathrm{C}$. Presence of a liquid phase $\mathrm{B}_{2} \mathrm{O}_{3}$ (probably triple alumoborosilicate phase $\mathrm{Al}_{2} \mathrm{O}_{3} \times \mathrm{SiO}_{2} \times \mathrm{B}_{2} \mathrm{O}_{3}$ ), impregnating the coating layer, provides density and protective properties [24].

Lower coating zone, adjacent to surface of substrate $-\mathrm{CM} \mathrm{C/C}-\mathrm{SiC}$ of around $150 \mu \mathrm{m}$ thickness, corresponds on composition to the coating in the initial sprayed state, i.e. $\mathrm{ZrB}_{2}-\mathrm{SiC}-\mathrm{AlN}$ with oxide inclusions.

Thus, under these experimental conditions with performance of thermal cycling heating there was formed a three-layer coating consisting of $\mathrm{Al}_{2} \mathrm{SiO}_{5}$ $\mathrm{ZrO}_{2}$ porous external layer; intermediate dense one, having protective properties of $\mathrm{Al}_{2} \mathrm{SiO}_{5}-\mathrm{ZrO}_{2}$ layer, containing $\mathrm{B}_{2} \mathrm{O}_{3}$, and a layer in contact with $\mathrm{C} / \mathrm{C}-\mathrm{SiC}$ base, consisting of components of initial plasma coating $-\mathrm{ZrB}_{2}, \mathrm{SiC}, \mathrm{AlN}$ with presence of products of their oxidation.

Cn clusin . Formation of protective coating on surface of $\mathrm{C} / \mathrm{C}-\mathrm{SiC} \mathrm{CM}$ under conditions of atmospheric (in open air) plasma spraying using composite powder (CP) $60 \mathrm{ZrB}_{2}-20 \mathrm{SiC}-20 \mathrm{AlN}$ (wt.\%) takes place by means of heating of $\mathrm{CP}$ particles during movement in volume of plasma jet to melting stage in related processes of their interaction with environment and interphase phenomena in the volume of composite $\mathrm{ZrB}$ - $-\mathrm{SiC}-\mathrm{AlN}$ particle with their next deformation and laying on the surface of $\mathrm{C} / \mathrm{C}-\mathrm{SiC}$ base under effect of impact pressure.

Composition of sprayed plasma $\mathrm{ZrB}_{2}-\mathrm{SiC}-$ AlN-coating depends on level of heating of CP particles and development of interphase interaction of their components $\left(\mathrm{ZrB}_{2}, \mathrm{SiC}, \mathrm{AlN}\right)$ with high-temperature gas medium $\left(\mathrm{O}_{2}, \mathrm{~N}_{2}, \mathrm{Ar}\right)$ as well as into a volume of particles between their components. Time of staying of CP particles in the plasma jet and dynamics of the processes of their heating and acceleration are caused by the parameters of the process of plasma spraying (composition and consumption of plasma gases, plasmatron power, spraying distance).

Experimental work on atmospheric plasma spraying of coatings from $\mathrm{CP} 60 \mathrm{ZrB}_{2}-20 \mathrm{SiC}-20 \mathrm{AlN}$ on surface of $\mathrm{C} / \mathrm{C}-\mathrm{SiC} \mathrm{CM}$ was carried out using subsonic plasma jet obtained at plasmatron power $24 \mathrm{~kW}$ and plasma gas $\mathrm{Ar} / \mathrm{N}_{2}$, and supersonic plasma jet forming at plasmatron operation of $82 \mathrm{~kW}$ power with air as plasma gas.

A calculation-theoretical evaluation of the main characteristics of the process of plasma spraying of coating from $60 \mathrm{ZrB}_{2}-20 \mathrm{SiC}-20 \mathrm{AlN} \mathrm{CP}$ (wt.\%), having $4.4 \mathrm{~g} / \mathrm{cm}^{2}$ calculation density of particle material, such as temperature and velocity of plasma jet, velocity of particles of average diameter $(60 \mu \mathrm{m})$, time of their spraying in plasma jet was carried out using CASPSP program for computer simulation of process of plasma spraying. In the case of parameters of subsonic and supersonic plasma spraying used in the experiments performance the approximate calculation values of the temperature of plasma jet made 10000 and $6000{ }^{\circ} \mathrm{C}$, jet velocity -600 and $2500 \mathrm{~m} / \mathrm{s}$, time of staying of spray particles in jet volume $-0.5-3.0$ and $0.2-1.5 \mathrm{~ms}$, respectively.

The calculation value of impact pressure in particle impact on substrate made $47-75$ and $400-500 \mathrm{MPa}$, respectively.

XRD data of coatings obtained under conditions of atmospheric plasma spraying in comparison with XRD of initial $60 \mathrm{ZrB}_{2}-20 \mathrm{SiC}-20 \mathrm{AlN} \mathrm{CP}$ indicate appearance in the coatings of new phase-products of interaction of sprayed particles with environment oxygen $\left(\mathrm{ZrO}_{2}, \mathrm{Al}_{2} \mathrm{SiO}_{5}, \mathrm{ZrSiO}_{4}\right)$. This phenomenon was absent in the case of application of the technology of plasma spraying of $\mathrm{ZrB}_{2}-\mathrm{SiC}$ coating in closed chambers with controlled medium [11].

Analysis of the results of XRD and optical metallography allowed determining some difference of phase composition of the coatings, obtained using plasma jet with subsonic and supersonic flow velocity.

Testing the heat resistance of $\mathrm{ZrB}_{2}-\mathrm{SiC}-\mathrm{AlN}$-coating by means of cyclic heating by oxygen-propane-butane torch flame and following air cooling were carried out for 15 cycles, without failure and delaminations of coating of around $400 \mu \mathrm{m}$ thickness.

Three-zone structure of plasma $\mathrm{ZrB}_{2}-\mathrm{SiC}-$ AlN-coating with change of content of oxygen deep inside the coating from 50 to $30 \mathrm{wt} . \%$ is formed under effect of thermal cyclic heating. An upper zone consists of mullite $\mathrm{Al}_{2} \mathrm{SiO}_{5}$ being a matrix constituent of the coating with multiple $\mathrm{ZrO}_{2}$ inclusions of submicrone size and has porosity formed as a result of evaporation of initially formed sections of $\mathrm{B}_{2} \mathrm{O}_{3}$ phase. A middle zone contains a mixture of $\mathrm{ZrO}_{2}$ phases and silicates (or borosilicates) and $\mathrm{Al}_{2} \mathrm{O}_{3}-\mathrm{SiO}_{2}-\mathrm{B}_{2} \mathrm{O}_{3}$ system. It is characterized with high density and resistance to $\mathrm{O}_{2}$ diffusion that determines its protective properties. A lower zone located in contact with $\mathrm{C} / \mathrm{C}-$ $\mathrm{SiC} C \mathrm{CM}$ surface corresponds on composition to initial sprayed coating $\mathrm{ZrB}_{2}-\mathrm{SiC}-\mathrm{AlN}$ with inclusions of oxide phases - its oxidation products. 
High-temparature resistance testing of plasma $\mathrm{ZrB}_{2}-\mathrm{SiC}-\mathrm{AlN}$ coating under conditions of cyclic heating with oxygen-propane-butane torch flame during 2 min with cooling on air showed that the coating conserved integrity and its protective properties after 15 cycles of heating.

1. Sorokin, O.Yu., Grashchenkov, D.V., Solntsev, S.St., Evdokimov, S.A. (2014) Ceramic composite materials with high oxidation resistance for perspective aircrafts (Review). Trudy VIAM, 06-08 [in Russian].

2. Roger, R., Naslain, R. (2005) Fiber-reinforced ceramic matrix composites: state of the art, challenge and perspective. Composites, 5(1), 3-19.

3. Krenkel, W., Berndt, F. (2005) C/C-SiC composites for space applications and advanced friction systems. Mat. Sci. and Engng. A, , 177-181.

4. Heidenreich, B. (2007) Carbon fibre reinforced SiC materials based on melt infiltration. Proc. of 6th Int. Conf. on High Temperature Ceramic Matrix Composites (HTCMC 6).

5. Kumar, S., Chandra, R., Kumar, A. et al. (2015) C/SiC composites for propulsion application. Composites and Nanostructures, 7(4), 225-230.

6. Tkachenko, L.A., Shuvalov, A.Yu., Berlin, A.A. (2012) High-temperature protective coatings of carbon materials Neorganicheskie Materialy, 48(3), 261-271 [in Russian].

7. Lebedeva, Yu.E., Popovich, N.V., Orlova, L.A. (2013) Hightemperature protective coatings for composite materials based on SiC. Trudy VIAM, $\mathbf{2}, 1-7$ [in Russian].

8. Xiang Yang, Chen Zhao-hui, Cao Feng (2014) High-temperature protective coatings for $\mathrm{C} / \mathrm{SiC}$ composites. J. of Asian Ceramic Societies, 2(4), 305-309.

9. Sufang Tang, Jingyi Deng, Shijun Wang et al. (2007) Ablation behaviours of ultra-high temperature ceramic composites. Mat. Sci. and Engng. A, , 1-7.

10. Marschall, J., Pejakovic, D.A., Fahrenholtz, W.G. et al. (2009) Oxidation of $\mathrm{ZrB}_{2}-\mathrm{SiC}$ ultrahigh-temperature ceramic composites in dissociated air. $J$. of Thermophysics and Heat Transfer, 23(2), 267-278.

11. Valente, T., Bartuli, C., Visconti, G., Tului, M. (2000) Plasma sprayed ultra high temperature ceramics for thermal protection systems. In: Proc. ITSC'2000, 837-841.

12. Bartuli, C., Valente, T., Tului, M. (2001) High temperature behavior of plasma sprayed $\mathrm{ZrB}_{2}-\mathrm{SiC}$ composite coatings.
In: Thermal Spray 2001: New Surfaces for a New Millenium. Ohio, USA, 259-262.

13. Bartuli, C., Valente, T., Tului, M. (2002) Plasma sprayed deposition and high temperature characterization of $\mathrm{ZrB}_{2}-\mathrm{SiC}$ protective coatings. Surfaces and Coating Technology, $\mathbf{5}$, 260-273.

14. Tului, M., Ruffini, F., Arezzo, F. et al. (2002) Some properties of atmospheric air and inert gas high-pressure plasma sprayed $\mathrm{ZrB}_{2}$ coatings. Ibid., $1483-489$.

15. Tului, M., Marino, G., Valente, T. (2006) Plasma spray deposition of ultra high temperature ceramics. Ibid., , 21032108 .

16. Tului, M., Lionetti, S., Pulci, G. et al. (2008) Effects of heat treatments on oxidation resistance and mechanical properties of ultra high temperature ceramic coatings. Ibid., $\mathbf{0}, 4394$ 4398.

17. Tului, M., Lionetti, S., Pulci, G. et al. (2010) Zirconium diboride based coatings for thermal protection of re-entry vehicles: Effect of $\mathrm{MoSi}_{2}$ addition. Ibid., , 1065-1069.

18. Zou, B., Khan, Z.S., Fan, X. et al. (2013) A new double layer oxidation resistant coating based on $\mathrm{Er}_{2} \mathrm{SiO}_{8} / \mathrm{LaMgAl}_{11} \mathrm{O}_{19}$ deposited on $\mathrm{C} / \mathrm{SiC}$ composites by atmospheric plasma spraying. Ibid., $\mathbf{2}, 101-108$.

19. Zou, B., Khan, Z.S., Gu, L., Fan, X. et al. (2012) Microstructure, oxidation protection and failure mechanism of $\mathrm{Yb}_{2} \mathrm{SiO}_{5} /$ $\mathrm{LaMgAl}_{11} \mathrm{O}_{19}$ coating deposited on $\mathrm{C} / \mathrm{SiC}$ composites by atmospheric plasma spraying. Corrosion Sci., , 192-200.

20. Grigoriev, O.N., Panasyok, A.D., Podchernyaeva, I.A. et al. (2018) Mechanism of high-temperature oxidation of composite ceramics based on $\mathrm{ZrB}_{2}$ of $\mathrm{ZrB}_{2}-\mathrm{SiC}-\mathrm{AlN}$ system. Poroshk. Metallurgiya, 1 2, 93-98 [in Russian].

21. Borisov, Yu.S., Krivtsun, I.V., Eritt, U. (2000) Computer modelling of plasma spraying process. The Paton Welding J., $\mathbf{2}$, 40-50.

22. Petrov, S.V., Karp, I.N. (1993) Plasma gas-air spraying. Kiev, Naukova Dumka [in Russian].

23. Ordanyan, S.S., Dmitriev, A.I., Moroshkina, E.S. (1987) Interaction of $\mathrm{SiC}$ with $\mathrm{ZrB}_{2}$. Izv. AN SSSR. Neorganicheskie Materialy, 1752-1754 [in Russian].

24. Krivoshein, D.A., Maurakh, M.A., Dergunova, V.S. et al. (1980) Mechanism of formation of glass-like films on surface of material of $\mathrm{ZrB}_{2}-\mathrm{ZrC}-\mathrm{SiC}-\mathrm{C}$ system in its oxidation. Poroshk. Metallurgiya, 8, 58-62 [in Russian].

25. Toropov, N.I., Barzakovsky, V.P., Lapin, V.V. et al. (1972) State diagrams of silicate systems: Handbook, Issue 3. Leningrad, Nauka, 290-293 [in Russian].

\title{
FRONIUS UKRAINE LLC HOLDS THE SEIIINAR
}

\author{
June 20, 2019 - «Robotization of Welding Processes» \\ Fronius Ukraine GmbH \\ Browarskij r-n, s. Knjashitschi, ul. Slavy 24 \\ 07455 Kievskaya obl. \\ Tel.: +380 442772141 \\ Fax: +380 442772144 \\ sales.ukraine@fronius.com \\ http://www.fronius.ua /
}




\title{
GAS-POW ER SPRAYING AS A HIGH-EFFICIENT METHOD OF INCREASING THE OPERATION RELIABILITY OF POW R EQUIPMENT
}

\author{
A.V .G RUZEVICH ${ }^{1,2}$ and DA .D ERECHA ${ }^{2,3}$ \\ ${ }^{1}$ Tripolskaya TPP \\ 08720, Ukrainka. E-mail: Gruzevich@bigmir.net \\ ${ }^{2}$ Institute of Magnetism of the NAS of Ukraine and MES of Ukraine \\ 36b Academician Vernadsky Blvd., 03142, Kyiv, Ukraine \\ ${ }^{3}$ National Technical University of Ukraine «Igor Sikorsky Polytechnic Institute» \\ 57 Peremohy Prosp. , 03056, Kyiv, Ukraine
}

\begin{abstract}
In the work the spraying is suggested as the promising and high-efficient method for improvement of operation reliability of TPP power equipment. As the main type of wear of pipe elements of TPP power equipment is the ash wear and corrosion, then to increase their reliability, service life and working capacity it is suggested to apply the electric arc spraying using material PP 70Kh10R3Yu5 as a method of thermal modification of heating surfaces. The aim of the work is the investigation of efficiency of spraying application for improving the operation reliability of TPP power equipment. Spraying of heating surfaces was carried out in two thermal power plants of PJSC «Centrenergo» in 2013. A feasibility study showed that the implementation of spraying technology allows 1.5-2.0 times decreasing the expenses as compared with losses, incurred by TPP in case of emergency shutdowns, and increasing the service life of the equipment approximately by 1.4 times. 15 Ref., 7 Tables, 12 Figures.
\end{abstract}

Ke ywords : spraying, power equipment, pipes, bends, reliability, boilers, economizer, thermal power plant

The intensive wear of heat-exchange surfaces of boilers of thermal power plants (TPP), in particular, water-wall tubes and pipes of economizers, is caused by use of a coal dust with a large part of hard incombustible impurities [1-3]. Analysis of damages by the classification features [4] shows that the main cause of damage of boiler pipes is a corrosion-erosion wear. From the data of work [5], its share on separate units reached $60 \%$. Coiled pipes of water economizers are mostly often subjected to erosion. The abrasive ash particles, trapped by smoke gases, strike againts the surface of pipes at high rate and cause an ash wear (Figure 1). At the surface of water-wall tubes of steel $12 \mathrm{Kh} 1 \mathrm{MF}$ at elevated temperatures up to $585^{\circ} \mathrm{C}$ the films of iron oxides are formed, which have a weak adhesion with a steel surface and they are easily worn-out by abrasive particles. The wear of outer

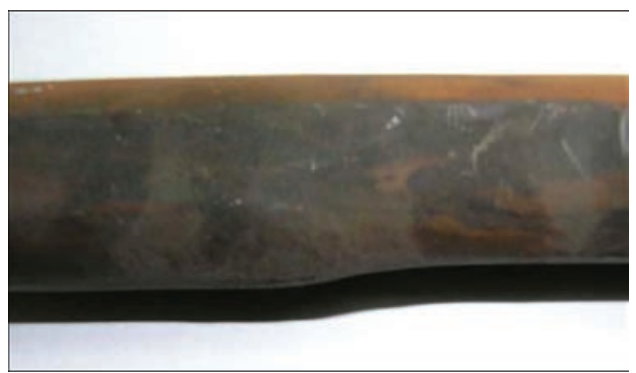

Fig re 1 Nature of damage of $32 \times 6 \mathrm{~mm}$ diameter pipe of water economizer as a result of ash wear effect

C) A.V. GRUZEVICH and D.A. DERECHA, 2019 pipe surface occurs nonuniformly over a large area, it is localized in definite places and when reaching the critical thickness of pipe wall its burst takes place, which leads to the power unit shutdown. The thermal load to the outer pipe wall is also increased due to sedimentation of salts on inner surfaces of water-wall tubes, which, in addition, undergo the corrosion-erosion damages. Therefore, the development of new effective methods of improving the operation reliability of power equipment of TPP is the urgent direction.

The damage of pipe elements of heating surfaces of TPP power equipment have a nature of creep mechanisms with a fatigue pronounce, proceeding of processes of erosion and gas corrosion (oxidizing) due to extremely-high conditions of service, connected with high values of temperature, available cyclic loads and aggressive working environment, as well as due to abrasive action of combustion products of the coal fuel $[2,3]$.

Anh $\mathbf{y}$ is 6 methd $s 6$ impri $n g$ the $p$ ert in relib ility 6 pw er equipment. As the main type of wear on water economizer (WE) of TPP boilers is an ash wear, and corrosion between the distance-type straps, then in works $[3,6]$ an integrated solution of the problem of extension of the service life of water-wall tubes of boilers and pipes of economizer due to development of new heat-resistant and wear-resistant thermal coatings was suggested. As a result, in structure of such coatings during the service of boiler tubes and pipes of economizers the dispersion pro- 
cesses of strengthening due to precipitation in metal of fine-dispersed phases of carbides, nitrides and intermetallics, will be proceeding, which will increase greatly their service properties in operation.

It is shown in works $[7,8]$, that it is possible to apply surfacing for improvement of operation reliability of power plants equipment in ash and corrosion wear. The presently developed powder self-fluxing wear-resistant and anticorrosion alloys, as well as the technologies of their deposition allow producing the metallic coatings with preset properties on the surface of parts. The gas-powder surfacing using self-fluxing wear-resistant alloys found a wide application in restoration of worn-out pipe regions and protection of new ones in water-wall economizers of boilers at the unitized TPP.

The modern industry has in its disposal a large selection of special powders for surfacing and spraying, which impart the various properties to surface being sprayed, including also an abrasive wear resistance, corrosion resistance, wear resistance at elevated temperatures and aggressive environments. These are powders on the base of chromium, nickel and carbide-forming elements.

As a protective coating the metallic powder PG-SR of grade PR-N80Kh13S2R TUN-1-3785-84 of fraction «OM» or powder PR-N77Kh15S3R2 (PG$12 \mathrm{~N}-02$ ) [9], fused as a result of coating deposition, are used. The powder deposition of pipe elements of boiler heating surfaces is performed during surfacing in several layers with a different thickness and width. The selection of required characteristics of a protective layer is made by the surfacing modes. This allows increasing their service life by $10-15$ years.

In work [3] for restoration and protection of pipes and elements, which were subjected to the ash wear, the welding technologies are used, at which the restoration treatment of a thin region of a pipe element of steel 20 of water-wall economizer is performed by the manual arc (argon arc) welding. The application of the manual arc welding in case of surfacing of pipe elements of economizers of boilers envisages the use of electrodes E50A for steel 20 and E-09Kh1MF for steel $12 \mathrm{Kh} 1 \mathrm{MF}$. For manual argon arc welding the filler wires Sv-08GS and Sv-08G2S for pipes of steel $20, \mathrm{~Sv}-08 \mathrm{KhM}$ for pipes of steel $12 \mathrm{KhMF}$ with service temperature up to $510^{\circ} \mathrm{C}$ and $\mathrm{Sv}-08 \mathrm{KhMFA}$ for pipes of steel $12 \mathrm{Kh} 1 \mathrm{MF}$ with service temperature above $510{ }^{\circ} \mathrm{C}$ are used.

Also, on water economizers of TPP boilers the individual collars are used to protect bends and straight pipe regions, subjected to wear (Figure 2).

Undoubtedly, the given method allows increasing the service life and reliability of pipe operation, however, the application of collars for protection of pipes

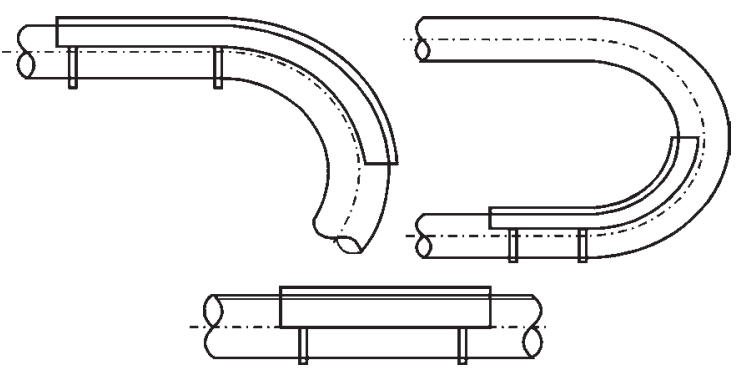

Fig re 2 Individual collars for protection of bends and straight regions of pipes of a water economizer of TPP boilers

of heating surfaces in places of distance-type straps location is not rational due to a local increase in section, as the collars do not possess special properties for pipes protection from the corrosion-erosion effect. The corrosion-erosion processes will be proceeding in any case, and the additional increase in pipes weight (due to collars application) will increase the load on coiled pipes, which was not taken into account in designing, that can influence the workability of welded joints (cracks in welded joints and HAZ, pinchings). Moreover, due to application of collars the local increase in pipe diameter occurs, resulting in decrease of a passing section for fuel gases between the separate pipes, which deteriorates the aerodynamics of gas flows and leads to increased wear of pipes of the neighboring coiled pipes, complicates access to separate packs of coiled pipes and reduces their maintainability.

The corrosion developing can be seen in a technological gap of an overlap joint (between pipes), and the presence of collar outside do not allow making required inspection of pipe metal state under it.

It was suggested to apply a local gas-powder spraying with special metallic coatings to provide local protection of pipes under the distance-type straps [10].

The drawbacks of the above-given methods of gas-powder and arc surfacing are the high heat inputs, which can cause a possible distortion of coiled pipes, structural changes in ferrite-pearlite structure of steel and high requirements specified to the welder qualification.

One of the promising methods of increasing the operation reliability of power equipment is the electric arc spraying.

V. Karpenko Physical-Mechanical Institute of the NAS of Ukraine has developed the technology of protection of heating elements of thermal power plants from the abrasive wear and gas corrosion [11], which envisages the deposition of scarcely-alloyed electric arc coatings from flux-cored wire to the surface of water-wall tubes and pipes of economizers of thermal power plants for their effective protection from the abrasive wear and gas corrosion at service temperatures up to $600{ }^{\circ} \mathrm{C}$. This technology allows twice increasing service life of protected pipes. 
Tb le 1 Mechanical characteristics of pipes before metallization

\begin{tabular}{|c|c|c|}
\hline$\sigma_{\mathrm{t}}, \mathrm{MPa}$ & $\delta, \%$ & $\psi, \%$ \\
\hline 50.3 & 28.8 & 60 \\
\hline \multicolumn{3}{|c|}{ According to requirements of } \\
TS 14-3-460:2009/TS U 27.2-05757883-207:2009 \\
«Steel seamless pipes for steam boilers and pipelines» \\
\hline $42-56$ & 24 & 45 \\
\hline
\end{tabular}

The application of metallization will allow:

- imparting the corrosion-erosion resistance to pipe regions at elevated temperatures;

- not increasing the total weight of heating surfaces;

- not hindering the access to separate packs of coiled pipes;

- not hindering the visual inspection of outer surface of pipes in places of location of the distance-type straps;

- decreasing the labor consumption for suggested measures due to elimination of operations for manufacture of sleeves, assembly of welded joints for collars.

So, the application of metallization is the most profitable method for protection of pipes of the heating surfaces.

The aim of the present work is the investigation of application of electric arc spraying (metallization) for improving the operation reliability of TPP power equipment.

Gra nding the selectio $6 \mathrm{~h}$ lig $\mathrm{ng}$ sy tem a d flux-cored wire. The heat resistance of metal of alloying system $\mathrm{Fe}-\mathrm{Cr}-\mathrm{B}-\mathrm{Al}$ is provided by the formation of oxide film $\mathrm{Al}_{2} \mathrm{O}_{3}$ on its surface, which is characterized by a high chemical and thermal stability. At elevated temperatures the diffusion of oxygen and nitrogen into transient layers leads to the formation of iron oxides $\mathrm{Fe}_{2} \mathrm{O}_{3}$ and aluminium nitrides $\mathrm{AlN}$, which reduces the coating heat resistance. To soften the negative effect of the mentioned oxides, the silicon is added into the coating system, which promotes the formation of a diffusion layer $\mathrm{SiO}_{2}$, preventing the oxidation of an under-scale layer. The wear resistance of coating is proved by the content in the coating composition of fine-dispersed iron-chrome carbides $(\mathrm{Fe}$, $\mathrm{Cr})_{7}, \mathrm{C}_{3}$, spinels $(\mathrm{Fe}, \mathrm{Cr})_{2} \mathrm{O}_{3}$.

Procedure. The electric arc spraying in a compressed air jet of heating surfaces was performed at two thermal power plants of PJSC «Centrenergo» in 2013. The coiled pipes of water-wall economizers of Tripolskaya TPP

Tb le 2 Structural characteristics of pipes before metallization

\begin{tabular}{|c|c|c|c|}
\hline Microstructure & $\begin{array}{c}\text { Number of } \\
\text { structure by } \\
\text { scale } \\
\text { TS 14-3-460 }\end{array}$ & $\begin{array}{c}\text { Number of } \\
\text { striation by } \\
\text { scale } \\
\text { TS 14-3-460 }\end{array}$ & $\begin{array}{c}\text { Number of } \\
\text { graphitization acc. } \\
\text { to SOU-N EE } \\
20.321: 2009\end{array}$ \\
\hline $\begin{array}{c}\text { Cut-out from } \\
\text { WE }\end{array}$ & 0 & 0 & $\begin{array}{c}1 \text { (graphitization } \\
\text { was not revealed) }\end{array}$ \\
\hline
\end{tabular}

(TrTPP), having two-year service in unit No.2, were dismantled and subjected to spraying by the metallization method. Before spraying the test specimens were cut out from pipes, being in service in coiled pipes, for determination of mechanical and metallographic properties of metal. Results of mechanical tests for determination of tensile strength are given in Table 1.

During carrying out of metallographic analysis the investigations were performed around the whole perimeter of the pipe at magnification $\times 100$ and $\times 500$. Ferrite-pearlite structure of metal across the whole section of test specimen was similar. Results are given in Table 2.

During carrying out of mechanical and metallographic tests of pipe specimens the deviations from standard requirements [12] were not revealed, and then the decision was taken about the deposition of protective coating by the metallization method.

The works on coating deposition were carried out at the repair platform of TrTPP in accordance with the developed procedure [13].

The preparation of pipe elements for metallization consisted of cleaning and activation of the surface by the method of sand blasting treatment. The quality of preparation of pipe elements for spraying was visually inspected.

To perform works for deposition of the protective coating on pipes of heating surfaces a set of equipment was used, consisting of: machine for sand blasting treatment, electric arc metallization device, filter-moisture separator, cassettes with flux-cored wire, electric cabinet, power source.

During spraying the in-process control was made, which included checking of the quality of preparation of heating surfaces for spraying, spraying mode, sequence of deposition of layers of metal being sprayed, granularity and coating color. The spraying was carried out without using of substrate. The pipes after metallization were not subjected to heat treatment.

After spraying of a protective layer the coiled pipes were mounted on a steam boiler of a supercritical pressure TPP-210 A, power plant unit No.1, building A. As a fuel, coal of grade ASh was used according to the project for boiler TPP-210 A.

At Uglegorskaya TPP (UgTPP) two heating surfaces were subjected to spraying: KPP n.p. (steel $12 \mathrm{Kh} 1 \mathrm{MF}$ ) between distance-type straps and bends near walls of steam boiler TPP-312 A of supercritical pressure power plant unit No.4. Also, the water-wall economizer (steel 20) of steam boiler of supercritical pressure TPP-312 A of power plant unit No.2 were subjected to spraying. According to the project as a fuel for boiler TPP-312 A the coal of grade G was used. It was found that at TrTPP and UgTPP the 
Tb le 3 Composition of sprayed layer

\begin{tabular}{|c|c|c|c|c|c|c|c|c|c|}
\hline \multirow{2}{*}{$\begin{array}{l}\text { Specimen } \\
\text { number }\end{array}$} & \multicolumn{9}{|c|}{ Content of alloying elements, wt. $\%$} \\
\hline & $\mathrm{Fe}$ & $\mathrm{Cr}$ & $\mathrm{Al}$ & $\mathrm{Si}$ & $\mathrm{Ni}$ & $\mathrm{Cu}$ & $\mathrm{Ti}$ & $\mathrm{Zn}$ & Mo \\
\hline 1 & 76.04 & 11.76 & 5.41 & 5.36 & 0.17 & 0.08 & 0.14 & 0.13 & 0.05 \\
\hline 2 & 77.39 & 11.27 & 5.58 & 4.66 & 0.15 & 0.09 & 0.11 & 0.1 & 0.09 \\
\hline 3 & 75.13 & 11.33 & 5.52 & 5.67 & 0.19 & 0.09 & - & 0.04 & - \\
\hline 4 & 76.95 & 12.37 & 6.04 & 3.5 & 0.18 & 0.11 & 0.11 & 0.06 & 0.04 \\
\hline
\end{tabular}

main type of wear on water-wall economizer was an ash type, and between the distance-type straps was a corrosion one, therefore the spraying on the heating surfaces was carried out by the same material, namely flux-cored wire PP 70Kh10R3Yu5.

The composition of the sprayed layer is given in Table 3. At Tripolskaya TPP the composition was controlled by the X-ray fluorescent spectrometer NITON XL2.

The electric arc spraying was carried out in 2013 at the most abrasively worn-out regions of coiled pipes of the water-wall economizer of boilers TPP-210 A and TPP-312 A, corrosion-damaged regions of coiled pipes $\mathrm{KPP} n / \mathrm{p}$ in distance-type straps of boiler TPP-312 A.

The appearance of sprayed coiled pipes is given in Figure 3.

After the spraying and during service the cut-outs from pipes were made of heating surfaces, the microstructure of which should correspond to the requirements for safe service [12].

At Uglegorskaya TPP after metallization 2 reference specimens were cut out from the sprayed pipe KPP n.p. for metallographic examination: one was cut out from a bend (with spraying on surface) and another one (reference) was cut out at the distance of $150 \mathrm{~mm}$ from the sprayed zone. Sections were manufactured by a successive grinding and polishing. Etching of sections was made in $4 \%$ solution of nitric acid in ethyl alcohol. For metallographic analysis the microscope MIM-8M was used at magnification $\times 100$ and $\times 500$. Structure of reference sample was ferrite-pearlite.
Steeloscoping was made at the stationary steeloscope SL-13. Sprayed pipes and bends were subjected to visual inspection. Mechanical tests were carried out for flattening and determination of mechanical properties.

At Tripolskaya TPP after metallization of coiled pipes of water-wall economizer of $\varnothing 32 \times 6 \mathrm{~mm}$ of steel 20 the coils were cut out (industrial specimens), then the templates were cut out from them, which were tested for flattening. Delamination of coating layers occurs after convergence of inner sides up to $H_{\text {in }}=15 \mathrm{~mm}$. Convergence of sides was made up to $H_{\text {in }}=10 \mathrm{~mm}$. The sprayed layer was subjected to hardness measurement in the ultrasonic hardness meter TKM-459.

Results 6 ine stig in . Visual inspection of pipes and bends showed that the sprayed layer has a rough surface with a metallic glittering. During the detailed inspection of the sprayed surface the separate large crystals are seen, which impart the roughness to the surface. The spraying has a uniform and continuous distribution over the outer surface of bends. Figure 4 shows the appearance of pipe bend and macrostructure of its surface, and Figure 5 presents microstructure of pipe surface. The structure after metallization did not subjected to changes and corresponded to the standard requirements.

The quality spectral analysis showed that the sprayed protective layer of pipe of the water-wall economizer, produced by the method of electric arc metallization, represents a composite with a strengthening carbide phase in a metal matrix and contains such alloying elements as chromium and aluminium. The content of
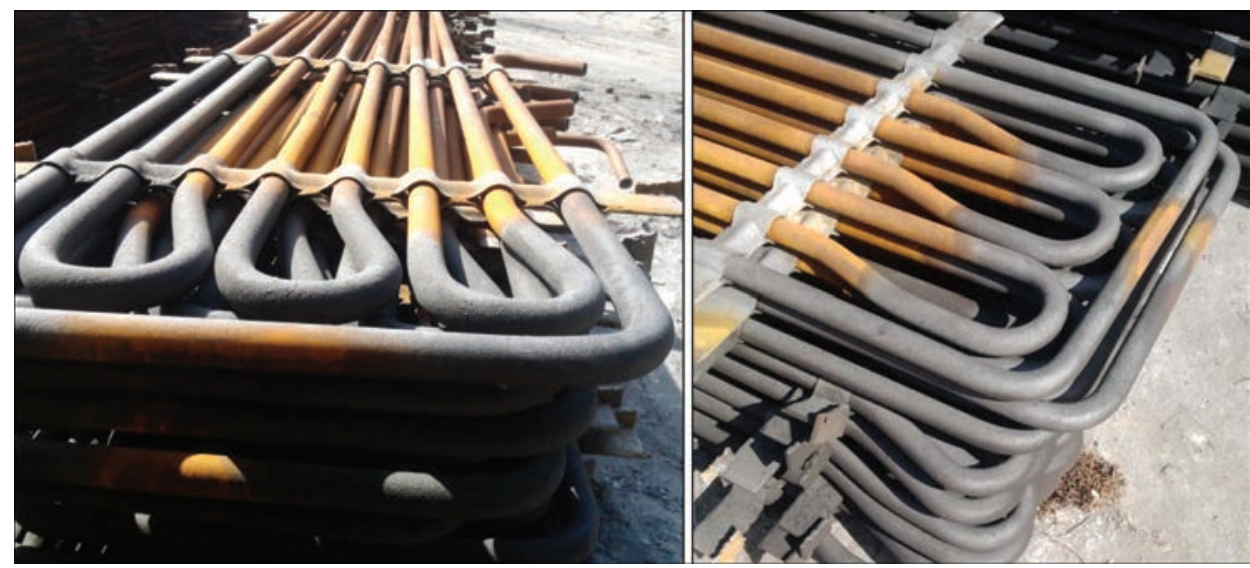

Fig re 3 Appearance of sprayed coiled pipes 

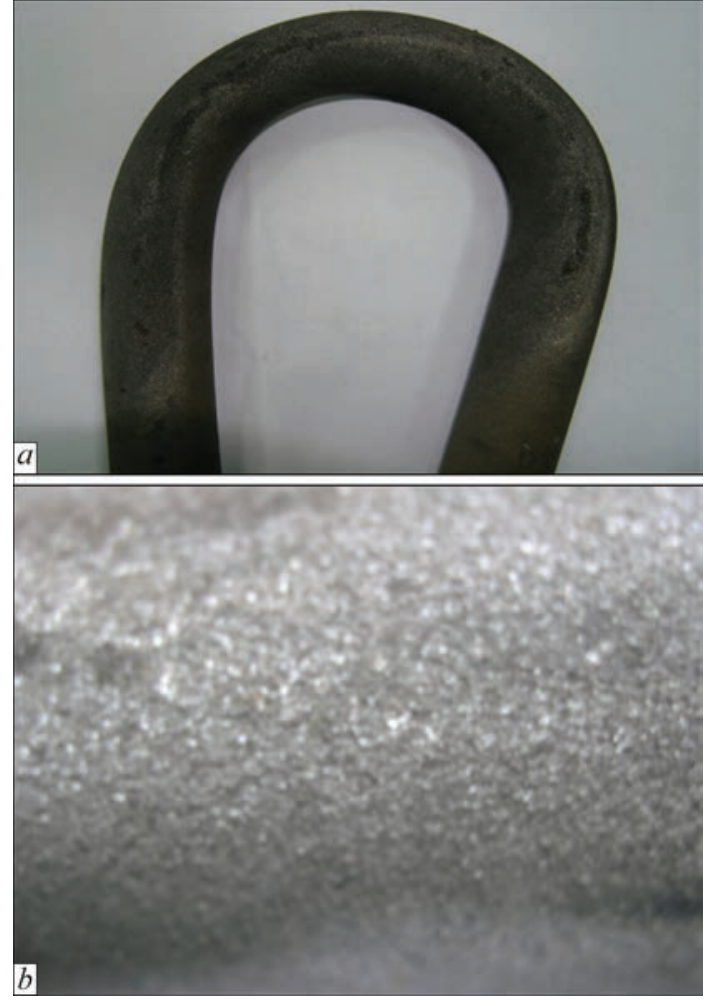

Fig re 4 Appearance of pipe bend $(a)$ and macrostructure of its surface $(b)$

a carbide phase was about $40 \%$. The base metal is a carbon steel (alloying elements were not revealed).

In the microstructure of sprayed pipes of steel 20 (Figure 6) the orientation by Widmanstatten structure should not exceed the third point of scale 2 of Appendix $\mathrm{B}$ «Scales of striation and Widmanstatten structure of metal of boiler pipes».

During metallographic examinations of pipes KPP n.p. of Uglegorskaya TPP it was found that a pronounced segregation banding is characteristic for initial metal structure, that is a deviation from standards and testifies the nonquality heat treatment of pipes after rolling in the process of their manufacture. Structure of sprayed specimen is the same as in the reference specimen, i.e. ferrite-pearlite. Visible structure changes were not found.

Under the sprayed layer a narrow boundary band of base metal of thickness from 0.07 up to $0.15 \mathrm{~mm}$ is seen, which was subjected to interaction with a

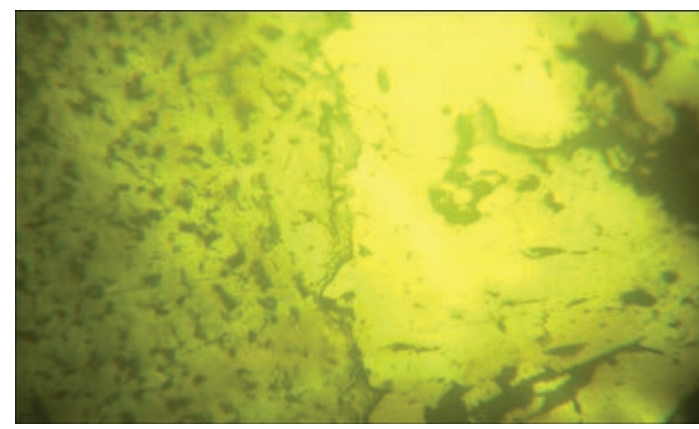

Fig re 5 Microstructure $(\times 500)$ of sprayed layer 
Tb le 4 Mechanical properties of pipe metal after spraying

\begin{tabular}{|c|c|c|}
\hline$\sigma_{\mathrm{t}}, \mathrm{MPa}$ & $\delta, \%$ & $\psi, \%$ \\
\hline 51.1 & 28.2 & 58 \\
\hline \multicolumn{2}{|c|}{ TU 14-3-460:2009/TU U 27.2-05757883-207:2009 } \\
\hline $420-560$ & 24 & 45 \\
\hline
\end{tabular}

Th le 5 Composition of sprayed layer after 30-year service at TPP

\begin{tabular}{|c|c|c|c|c|c|}
\hline \multirow{2}{*}{$\begin{array}{c}\text { Number of } \\
\text { specimen }\end{array}$} & \multicolumn{5}{|c|}{ Content of alloying elements, \% } \\
\cline { 2 - 6 } & $\mathrm{Fe}$ & $\mathrm{Cr}$ & $\mathrm{Al}$ & $\mathrm{Si}$ & $\mathrm{Ni}$ \\
\hline 1 & Base & 11.41 & 5.67 & 5.67 & 0.15 \\
\hline 2 & Same & 10.89 & 5.87 & 5.5 & 0.17 \\
\hline
\end{tabular}

chanical tests for determination of tensile strength of pipe after spraying the results were obtained, which are given in Table 4.

The obtained results of mechanical tests are in compliance with requirements of TS 14-3-460:2009/ TS U 27.2-05757883-297:3009.

The sprayed layer regions have hardness $H R C 54$ 58. The surface layer under the separated coating has the following chemical composition: $91.47 \% \mathrm{Fe}$; $2.78 \% \mathrm{Cr} ; 3.9 \% \mathrm{Si} ; 1.1 \% \mathrm{Al} ; 0.26 \% \mathrm{~S}$. Hardness of surface under the layer of spraying $H V 200-217$.

Thus, the obtained results can prove, that the base metal after spraying did not undergo the large changes in microstructure and mechanical properties and was in compliance with appropriate technical conditions.

After the 3-year service of pipes and bends at Tripolskaya TPP a spectral analysis of the coating surface layer was carried out. The layer composition was negligibly changed (Table 5).

In making cut-outs after 6 years of service the macro- and microstructure of sprayed pipes (Figures 9, 10), composition of surface layer (Table 6) were also recorded. Technological tests for flattening were performed, hardness was not measured.

Macrostructure of sprayed pipes after 6 years of service is given in Figure 9.

During service the surface becomes rougher, projected carbides of different size are seen on the surface. Examination of microstructure before and after wear in the flow of coal dust at working parameters of the water-wall economizer shows reorientation of carbide frame in matrix. The surface diffusion layer has the following chemical composition: $3.27 \% \mathrm{Cr}$; $1.87 \% \mathrm{Si} ; 0.9 \% \mathrm{Al} ; 0.3 \% \mathrm{~S}$.

Tb le 6 Composition of sprayed layer after 6-year service at TPP

\begin{tabular}{|c|c|c|c|c|c|}
\hline \multirow{2}{*}{$\begin{array}{c}\text { Number of } \\
\text { specimen }\end{array}$} & \multicolumn{5}{|c|}{ Content of alloying elements, wt.\% } \\
\cline { 2 - 6 } & $\mathrm{Fe}$ & $\mathrm{Cr}$ & $\mathrm{Al}$ & $\mathrm{Si}$ & $\mathrm{Ni}$ \\
\hline 1 & Base & 12.9 & 6.67 & 7.9 & 0.1 \\
\hline 2 & Same & 12.7 & 5.79 & 7.1 & 0.1 \\
\hline
\end{tabular}

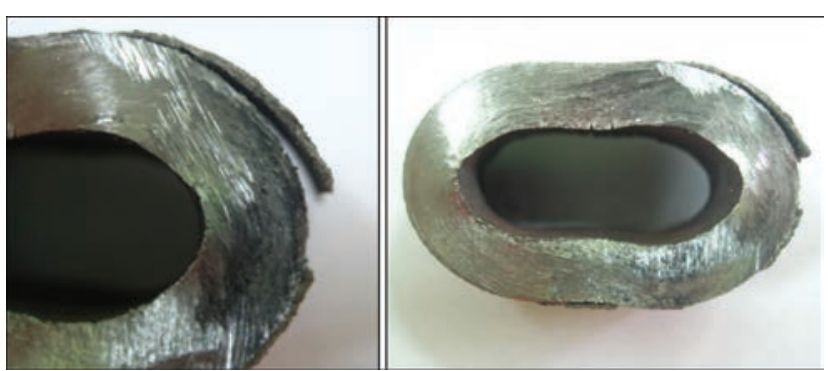

Fig re 7 Specimens after tests for flattening

The horizontal nature of line in Figure 11 shows that during 6 years the concentration of chromium in surface layer almost was not changed and even increased a little, its storage in surface layer is occurred. The increase in aluminium concentration in surface layer is largely connected with deposition of aluminium-containing elements, formed in the process of combustion of organic fuel, on coiled pipes.

Fracture of surface layer during testing of specimens is occurred by cracking of coating into fine fragments and its spalling (Figure 12). As we see, holding of coatings at working parameters leads to change in mechanics of their fracture, which is possibly caused by change in structure of dispersed phases. It was not managed to measure the hardness of the sprayed layer. Hardness of surface under the layer of spraying is $H V 180$.

At each power plant the data are collected up by a real thickness of pipe walls of heating surfaces by using destructive and nondestructive methods. In making cut-outs from pipes the data are recorded as to its thickness, microstructure and mechanical properties. To measure the pipe thinning the method of direct measurement of wall thickness is used. The resulted data on characteristic of pipes before spraying, as well during operation of each cut-out specimen are generalized in Table 7.

By analyzing the data on thinning, it is possible to conclude that in all the cases with increase in time of service the value of wall thinning due to ash wear is also increased.

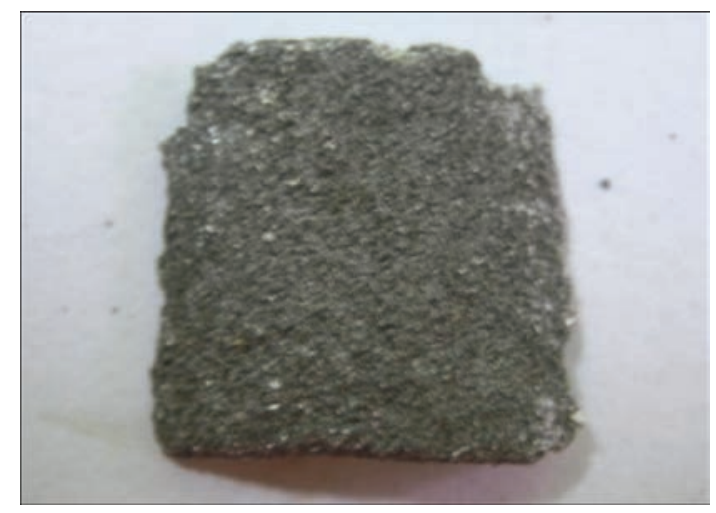

Fig re 8 Appearance of separated sprayed layer after test for flattening 


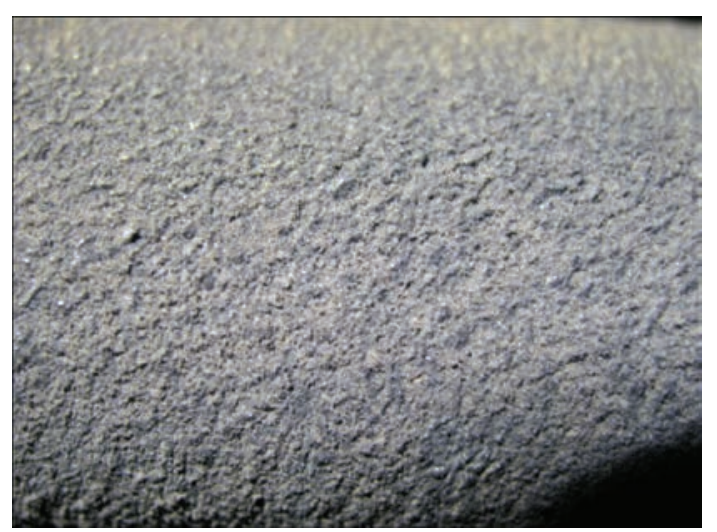

Fig re 9 Macrostructure of sprayed pipes after 6-year service

The highest intensity of ash wear is observed on the first two pipes of twenty edge coiled pipes of water-wall economizer. This phenomenon, first of all, is connected with a design peculiar feature of gas tract of coal dust П-shaped boiler. At output from URP (upper radiation part), in rotation chamber, gases change their direction and the largest particles of fuel combustion products are coming to the periphery of the general flow. The increase of their density in flow promotes the intensification of ash wear of twenty edge coiled pipes of the water-wall economizer.

After metallization of surface of coiled pipes of water-wall economizer the decrease in intensity of ash wear of coiled pipes was revealed. During measurement of wall thickness, thinning on the reference cut-outs was not observed.
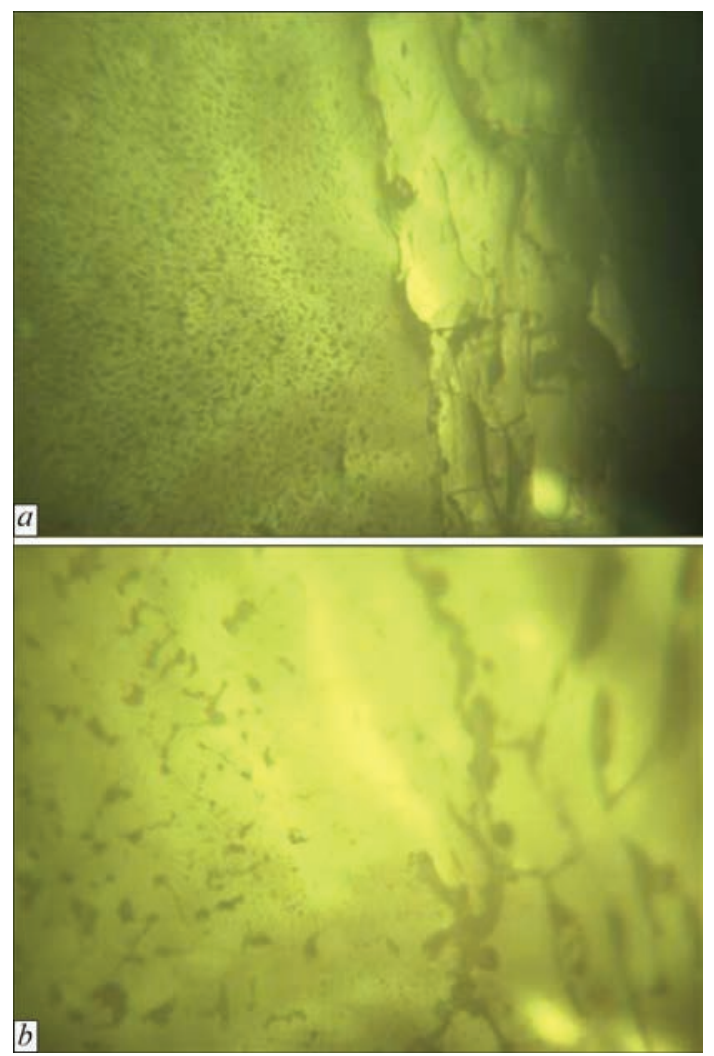

Fig re . Microstructure of sprayed pipes after 6-year service: $a-\times 100 ; b-\times 500$

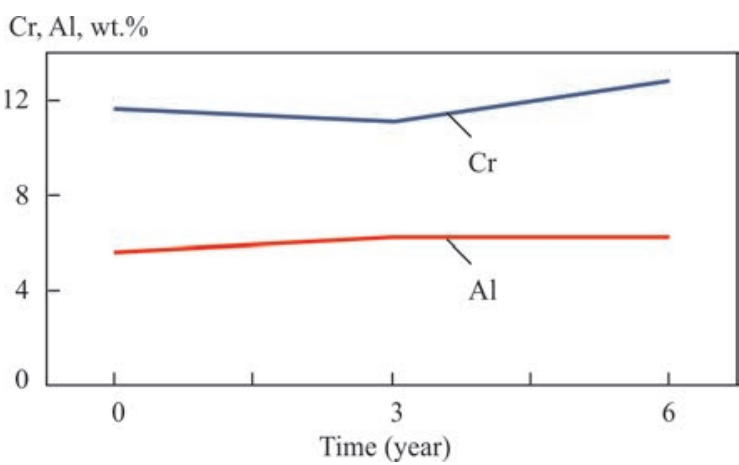

Fig re 11. Change in concentration of chromium and aluminium in coating surface layer depending on service life term

Thus, in this case the dependence of hardness effect on the ash wear rate can be assumed and it is possible to conclude that with increase in hardness the wear resistance is growing. This observation is correlated with an erosion wear model [14].

Welding. At Tripolskaya TPP two variants of welding of steel 20 pipes after metallization were investigated. The first one is the electric arc welding of pipes after metallization with electrodes TsU-5 of $2.5 \mathrm{~mm}$ with pipes, not subjected to metallization. The second one is the welding with electrodes TsU-5 at abutting of pipes, passed the metallization between themselves.

Welding was carried out in accordance with [15]. Before welding the pipe edges were beveled at 40 $45^{\circ}$ with their cleaning at edge regions. Diameter of rod of electrodes TsU-5 was $2.5 \mathrm{~mm}$. As to the appearance, the welds were in a good state. Cracking, pores, cavities, undercuts and other external defects were not observed. The surface layer of pipes with metallization in the region of weld joint was cleaned for inspection by nondestructive methods. Ultrasonic testing did not reveal any inner defects in butt joints. Microstructure of metal in a near-weld zone and in the region of welds is good in both cases. The X-ray fluorescent analysis of welded joints revealed the slightly increased chromium content. The increased content of silicon in welded joint is probably connected with an insufficient quality of surface preparation. During

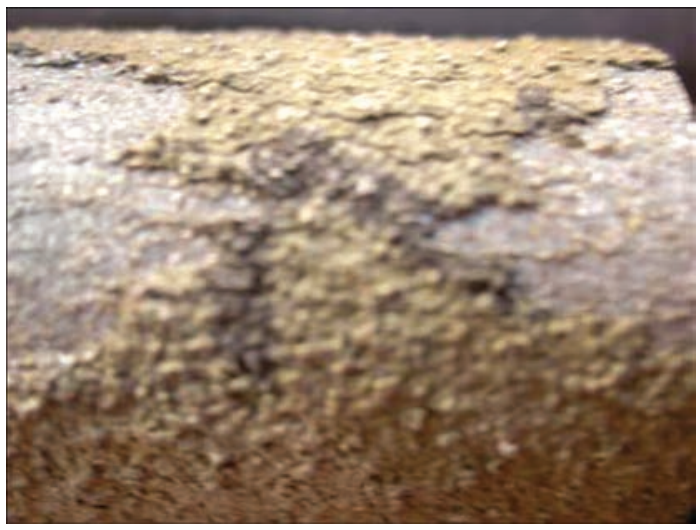

Fig re 12 Appearance of pipe after 6-year service (test for convergence of sides) 
Tb le 7 Characteristic of pipes before spraying

\begin{tabular}{|c|c|c|c|c|c|c|c|c|c|c|}
\hline \multirow[b]{2}{*}{$\begin{array}{l}\text { Number } \\
\text { of unit }\end{array}$} & \multirow[b]{2}{*}{$\begin{array}{c}\text { Surface } \\
\text { from heating } \\
\text { side }\end{array}$} & \multirow{2}{*}{$\begin{array}{c}\text { Surface } \\
\text { from } \\
\text { working } \\
\text { environment } \\
\text { side }\end{array}$} & \multirow[b]{2}{*}{$\begin{array}{l}\text { Material } \\
\text { grade }\end{array}$} & \multirow[b]{2}{*}{$\begin{array}{l}\text { Number of } \\
\text { coiled pipe }\end{array}$} & \multirow[b]{2}{*}{$\begin{array}{c}\text { Number of } \\
\text { pipe }\end{array}$} & \multicolumn{4}{|c|}{ Thinning, mm } & \multirow[b]{2}{*}{$\begin{array}{c}\text { Operating } \\
\text { time }\end{array}$} \\
\hline & & & & & & Left side & Right side & External & Inner & \\
\hline 1 & $\mathrm{~W} / \mathrm{E}$ & ASh & Steel 20 & 152 & 1 & -0.4 & -0.4 & -0.5 & +0.2 & 11296 \\
\hline 1 & $\mathrm{~W} / \mathrm{E}$ & $\mathrm{ASh}$ & Steel 20 & 150 & 1 & -0.5 & -0.5 & -0.8 & +0.1 & 12138 \\
\hline 1 & $\begin{array}{l}\text { W/E (after } \\
\text { spraying) }\end{array}$ & ASh & Steel 20 & 151 & 1 & +0.4 & +0.5 & +0.7 & +0.2 & 9084 \\
\hline
\end{tabular}

mechanical tests of welded joint the fracture of specimen occurs in base metal, thus proving the good mechanical properties of weld. Microstructure of metal in near-weld zone and weld zone in both cases are within the standards.

The total sum of financial expenses, paid by the energy-generating enterprise during damage of heating surfaces (failures), which lead to emergency shutdown of power unit, without accounting for lack in profit, is $1011000 \mathrm{UAH}$. Thus, taking into account the sums of penalties because of failures on the heating surfaces of TPP power units, which can reach several millions of UAH, the implementation of spraying technology has a significant positive effect, because the expenses for implementation of the new technology are 1.5-2.0 times lower as compared with losses, having by TPP during emergency shutdowns. The electric arc spraying will allow extending the service life of the heating surfaces.

\section{Co clusin $s$}

In the work the application of method of spraying (metallization) for increasing the operation reliability of TPP power equipment was investigated.

From the data, obtained about mechanical, chemical and structural state of metal of pipe and coating layer, it is possible to make conclusion about the positive experience of implementation of method of electric arc spraying as a promising and high-efficient method of improving the operation reliability of the power equipment.

In spite of a large volume of works, carried out on spraying, there are still problems, which are not completely studied. Among them, the investigation and application of metallization method in the conditions of high-temperature gas corrosion of heating surface of the lower radiation part (LRP), working out of separate instructions and standard documents.
1. Panteleenko, F.I., Snarsky, A.S., Krylenko, A.V. (2012) Specifics of structure degradation and mechanical properties of components of furnace and heat-and-power engineering equipment after long-term operation. Nauka i Tekhnika, 1, 16-20 [in Russian].

2. Som Dutt Sharma, S.D., Saluja, R., Moeed, K.M. (2013) A review on effect of preheating and/or post weld heat treatment (PWHT) on hardened steel. Int. J. of Technical Research and Applications, 1, 2 (May-June), 5-7.

3. Khromchenko, F.A. (2005) Welding technologies in repair works. Intermet Engineering [in Russian].

4. Yatsenko, V.P. (2006) Prediction of erosion wear of heat exchange surfaces of boiler equipment. Problemy Zagalnoi Energetyky, $\mathbf{3}, 81-85$ [in Ukrainian].

5. Shrajber, A.A., Yatsenko, V.P. (2008) Modeling of abrasive wear of convective heat exchange surfaces of boiler. Ibid., $\mathbf{1}$, 37-40 [in Ukrainian].

6. Korzh, V.M. (2005) Thermal processing of materials. Kyiv, Ekotekhnologiya [in Ukrainian].

7. Lashchenko, G.I. (2012) Modern technologies of welding production. Kyiv, Ekotekhnologiya [in Ukrainian].

8. Shatov, A.P. (2009) Welding and repair of metal structures with corrosion-resistant coatings. Moscow, Bauman MGTU [in Russian].

9. (1987) I 34-70-027-87: Instruction on reconstruction of worn pipe bends and protection of new bends and straight sections of pipes of heating surfaces of high-pressure boilers by method of gas powder surfacing. Moscow, Soyuztekhenergo [in Russian].

10. Grechneva, M.V., Goppe, G.G. (2015) Gas powder spraying of pipes of heating surfaces of boiler units of thermal power stations. Vestnik IrGTU, 106(11), 23-27 [in Russian].

11. (2017) Advanced scientific and technical developments. Power engineering and power efficiency. Kyiv, Akademperiodika [in Ukrainian].

12. (2009) TU 14-3-460:2009/TU U 27.2-05757883-207:2009: Steel seamless pipes for boilers and pipelines. Technical specification [in Russian].

13. (2004) TI 00130044.25101.00549: Deposition of protective coating on water economizer coils and waterwall tubes of boiler TP-100. Lviv, DP LKB [in Ukrainian].

14. Ruff, A.W., Wiederhorn, S.M. (1979) Erosion by solid particle impact. New York, Academic Press, 69-126.

15. RD.15.027-89: Welding, heat treatment and control of pipe systems of boilers and pipelines in erection and repair of equipment of power stations [in Russian].

Received 27.02.2019 


\title{
PECULIARITIES OF TECHNOLOGY AND MODERN TRENDS IN THE FIELD OF BUTT W LDING OF POLYETHYLENE PIPES (Rei ew)
}

\author{
M.V . YURZHENKO \\ E.O. Paton Electric Welding Institute of the NAS of Ukraine \\ 11 Kazimir Malevich Str., 03150, Kyiv, Ukraine. E-mail: office@paton.kiev.ua
}

\begin{abstract}
Pipelines for the transportation of natural gas, cold water supply and drainage are one of the most significant elements of urban and rural infrastructure. Pipelines from polymer materials, in particular polyethylene, are a modern alternative to steel pipelines, which during 15-20 years of operation are destroyed under the influence of chemical and electrochemical corrosion. In the world and in Ukraine, almost all new distribution pipelines for gas, cold water supply and drainage are constructed from polyethylene pipes. In Ukraine, especially in large cities, a practice of replacing old worn-out steel pipelines by new polyethylene ones and renovation using the method of inserting a polyethylene pipe into steel pipeline has become widespread. One of the most technological methods of joining of polyethylene pipes of almost the whole range of outer diameters is butt welding with a hot tool. The equipment for this welding method is currently not manufactured in Ukraine. The imported installations for butt welding of polyethylene pipes are operating according to the conventional technological scheme developed a long time ago, some elements of which, due to the improvement of the polymer materials themselves, can be revised and simplified preserving a high quality of final welded joints. The aim of the work is to review the state of the art in the field of butt welding of plastic products, first of all, polyethylene pipes with a hot tool and its modifications, which are the most interesting from the technological point of view. 28 Ref., 5 Figures.
\end{abstract}

Keywords : butt welding with a hot tool, plastics, polyethylene pipes

Joining of polyethylene pipes is virtually the final and, on the other hand, the most responsible stage in the whole complex technological chain of construction of a technological pipeline. The world and domestic experience proves that in most cases such joining is performed by welding, in particular using butt welding with a hot tool. Welds play a decisive role in providing the reliability of the entire polyethylene pipeline. Therefore, in the whole world, a great attention is paid to investigations of technological features of such welds [1-3].

According to the standard documentation, valid in Ukraine, the polyethylene pipes for supplying cold water can be joined by butt welding with a hot tool, taper welding, electrofusion welding, and also mechanically with the help of special clamping parts [4]. Polyethylene pipes for gas pipelines can be joined only by two methods: butt welding with a hot tool and electrofusion welding [5]. As far as mechanical joints of pressure polyethylene pipes are used quite rarely in practice, the main method for joining such pipes during construction of technological pipelines is welding. All three of the above-mentioned methods of welding of polyethylene pipes have long been known. The technology and equipment for them are quite well developed [6-8]. However, taper welding and electrofusion welding need the use of special joining parts:

(C) M.V. YURZHENKO, 2019 couplings, which increase the cost of construction of pipelines, increase the external dimensions of a butt joint. In addition, these welding methods require a fairly accurate compliance with the geometric shape and dimensions of a pipe and a joining part due to a high risk of formation of lack of penetrations or pores during upsetting of the weld material [9].

Butt welding with a hot tool is currently the most versatile method for joining polyethylene pipes and can be used for the most types and sizes of pipes, except of thin-walled with a wall thickness of less than $5 \mathrm{~mm}$. In recent years, this technology is constantly being developed and improved. It is used for welding pipes of large and superlarge diameter and pipes of new grades of polyethylene composition [10]. The equipment for this welding method demonstrates the tendency to differentiating the design depending on the purpose. For welding in the field conditions, the powerful and robust machines with four clamps are used. In the shop conditions, as a rule, short sections of pipes are welded with the help of stationary machines with rotary clamps. For repair and site works the lightweight welding devices are used [11].

Over the past 30 years, the pipe grades of polyethylene were rapidly developed and passed the evolution from PE 32 to PE 100. In practice, a constant need arises to weld pipes, made of «old» and «new» types of polyethylene. Very often, builders mistakenly 
consider polyethylene of different grades as similar and equivalent, although they differ significantly by their molecular structure and physical properties [12]. It was experimentally proved that a long-term quality of welded joints of polyethylene pipes, operating under loads, depends on the micro- and macromolecular structure of the material, the peculiarities of which formation should be studied separately for each pair of polymers to be welded. The quality of welded joint of polyethylene pipes is determined, mainly, by thermophysical and rheological processes in the zone of a weld. The butt welding with a hot tool is characterized by a strong flow of a molten material, which in the process of upsetting is squeezed out from the middle of a joint outside as a flash. The kinetic regularities of this process depend on basic parameters of the welding process and, on the other hand, essentially depend on the properties of the polyethylene composition.

The simplest way for supplying the heat energy required for welding of thermoplastic polymers is by the direct contact of the surface of a part being welded with a hot tool. Most often, in such a way the uniaxially-directed parts are butt joined, but this method is also used for other types of a joining. Using the method of heat transfer, this type of welding is often called thermal. In the cases, when a direct contact with the surface of the joint is impossible, the external surface of the parts is heated: this is the so-called welding by indirect heating [13].

The method of butt welding with a hot tool (direct heating) is widely used in practice due to the simplicity of technological process of welding, equipment and rigging. Mainly, this method of welding is used in the construction of polymer pipelines (most of all polyethylene ones) for transportation of combustible gas and water. The other fields of application of thermal butt welding is joining of plastic profiles in the manufacture of window frames, welding of rods, plates and other parts of different structures of plastics. In the recent years, this method of welding with the use of special equipment is used for welding of engineering plastic products in automotive and other industries [14]. The butt welding with a hot tool is used also for welding of composite polymer materials [15].

Traditionally, the butt welding process with a hot tool is performed at a preset value of pressure during upsetting. A typical diagram of the change in working pressure during welding is shown in Figure 1, $a$.

During welding of plastics, having a wide temperature range in a molten condition with a low level of toughness, the traditional butt welding technology with a controlled working pressure is justified (Figure $1, a)$, as far as when the preset pressure is achieved

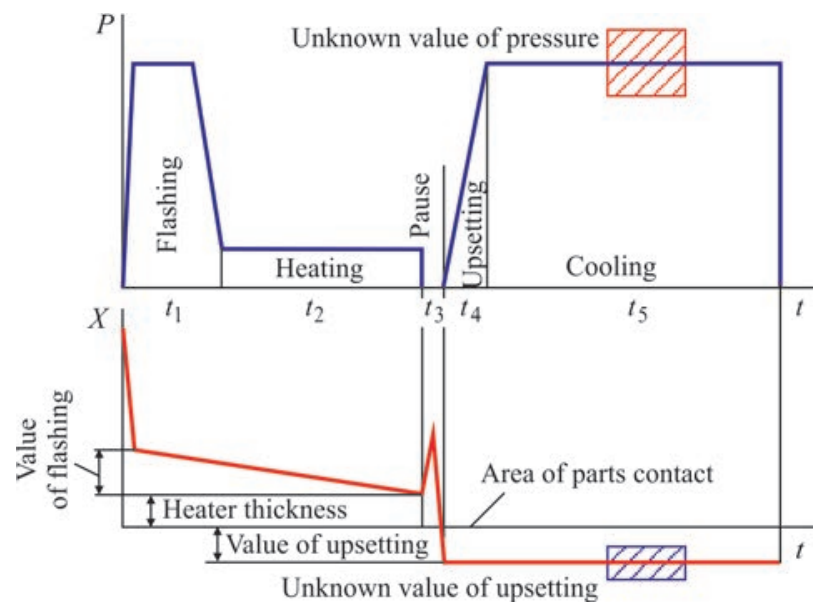

Fig re 1 Time diagrams of pressure $(P)$ and displacement of the ends of parts $(X)$ at different technologies of the butt welding process of plastics (including polyethylene pipes) with a hot tool: $a$ - welding with controlled pressure; $b$ - welding with controlled upsetting

in the course of upsetting, the molten material can be surely squeezed out into the flash.

During welding of plastics, whose toughness essentially changes depending on the temperature, the technology of welding with a hot tool at a fixed value of upsetting (Figure 1,b) is used, as during cooling of surfaces being welded the toughness of the melt can grow to lower than the optimal level as much, that the established level of working pressure will not be able to provide a squeezing out of the melt during upsetting and a normal weld formation. In this case, special devices (usually rests) are applied to control both the value of flashing of the surface of the parts during heating, as well as the value of upsetting, i.e., the zone of flashing during squeezing out of a heated melt into the flash. The same rests determine the final size of the weld after welding. Applying this technology, depending on the specific conditions of welding, the value of working pressure may change, as the melt with a lower toughness will be squeezed out by a lower pressure and vice versa. Similarly, applying the traditional technology, an uncertainty in the value of upsetting exists, which will also depend on the toughness of the polymer melt.

The purity of surfaces of parts to be welded is one of the main factors which provide the quality of joining during butt welding with a hot tool. Contamination deteriorates the integrity of a weld, and the foreign inclusions can act as stress concentrators, which becomes a prerequisite for initiation of cracks under loading. Since most of welded joints of polymer pipes are carried out in the field conditions, the risk of contamination of such welds is particularly significant. The following types of contaminations of the surface of pipes are distinguished: strong contamination with soil, resin and other dirt, negligible contamination 
with dust, fat and oil traces, moisture on the surface, surface oxidation by atmospheric oxygen, surface erosion under the effect of solar ultraviolet radiation. The automation of welding process with a hot tool should provide the maximum possible cleaning of surfaces of the parts before welding [16].

A direct nature of heating surfaces and their direct contact during upsetting specifies increased requirements to the geometry of pipe ends being welded. Therefore, in accordance with the requirements of the standards, before welding the fixed and aligned ends of pipes and parts are subjected to mechanical treatment: facing in order to align the surfaces to be welded directly in the welding installation. The maximum allowable value of gaps between the ends to be welded is specially determined depending on the thickness of a pipe wall [5]. The device for facing is usually a complex electromechanical device with specially sharpened blades, which align the surfaces of pipe ends. The process of mechanical facing of pipes substantially complicates the preparation for welding, especially with the increase in the outer diameter of the pipes to be welded. The presence of a complex mechanical facing device, which must be constantly maintained and adjusted, greatly increases the cost of butt welding equipment.

After a proper preparation of pipe ends, welding of the joints begins directly. The use of an external tool for heating the surfaces being joined involves the interruptions in the process of butt welding of pipes. Typically, these are the main stages of the process, which are also divided into stages [17] (Figure 1):

- heating of surfaces of the pipe ends, including the stages of flashing $t_{1}$ and heating $t_{2}$;

- technological pause $t_{3}$, which is necessary for the removal of the hot tool;

- upsetting of welded parts $t_{4}$ with a gradual increase in working pressure and cooling of the weld under the pressure $t_{5}$ until its final formation.

At the stage of flashing, the pipe ends enter into direct contact with the surface of the hot tool. The heater temperature is preliminary set higher than the melting point of the polymer material, from which the products are made, therefore, the process of ends flashing begins immediately. The heating of the pipe ends is carried out exclusively due to the heat transfer from the surface of the hot tool and a gradual thermal conductivity of the polymer material deep inside the product. The process of ends flashing is necessary to provide their effective uniform heating at a tight contact of pipe surfaces and the hot tool. At this stage, due to melting of the polymer material, all the microroughness of the end surfaces disappears, as well as even the minimal gap between their planes, which could remain after mechanical facing. To accelerate the flashing process, the pipe ends are pressed against the hot tool at a maximum working pressure of $0.2 \pm 0.02 \mathrm{MPa}$ (Figure 1, $a$ ), which causes the active squeezing out of the polymer outwards. The criterion for the completion of a uniform flashing is the formation of small uniform beads of a primary flash along the perimeters of both pipe ends welded [7].

It is believed that in the process of flashing the pipe ends, the heating of the polymer mass into depth almost does not occur, since all the heat, transferred by the heater, is spent for melting the roughness of the pipe surfaces. Upon completion of the flashing stage $t_{1}$, the working pressure on the pipes decreases to a minimum value of $0.01-0.02 \mathrm{MPa}$ and the heating stage $t_{2}$ begins, the duration of which is separately determined for each standard size of a pipe and pipe material. At the stage of preheating, the melting of material is almost stopped, and its heating to the depth occurs due to its thermal conductivity.

The preheating of the mass of the pipe wall occurs nonuniformly, the lowest temperature is reached in the center, and the outer and inner surfaces of the pipe become the most heated. This is caused by the fact that not only the energy of the linear heat flux from the heater reaches the pipe surface, but also the additional heat energy from the melt squeezed into the flash and from the radiation of the heater surface. At the end of the heating stage, on the surface of each of the pipe ends, small uniform layers of viscous-flow material should be formed, which will form a welded joint at the subsequent stages [18].

The temperature of the heating tool and the preheating time are the main parameters during butt welding with a hot tool. The working area should be protected from cooling by a wind and low temperatures, and during welding under the conditions of a high temperature it is protected from the overheating and the effect of direct sunlight. The surface of the heating tool should not have scratches or other defects on the anti-adhesive coating, its temperature should be checked at different parts of the working surface. The operating temperature of the heating tool is recommended to be reduced by $5-10 \%$ with an increase in thickness of pipes being welded [19].

In some cases, for the purpose of reducing the volume of molten material during heating, the so-called high-temperature heating tool is used, having a temperature of $100-150^{\circ} \mathrm{C}$ above the melting point of the polymer [20]. In this case, to prevent the destruction of polymer, the duration of preheating is significantly reduced.

The intermediate stage of the process of butt welding with a hot tool is a technological pause $t_{3}$. During the pause, the pipe ends are disconnected from the 
heating tool, the latter is removed from the welding zone and the pipes are brought closer up to the contact of the end surfaces. During a pause, a heated material is cooled, it contacts with the atmosphere and can be oxidized and the flashed surfaces may contaminate with dust and moisture. Therefore, the duration of the pause is tried to be reduced as much as possible. The maximum allowable duration of the pause is set by the normative documents within 3-6 s, depending on the standard size of a pipe [5]. After the direct contact of the surfaces of the pipe ends the final stage of the process of butt welding begins: upsetting.

In the process of upsetting due to the working pressure, the physical contact of the flashed surfaces increases, which creates preconditions for the emergence of intermolecular interaction between the materials of the parts and the formation of a welded joint. Under the pressure, the squeezing out of the molten material from the welding zone and the formation of a secondary (welding) flash occur. With the flow of the melt from the weld, the pores, contaminations and other defects are removed, which could be occurred at the earlier stages of the process. The duration of the upsetting stage $t_{4}$, which determines the rate of growing the working pressure, is determined by the normative documents and grows with the increase in the thickness of the pipe wall. The excessive rate of upsetting can cause excessive stresses in the welding zone and promote the formation of defects in the welds [9] (Figure 2).

The quality of welding is largely determined by rheological processes occurring during upsetting in the zone of welded joint. It is believed that the lower the polymer's toughness, the easier it is welded. The speed of parts movement during upsetting is inversely proportional to the average toughness of the melt [21]. It is admissible to weld a pipe of different types of polyethylene, if the values of fluidity of the melts are differed little [22].

After upsetting, the last stage of a welded joint formation begins at a slow cooling of the weld while maintaining a working pressure, which lasts several minutes. The presence of pressure promotes relaxation of stresses and prevents the formation of cracks and other defects during shrinkage of material. In polymer materials, the cooling of heated regions occurs slower than in the metals, as the thermal conductivity of these materials is much lower. The heat-affected zone for the welds, which are butt welded with a hot tool, is located near the welded joint. Therefore, it is possible to control the temperature in the zone of welding by additional heating or cooling of the heat-affected zones with the use of additional tool [23]. Upon completion of the cooling stage $t_{5}$ duration, the welded joint is

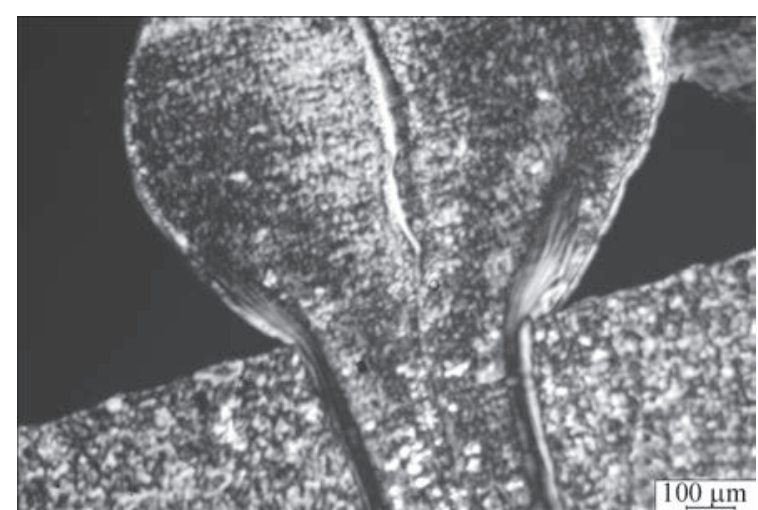

Fig re 2 Defect in the form of a through crack in the welded flash and weld

considered to be completely formed and removed from the welding equipment.

It is noted that in order to provide a high quality of welds of polymer pipelines, it is necessary to strictly observe all the recommended parameters of welding process. However, even under these conditions, a coincidence is possible, which leads to defects formation in welded joints. Lack of fusion in a welded butt joint occurs when a part of the material is destroyed because of the abnormally high temperature of the heater, at overcooling of the material during the technological pause, and also because of contamination. The separate small cavities and pores inside the welds can be formed as a result of shrinkage processes, caused by nonuniform preheating of the polymer material mass (Figure 3). The impossibility of shrinkage of near-surface layers of welded joints leads to cracks formation both in the fusion area as well as in the areas under the flash along the boundary between the melt and base material [9].

One of the technological conditions for producing quality butt welds is the arrangement of a convenient workplace for welders. In practice, this principle is often violated, especially when performing different types of repair works. The typical errors are the too

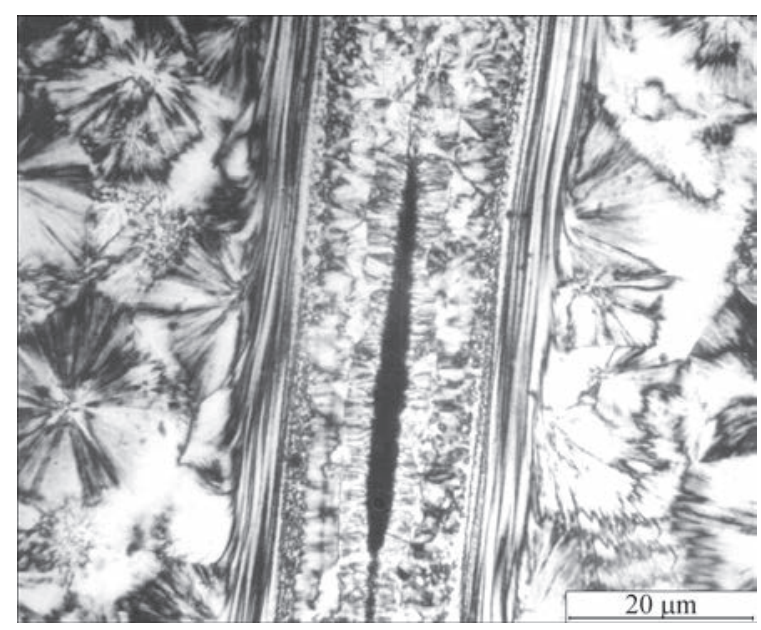

Fig re 3 Defect in the form of a cavity in the weld 


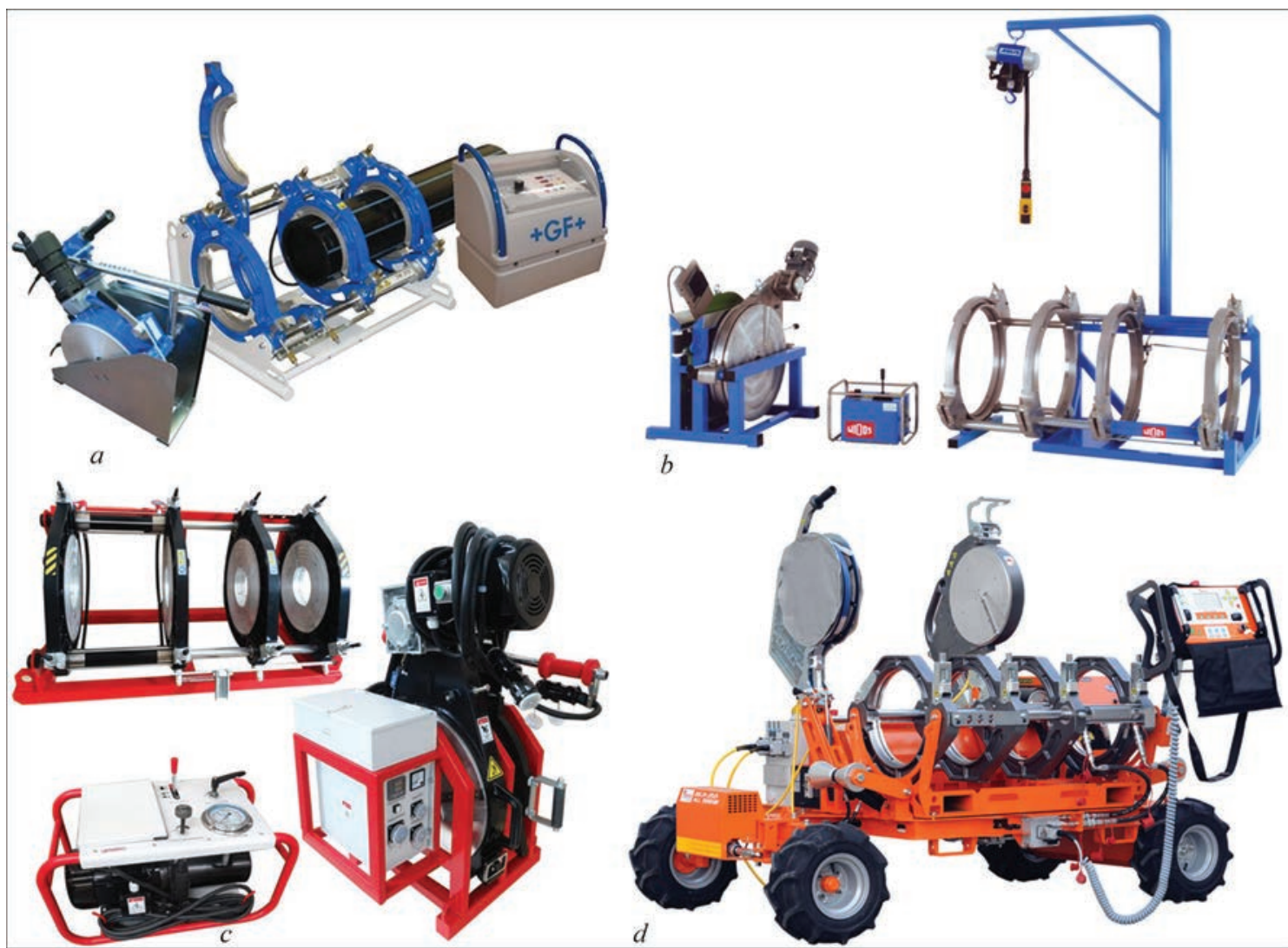

Fig re 4 Installations for butt welding of polymer pipes using a hot tool of different European manufacturers: $a$ - Georg Fischer; $b$ - Widos; $c$ - Rothenberger; $d$ - Ritmo

small sizes of foundation pits and trenches, which do not allow a proper arrangement of assembly equipment and setting of parts to be joined. Lack of a reliable support for the aligning device, exceeding the standard time of a technological pause, can cause lack of penetrations and other defects in welds [24]. Thus, compactness, reliability and easy access are among the main requirements to the equipment intended for welding of polymer pipelines.

At present, the construction companies of Ukraine use equipment for welding polymer pipes of such leading European and Asian manufacturers, as Georg Fischer (Switzerland), Widos, Rothenberger (Germany), Ritmo (Italy), Kamitech, NowaTech (Poland), Turan Makina (Turkey), Times Asia Group Ltd. (China), etc. (Figure 4). The similar equipment is produced in the CIS countries: Russia, Belarus, Kazakhstan [25]. It should be noted that the equipment for butt welding of polymer pipes with a hot tool of all manufacturers is intended for implementation of a traditional technological welding scheme and manufactured on the same layout scheme with a hydraulic upsetting drive. For welding pipes of small diameter, small installations with a manual mechanical drive are used. The installations of different manufacturers are differed between each other only by design features and the quality of manufacture of separate assemblies and units.
An important tendency in the development of modern technology for welding of polymer pipes is the differentiation of equipment by purpose. Depending on the types of welding works, the equipment for butt welding with a hot tool can have different design solutions and different auxiliary rigging. The aligning devices of the welding installations can have different amount and capacity of the clamps, can be equipped with hydraulic, pneumatic or mechanical drives for pipes displacement. For welding in the field conditions, rigid aligning devices with four clamps are used, and the workshop machines are usually have a lightweight design and can be equipped with rotary clamps. The mutual replacement of welding installations of different purposes is generally not permitted [11]. In some cases the efficiency in the use of equipment with a pneumatic drive for butt welding of polyethylene pipes is noted, which is less expensive and its range of admissible climatic conditions is higher [26] (Figure 5).

The world tendencies in the development of technology and equipment for welding with a hot tool is its application for welding of new polymer materials, expanding of the range of operating temperatures of heaters, etc. The heating tools of «normal» temperature (up to $270{ }^{\circ} \mathrm{C}$ ), elevated temperature (350$450{ }^{\circ} \mathrm{C}$ ), and tools of super-high temperature of 500 
$550{ }^{\circ} \mathrm{C}$ with the possibility of simultaneous heating by infra-red radiation are used [10].

The modification of the method of butt welding with a hot tool, which is called welding by displacement, is increasingly being used for welding of plane parts from polymers of different types [27, 28]. The depth of flashing at the first stage of the heating process is determined by special mechanical supports on the heating tool. Similarly, at the stage of upsetting, mechanical supports limit the relative displacement of the part ends by a preset value. Thus, the dimensions of a welded joint, formed after the weld formation, can be controlled at a great accuracy.

Despite a long historical period of using the method of welding with a hot tool and the simplicity of technology, it is considered relevant to improve and expand the application fields of this method. The traditional disadvantages of the method of butt welding with a hot tool are considered to be limited abilities to control the process and obtaining the data on its progress in real time, too long duration time of the process stages. At the moment, that welding equipment is considered to be challenging, which allows operators to perform a precise control of the movement of individual parts, the temperature of heated surfaces, and the force applied to the parts. [20].The hot tool can have different shapes, depending on the welded joint configuration. The devices for clamping of parts become interreplaceable and provide a precise alignment and maintenance of them during welding. They can function both in horizontal as well as in vertical planes. The improving of operation speed of equipment for welding with a hot tool is promoted by use of servodrives to control the displacement of parts. In order to control the basic parameters in the process of welding, such as force, speed, distance, temperature, the application of modern computer hardware and software is required.

A nonuniform distribution of temperature over the surface of a heating tool can negatively affect the final quality of a welded joint. The traditional designs of heaters usually provide the ability to control the temperature in one or two points of the working area. Some modern heating tools have up to 9 points of separate temperature programming on the surface.

The speed of displacement of parts during welding is another important parameter of the process, which affects the quality of a weld. Usually, only the rate of increase in the value of working pressure is regulated, while for the process of welded joint formation the absolute value of the displacement speed, the programmable acceleration or deceleration of movement at certain moments of time are important. The traditional welding installations have hydraulic or

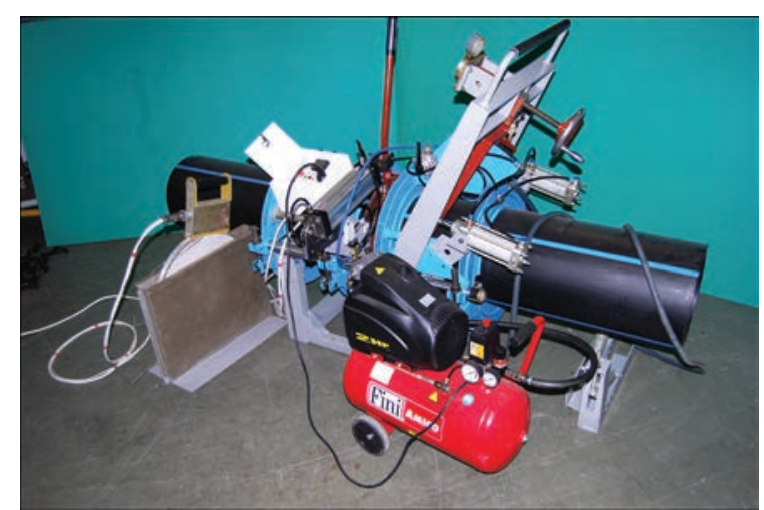

Fig re 5 Installation with pneumatic drives for butt welding of polymer pipes of manufacture of the E.O. Paton Electric Welding Institute of the NAS of Ukraine

pneumatic drives, which practically do not allow controlling the movement speed. The programming and control of parameters of parts movement during welding are possible with the use of modern servodrives.

Thus, a butt welding of plastic products, firstly polymer pipes, with a hot tool, was and remains one of the most widespread and popular welding methods. However, the improvement of the polymer materials themselves and the emergence of new fundamental knowledge create preconditions for simplification of welding technology, the problems of which are relevant in the modern polymer world.

1. Qi, F., Huo, L., Zhang, Y., Jing, H. (2004) Study on fracture properties of high-density polyethylene (HDPE) pipe. Key Engineering Materials, , 153-158.

2. Leskovics, K., Kollar, M., Barczy, P. (2006) A study of structure and mechanical properties of welded joints in polyethylene pipes. Mater. Sci. and Engin., , , 138-143.

3. Adnan, A. (2013) An analysis of electro-melting and hot element welding methods' safety used to join PE natural gas pipes. Int. J. of Electronics, Mechanical and Mechatronics, 3(2), 493-504.

4. DSTU-N B V.2.5-40:2009: Design and mounting of watersupply and severage systems from plastic pipes [in Russian].

5. DBN V.2.5-41:2009: Gas pipelines from polyethylene pipes. Design, construction [in Russian].

6. Shestopal, A.N., Vasiliev, Yu.S., Tarasenko, O.V., Tarnogrodsky, V.P. (1990) Reference book on welding and bonding of plastics. Ed. by Shestopal, A.N., G.N. Korab. Kiev, Tekhnika [in Russian].

7. Volkov, S.S. (2001) Welding and bonding of polymer materials. Moscow, Khimiya [in Russian].

8. Kataev, R.F. (2008) Welding of plastics: Manual. Ekaterinburg, UPI [in Russian].

9. Korab, N.G., Mineev, E.A. (2007) Critical remarks on welding methods of pipes from thermoplastic polymer materials. Polimernye Truby - Ukraina, 1, 53-55 [in Russian].

10. Grewell, D., Benatar, A.S. (2007) Welding of plastics: Fundamentals and new developments. International Polymer Processing XXII, Munich.

11. Kimelblat, V.I. (2014) Welding of PE pipes - tendencies of developments. Plastics, 135(6), 38-43 [in Russian].

12. Kargin, V.Yu., Stavskaya, T.V. (1999) To problem of polyethylene pipes PE 63, PE 80 and PE 100. Polimergaz, 2, 40-42 [in Russian]. 
13. Kataev, R.F. (2008) Welding of plastics: Manual. Ekaterinburg, UPI [in Russian].

14. Komarov G.V., Goncharenko, V.A. (2011) New technologies and equipment for welding of polymer materials. Pt 1. Polimernye Materialy, $\mathbf{2}, 18-22$ [in Russian].

15. Shadrin, A.A., Krivatkin, A.M. (1993) Butt welding of joints of composite material PA6-LT-20. Avtomatich. Svarka, 1, 42-44 [in Russian].

16. O'Konnor Kris (2012) Polyethylene pipelines: How to avoid defects of welding. Gaz Rossii, 3, 48-58 [in Russian].

17. Shestopal, A.N., Korab, G.N., Vasiliev, Yu.S. (1990) Reference book on welding and bonding of plastics. Kiev, Tekhnika [in Russian].

18. Goncharenko, V.A. (1995) Melting of thermoplast plate pressed to heated body. New materials and technologies. In: Abstr. of Papers of Russ. NTK. Direction: Composite, Ceramic, Powder Materials and Coatings (21-22 November 1995, Moscow). MGATU, 32 [in Russian].

19. Akkurt Adnan (2013) An analysis of electro-melting and hot element welding methods' safety used to join PE natural gas pipes. Int. J. of Electronics, Mechanical and Mechatronics, 3(2), 493-504.

20. Korab, G.N., Vakulenko, S.A., Savitsky, A.A. (1986) Criteria of selection of parameters in high-temperature welding of polyethylene pipes by hot tool. Avtomatich. Svarka, 6, 29-32 [in Russian].

21. Volkov, I.V., Kimelblat, V.I. (2011) Role of rheological properties in selection of main welding parameters. Vestnik $\mathrm{Ka}$ - zanskogo Tekhnologicheskogo Un-ta, 4 , 119-123 [in Russian].

22. Kimelblat, V.I., Volkov, I.V., Glukhov, V.V. (2010) Optimization of technology of resistance butt welding. Taking into account the polymer properties. Polimernye Truby, 28(2), 32-36 [in Russian].

23. Starostin, N.P., Gerasimov, A.I. (2009) Welding of polymer pipes for gas pipelines at low temperatures. Neftegazovoe Delo, 25-27 [in Russian].

24. Prokopiev, N., Kimelblat, V.I. (2015) Practical problems of welding of polyethylene pipes. Polimernye Truby, 48(2), 6063 [in Russian].

25. Zuev, M.A., Sheshnev, D.A. (2014) Equipment for welding of polyethylene pipes: Experience of repair and maintenance. Gaz Rossii, 2, 74-75 [in Russian].

26. Nesterenko, M.P., Galchun, A.M., Kondratenko, V.Yu., Skok, O.G. (2013) On efficiency of application of equipment with pneumatic actuator for butt welding of up to $400 \mathrm{~mm}$ diameter pipes from crystal amorphous polymers. In: Proc. of Int. Conf. on Welding and Related Technologies - Present and Future (Ukraine, Kyiv, 25-26 November 2013), 47-48.

27. Stokes, V.K. (1997) The hot-tool and vibration welding of acrylonitride-butadiene-styrene. Polymer Engineering and Science, 37(4), 372-377.

28. Stokes, V. (2001) A phenomenological study of the hot-tool welding of thermoplastics. Pt 3: Polyetherimide. Polymer, , $775-792$

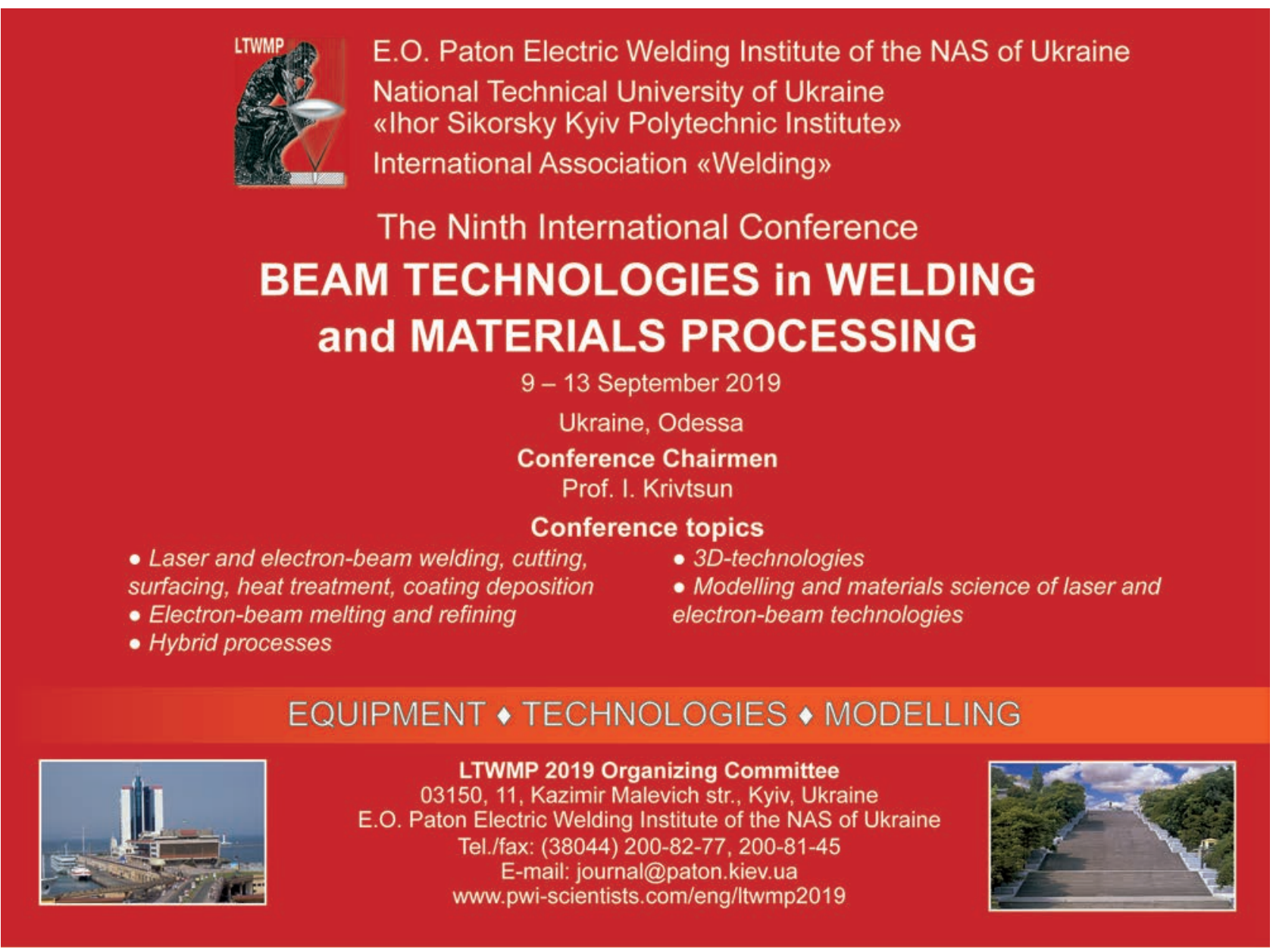




\section{K YIV TECHNICAL FAIR -}

The XIth International Specialized Exhibition «Kyiv Technical Fair - 2019» took place on April 2-5 in Kyiv at the International Exhibition Center. The International Exhibition Center is an organizer of the Exhibition. The main aim of the Exhibition is demonstration of the best achievements of science, technology and equipment, necessary for the innovative development of Ukrainian economy as well as assistance in establishing business, economic and trade relationships between domestic enterprises and countries of near and far abroad. Specialized Exhibition permits the enterprises to become acquainted with the world novelties in their field and demonstrate own developments, check compatibility of their products. Kyiv Technical Fair is a logical continuation of the International Industrial Forum, the largest trade show of Ukraine, which has been hold in the last week of the November by the International Exhibition Center for more than 17 years.

Topics of the Exhibition included demonstration of the achievements in the field of machine building, metallurgy, welding, cutting, 3D technologies, metal-working, diagnostics and control automation, surface treatment, manufacture of instruments, engines, casting equipment, pumping equipment, nonmetallic materials in industry, which were presented by companies from 12 countries.

The visitors had a possibility to get acquainted with a wide spectrum of the products of different enterprises under conditions of healthy and fair competition; possibility to be consulted directly by manufacturer and ask all the questions of interest.

Each day was bright and full of events. In addition to novel technological developments the visitors also would remember education seminars and conferences, which took place in the open conference floors and halls. The specialists of leading companies of the branch shared their experience with colleagues, told about the peculiarities and perspectives of development of Ukraine on the world market.

The Exhibition gave a possibility to manufacturing companies and customers to meet under competitive conditions and make decisions based on particular criteria, see the equipment personally, test its operating capacity, directly communicate with corporate CEOs.
Visitors and participants had large interest to the seminar on 3D printing hold on April 4 in open air discussion area. The next reports were presented:

- «3D printing with metallic alloys. Technology of layer-by-layer laser melting as a main tool of modern machine-building», Additive Laser Technologies of Ukraine LLC, Dnepr. The Company proposes technologies and equipment for manufacture of products from metallic alloys using 3D printing method; complex innovative solutions for laser additive manufacturing; production of 3D printers based on technology of direct laser sintering (DMLS); development and manufacture of commercial prototypes and parts of
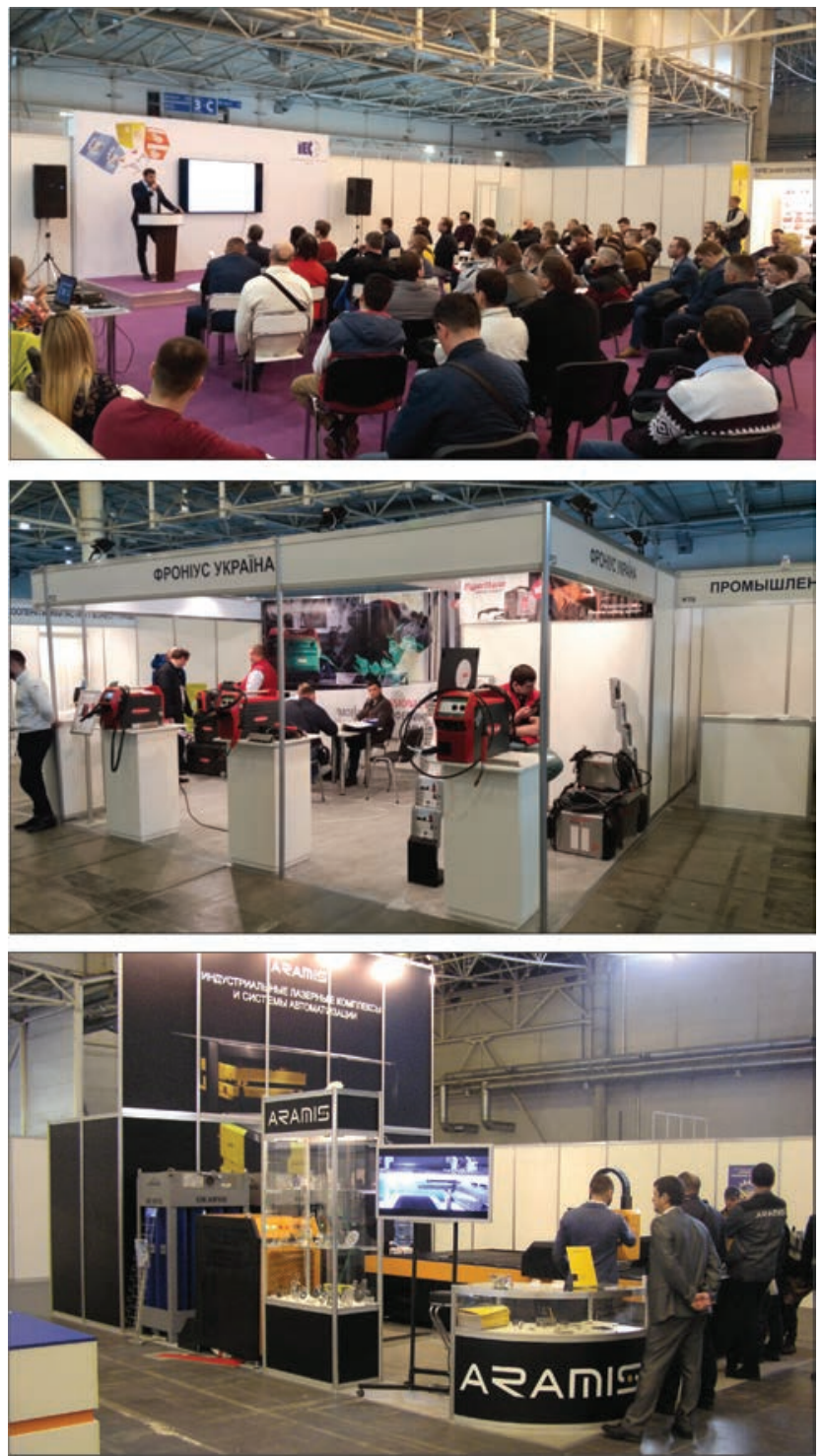

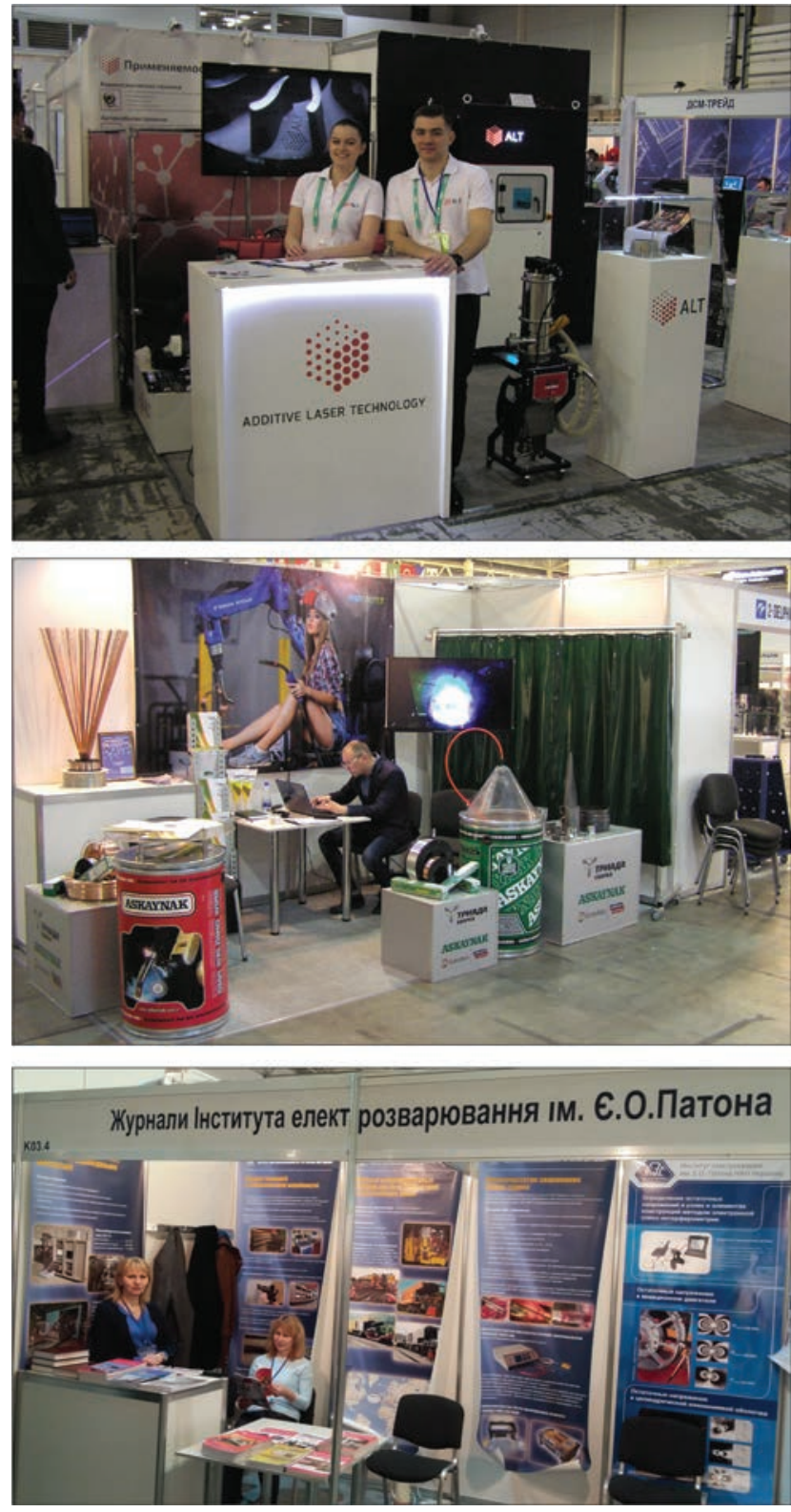

gas turbine engines including manufacture of metallic products of complex geometry.

- «Application of $3 D$ printing in medicine», Viva Art LLC, Kyiv. The Company specializes in sales of professional printers for $3 \mathrm{D}$ printing and all necessary materials for establishment of own production of 3D models; offers services on 3D printing: printing from plastic, color printing with white mineral and cobalt-chromium. Scanning of small objects as well as human sized scanning.

- «Commercial technologies of $3 D$ printing polymers, metals and ceramics». Smart Print Company, Kyiv is a leading company in Ukraine on 3D printing technology and accredited supplier of SC «Ukroboronprom». The company fulfils individual and serial orders on $3 \mathrm{D}$ printing.

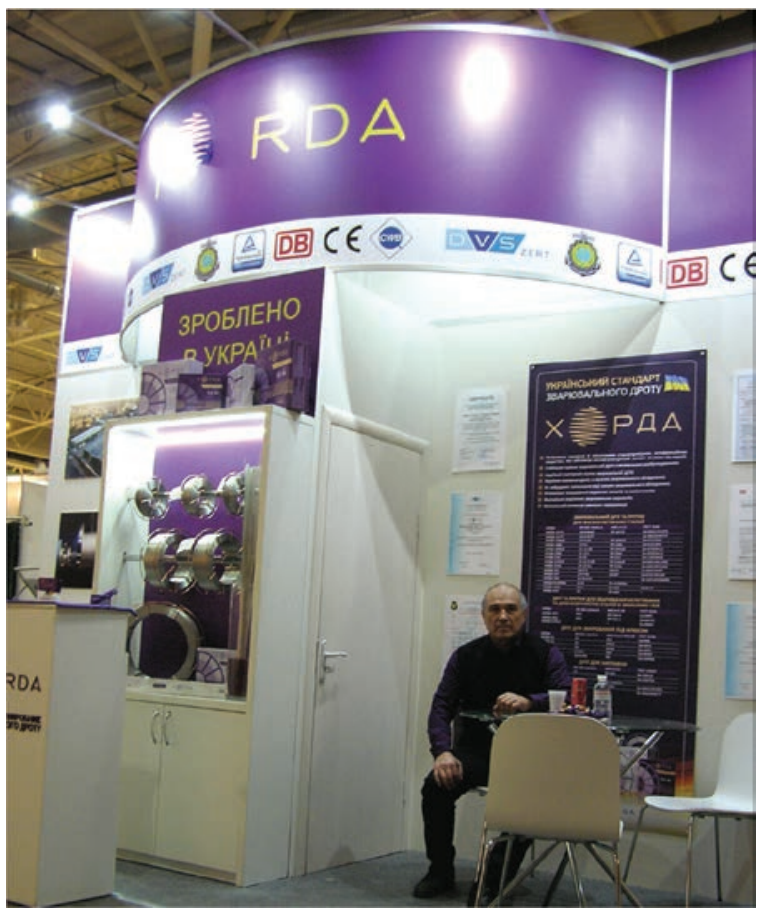

- «Simufact Additiv - 3D modelling of processes of metal printing», Engineering Company «Technopolis», Kyiv. It is a system integrator and authorized partner of the leading developers of engineering software.

- « $3 D$ printing for commercial enterprises», Imatek-Esko LLC, Kyiv. The Company is an exclusive representative of 3D Systems Inc. Company (USA) in Ukraine. Since 2005 it has been implementing the solutions based on 3D printers, 3D scanners and $3 \mathrm{D}$ printing services. It works with enterprises and companies in the field of motor car construction, architecture, medicine; sales of large-format printers and scanners of ROWE (Germany) and Context (Denmark) companies and program solutions for automation of document flow at enterprises.

By tradition Aramis LLC, Vitapolis LLC, Triada Svarka LLC, Fronius Ukraine LLC took part in the Exhibition. They propose equipment for welding and cutting, consumables and services for integration of commercial robotic welding complexes.

E.O. Paton Electric Welding Institute publishing house on its booth presented the journals, books, thematic collections and proceedings of the conferences published in 2018-2019. As always visitors of the Exhibition demonstrated high interest to «The Paton Welding J.», a leading Ukrainian journal in the field of welding, cutting, surfacing, spraying and 3D technologies. 


\section{Calendar of May}

MAY 1, 1893 Opening of Chicago World E冈 ibition where N.G. Slaj anov receie d the Gold Medal for the method of electric welding under a layer of crushed glass. In addition, iv sitors saw an amazing item - 12-sided glass $21 \mathrm{~mm}$ high from steel casting. The electric arc was used for elimination of casting flaws in it, which the metallurgists believed to be natural. In 1895 Slavjanov's method was used for casting ingots from crucible and hearth steel of 100-800 poods (1600-12800 kg) weight at the factory. In Perm Slaj anov began applying his own newest method for correction of casting flaws, repair operations with parts of locomotives, steam engines, gears and artillery guns

MAY 2, 1969 Ocean liner «Queen Elizabeth 2» went on its first voyage Southampton — New York. For 35 years it was

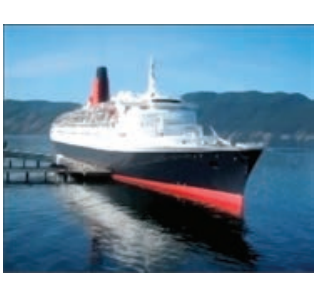
the flagship of the British Shipping Company «Cunard». The all-welded structure of the ship hull was divided into 13 waterproof transverse bulkheads. The outdoor deck, which is wood sheathed, was fastened on welded-on studs. As regards aluminium decks, because of application of thin material, the «springing» effect appeared when walking on the ship. This was largely overcome by cross-welding stiffeners on larger areas of the deck.

MAY 3, 1973 One day before the completion of the 108-storey building of Sears-Tower - a skyscraper in Chicago, USA, it becomes the tallest building in the world at that time $(442.1 \mathrm{~m})$. It is the hallmark of Chicago. Construction of such a building structure is a challenge for the construction and welding companies. About 76000 t of steels were used in construction. Lincoln Electric Company participated in the project as a construction partner. Its design contained $268 \mathrm{~km}$ of the main welds. Both electric arc and electroslag welding was used in construction of the building.

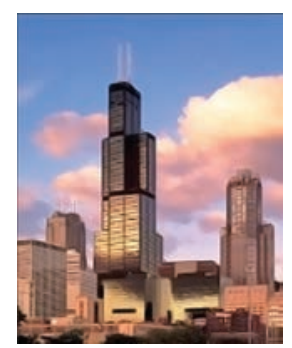

MAY 4, 1777 Birthday of Louis Jacques Thénard (1777-1857), French chemist, Member of Paris Academy of Scienc-

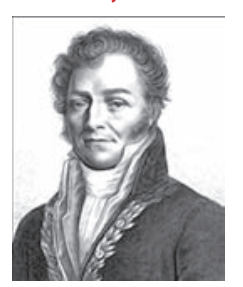
es (1810), its President in 1823. Louis Jacques Thénard is the author of numerous works in the field of chemistry and chemical technology. As the first of all the kinds of investigations, he studied conversion of electric energy into thermal energy - conductor heating by flowing current, which was conducted in 1801. Investigations, initially performed by Louis Jacques Thénard, form the base of many kinds of welding technologies.

MAY 5, 1961

Mercury-Redstone-3, the US first manned suborbital flight, began. During the fifteen minute suborbital flight by Mercury Program astronaut Alan Shepard piloted the single-seat space vehicle Freedom-7, made in the form of a capsule. The cockpit material was a titanium-nickel alloy, its $\emptyset$ lume was $1.7 \mathrm{~m}^{3}$. The astronaut was in the cradle, and was wearing a spacesuit during the flight. Flash-butt welding was used in manufacture of the ship hull. The equipment was provided by Sciaky Company.

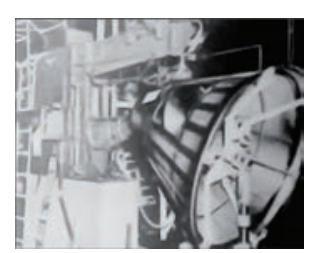

MAY 6, 1912 Birthday of Y.G.Derevyanko (1912-1994) - engineer-shipbuilder, Deputy Chairman of the State Committee of the USSR Council of Ministers on Shipbuilding, Deputy Minister of the USSR Shipbuilding Industry. In the pre-war years he supervised design and retrofitting of a test submarine with a welded hull. During the war, he was the Chief Designer and Chief Engineer of the shipyards in Leningrad, where the designs of self-propelled pontoons and tenders were dee loped and their building was ensured under his leadership for the Ladoga «Road of Life». Construction of welded sea hunters of BMO type and armour sea boats was conducted simultaneously.

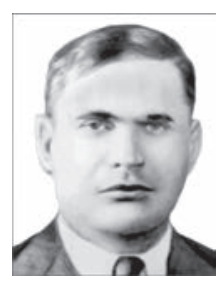

MAY 7, 1950 In May 1950, E.O. Paton supervised development of the design and technology of construction of Europe's largest all-welded bridge across the Dnieper in Kiev (now called the E.O. Paton Bridge).

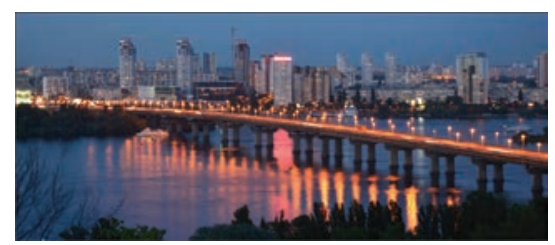

\footnotetext{
*The material was prepared by the Steel Work Company (Krivoy Rog, Ukraine) with the participation of the editorial board of the Journal. The Calendar is published every month, starting from the issue of «The Paton Welding Journal» No.1, 2019.
} 
MAY 8, 1915 Birthday of V.E. Moravsky (1915-1990) - representative of the Paton school. He laid the foundations for application of the new promising process of joining metals - capacitor-type welding. He devoted more than 40 years to studying the theoretical problems related to capacitor discharge, as well as solving technological tasks and development of equipment for capacitor-type and laser microwelding. Investigation results were realized in many plants of the former Soviet Union.

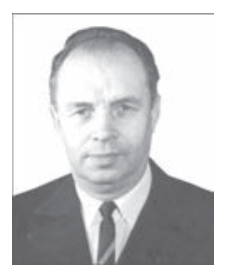

MAY 9, 1981

The sculpture-monument «Motherland», the largest statue in Ukraine $\left(17^{\text {th }}\right.$ in the world), was opened on Victory Day. The figure of a woman holding up the shield and sword is faced with stainless steel sheets. The Statue height from the pedestal to the tip of the blade is $62 \mathrm{~m}$, absolute height is $102 \mathrm{~m}$, its weight is about $500 \mathrm{t}$. For the first time in the USSR, the sculpture of such a scale was manufactured at the Kiev Parizhskaya Kommuna Plant with technical support of PWI. More than $30 \mathrm{~km}$ of welds were made during its construction.

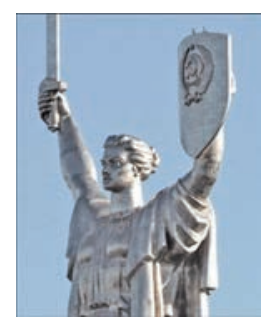

MAY 10, 1842 Birthday of D.A. Lachinov (1842-1902), Russian physicist and electrical engineer. The scientist pro-

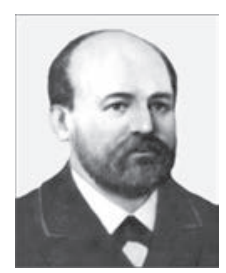
posed an industrial method of synthesis of hydrogen and oxg en through water electrolysis. In his patents D.A. Lachinov considered making and proposed the design of baths with unipolar and bipolar electrodes. In 1887 D.A. Lachinov, together with N.N. Benardos, performed underwater carbon electrode arc cutting in the laboratory for the first time in the word.

MAY 11, 1915 Adolph Messer (1853-1921) receives one of his patents for welding. Adolph Messer began producing acetylene generators and lighting installations in the town of Höhst, not far from Frankfurt-on-Mein, starting his own company. In 1903 the Company developed the first cutter, using oxy-acetylene mixture. In the period from 1924 to 1950, production of electric welding equipment was developed and set up. At present the Messer Group Company employs about 4700 staff at 120 plants, it has developed more than 150 applied technologies and produces more than 130 gases and gas mixtures.

MAY 12, 1903 Karl von Linde (1842-1934), German engineer and scientist, developed and patented the technology of cooling and separation of gases, actively applied in welding technology, particularly in autogenous processes. In addition, Karl von Linde founded the Linde Company in 1878, which actively studied the technology of arc and plasma welding. Investigations related to mixing of oxygen and nitrogen led to introduction of the acetylene torch in 1904.

MAY 13, 1940 World's first experimental flight of Vought Sikorsky VS-300 helicopter (S-46) the first test helicopter designed by I.I. Sikorsky (1889-1972), who was an outstanding helicopter designer, scientist, inventor and philosopher. He flew his first rotorcraft in Kiev in 1910. In 1941 by an order from the US Army, I.I. Sikorsky designed a two-seat helicopter for communication and observation. It was the world's first helicopter, which was put into mass production and the only helicopter during the Second World War. All the main load-carrying elements of the hull structure were welded.
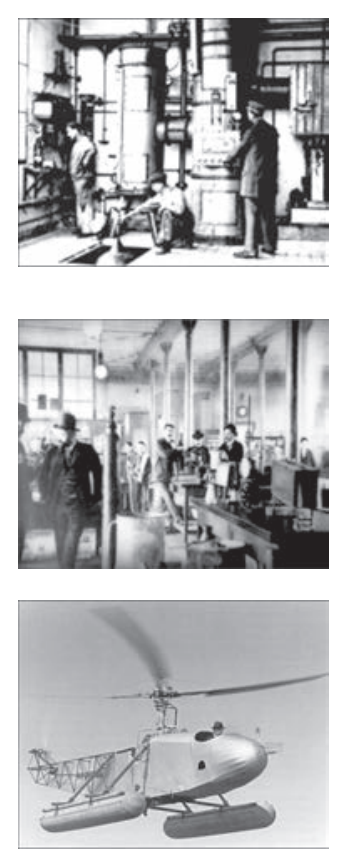

MAY 14, 1968

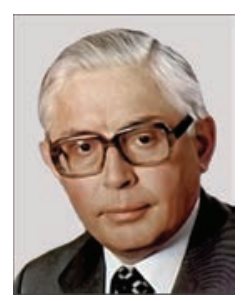

Karl-Heiniz Steigerwald built and patented the first electron beam chamber for metal processing. In 1963 Steigerwald founded Steigerwald Strahltechnik GmbH Company. The Company supplies vacuum installations, based on a universal concept. Chambers of different dimensions, fitted with modular mechanical and electronic equipment, are combined with electron beam generators of different power. The main application is welding large items with complex geometry of the weld or processing zone.

MAY 15, 2006

Cloud Gate sculpture was opened. It is located in the business quarter of Chicago, USA. Its author is the Indian-born British artist Anish Kapoor (born in 1954). The sculpture consists of 168 stainless steel plates, welded together and polished so well that its exterior has no visible welds. The dimensions of the sculpture are 10 (height), 20 (length) and 13 (width) m, its weight is about $100 \mathrm{t}$. Welders used hybrid laser-arc welding. Cloud Gate is one of the most famous and recognizable monuments of our time. It is beliee $d$ that the sculpture form was inspired by a mercury drop.

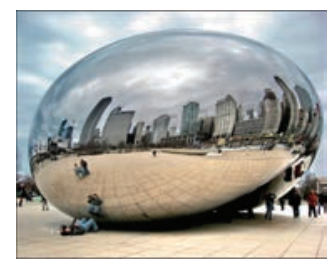


MAY 16, 1901 The Third Arctic Expedition on «Yermak» ship began. The world's first icebreaker of Arctic class of $15000 \mathrm{t}$ capacity was laid down in New Castle on the stocks of Armstrong Whitworth English Company by an order from Russia. In keeping with Admiral S.O. Makarov's idea, in addition to the cone ntional three stern propellers, the ship also had a bow propeller designed not only for drawing, but also for ice separation. Testing showed that this function was not fulfilled, and the yard received an order to replace the bow propeller by a wheel. The icebreaker bow part was dismantled, and a new one was welded in its place. The icebreaker demonstrated excellent seaworthiness and has operated for many years in heay ice conditions.

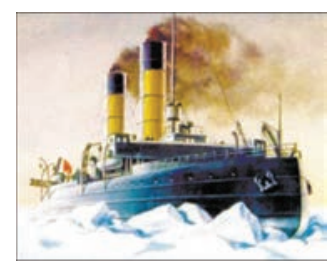

MAY 17, 1892 Birthday of K.V. Petran (1892-1976), outstanding engineer, developer of a series of unique electrodes

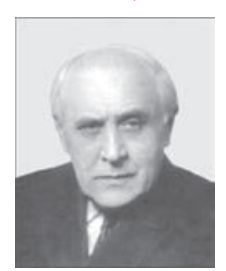

UONI-13 with calcium fluoride coating, for welding and surfacing. For more than 75 years now the electrodes of this series hae been ex ensie ly applied in many industrial sectors of the CIS countries in welding critical structures.

MAY 18, 1992

G.A. Nikolayev (1903-1992) died. He was a Soviet scientist, academician, Rector of N.E. Bauman MHTS, Hero of Socialist Labour. G.A. Nikolayev was the first to establish the main characteristics of vibration strength of welded structures and developed the specifications for their design. His work formed the scientific base for widespread introduction of welding instead of riveting in the structures of industrial facilities, in manufacture of boilers and carriages in the USSR.

MAY 19, 2008 The first flight of Sukhoi Superjet 100, developed by Sukhoi Civil Aircraft Company (Russia), took place. EBW KL-138 machine (PWI development) for electron beam welding was purchased for fabrication of the welded beam of a titanium pylon of this aircraft. A feature of this machine is the possibility of cosmetic smoothing of the root part of welds, also in difficult-of-access or remote locations. For this purpose the electron beam is rotated through $90^{\circ}$.
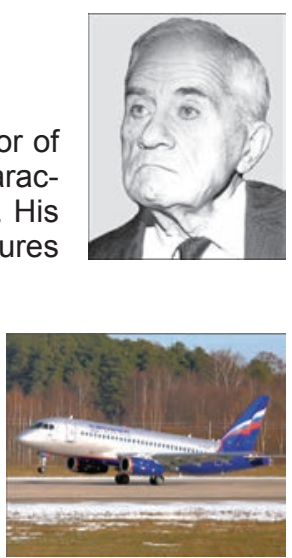

MAY 20, 1890 One of George Westinghouse's patents on welding was published. He was a US industrialist, engineer

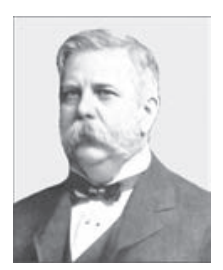
and entrepreneur, founder of Westinghouse Electric Company. His firm was one of the pioneers in development of welding consumables and apparatuses. In 1909 he created a direct current generator, making application of welding more accessible in many respects.

MAY 21, 1866 Birthday of Jackob Knappich — one of the founders of KUKA Systems GmbH Company. In 1889 Johann Josef Keller, together with Jackob Knappich, founded the acetylene plant for manufacture of ine ensie systems for lighting buildings and streets, household appliances and automobile headlights. Development and production of equipment for resistance welding began in 1936. In 1956 KUKA manufactures the first automatic welding lines, and supplies the first line for multispot welding for Volkswagen AG Company. Today the Company is one of the major suppliers of flexible automated solutions, including welding robots.

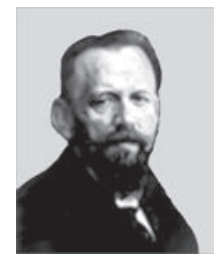

MAY 22, 2012 Opening of Tokyo Skytree - TV tower in Sumida district (Tokyo, Japan). It is the world's tallest TV tower of $634 \mathrm{~m}$ height and the second in height construction in the world after «Burge-Halifa». The entire structure of the tower consists of «lattice» elements, each of which is a combination of triangles, as part of other components. These elements are connected through branch joints and pipes. All the structures are joined by welding directly to the main support, without application of any other fastening systems or methods. This type of connection has a ry simple appearance and high seismic resistance.

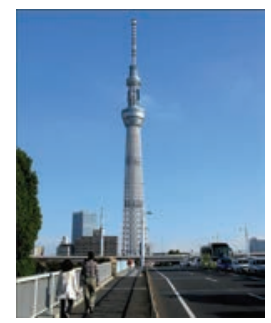

MAY 23, 1949 Veljekset Kemppi Oy Company was established in the city of Lahti (Finland). In mid1960s Veljekset Kemppi Oy Company marketed its first MIG/MAG welding machine. In 1990 Kemppi became the world's first manufacturer of welding machines, which received the ISO 9001 certificate. The Company was the first in the world to create an inverter power source, and became the first manufacturer applying digital welding technology.

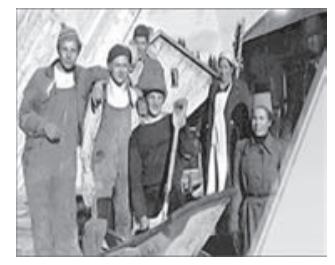




\section{CALENDAR OF MAY}

MAY 24, 1900 Russian cruiser «Aurora» was launched. The history of creation of this ship begins from riveting technology. After many years of berthing at Petrograd embankment as Museum-monument, Aurora came into disrepair. It was decided to replace the damaged elements of hull structures. Rie ting was not applied at «restoration», otherwise there may hae been not enough time before the ship's anniversary. Welding technology with simulation of rivet joints came to the rescue, which was used to make the repair.

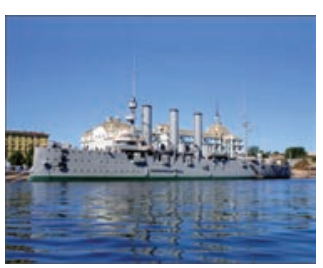

MAY 25 (Friday), 2018 On the last Friday of May all the welders celebrate their professional holiday — the Welder's

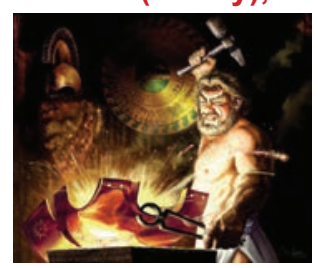
Day. The welder profession has been part of our life since ancient times. And today it is practically impossible to find a structure, which would be made without welding.

MAY 26, 1970 Tu-144 air liner exceeded the symbolic limit of 2 Mach, flying at an altitude of $16300 \mathrm{~m}$ at the speed of $2150 \mathrm{~km} / \mathrm{h}$. Soviet Tu-144 became the first type of supersonic air liners, which were used for commercial traffic and went supersonic. $20 \%$ of the air liner structure was made of titanium. Ailerons made from titanium alloys were located along the entire trailing edge of the wing. Application of titanium alloys in the structure required development of new machine tools and welding equipment. These problems, together with A.N. Tupolev EDTB, were solved by specialists of TsAGI, CIAM and other organizations.

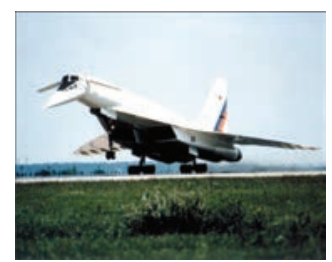

MAY 27, 1934 Birthday of V.M. Kudinov - representative of the Paton school. The scientist performed research connected with physico-mechanical phenomena at explosion treatment of metals. V.M. Kudinov supervised performance of a complex of fundamental research, associated with elaboration of the physical theory of the phenomenon of wae formation in esion welding. This research was the base for distinguishing a separate class of welding processes, which were called structural esion welding, performed on parts and items. In the field of explosion cutting, he performed developments of the design of elongated cumulatie charges, their optimization and creation of a safe technology of their manufacture.

MAY 28, 1896

N.G. Slavyanov (1854-1897), Russian engineer, inventor of the method of electric arc welding of metals, submitted an application for the ine ntion, and soon was granted the privileges for the «Method of Electric Compaction of Metal Castings». In 1888 Russian engineer N.G. Slavyanov applied arc welding by metal electrode under a layer of flux in practice for the first time in the world. In the presence of a State Commission, he welded a crankshaft of a steam engine in one of the shops of Perm cannon factories. Engineer Slaya nov called his

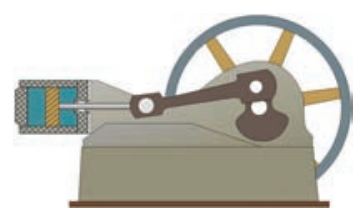
ine ntion «Electric Casting of Metals».

MAY 29, 1829 Humphry Davy (1778-1829) died. He was an English chemist, physicist and geologist, one of the found-

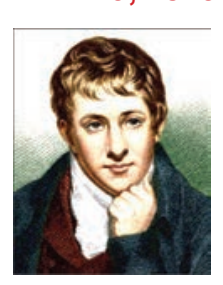
ers of electrochemistry. He obtained the electric arc, regardless of V.V. Petrov, but somewhat later (1809). Discovery of the electric arc was attributed to Humphrey Davy for some time, and it was known under the name of Voltaic arc. Davy pushed together two sharpened carbon electrodes, connected to poles of a battery, consisting of 2000 cells. The charcoals glowed red, owing to huge heat release. When Davy removed their tips from each other, the current was still transmitted across the air gap, spreading a blinding light, which was called Davy's light or Voltaic arc.

MAY 30, 2012 Stojkiy destroyer was launched. This project is one of the most recent developments of Russian shipbuilding. First cutting was used to make parts of the required shape, and then welding was applied to join the hull sections. Modern welding equipment for automatic submerged-arc, semi-automatic gas-shielded, argon-arc and manual electric arc welding was used in its construction.

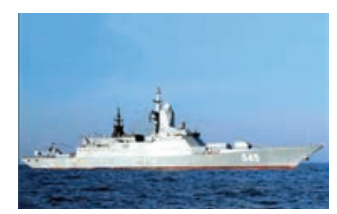

MAY 31, 1920 Matsu was launched - a battleship of the Imperial Japanese Navy, second ship of Nagato type. Nagato type ships are the first battleships fully designed and built in the Japanese shipyards. They were based on the concept of high-speed battleships. In keeping with the most recent engineering achiee ments, the relatie ly new technology of arc welding was ex ensie ly used at construction of the ship, ensuring the durability and strength of the armor. In particular, this technology was used to additionally strengthen the lower part of the armour belt.

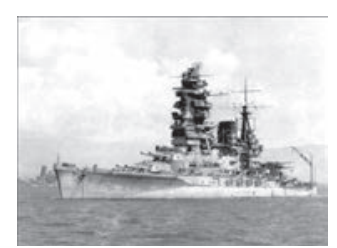

